\title{
CONSUMER EVALUATION: THE LINK BETWEEN BODY MASS INDEX, REWARD SENSITIVITY, PRODUCT LIKING AND EMOTION
}

\author{
A Thesis \\ presented to \\ the Faculty of California Polytechnic State University, \\ San Luis Obispo
}

In Partial Fulfillment

of the Requirements for the Degree

Master of Science in Agriculture with a Specialization in Food Science

by

Malori Comer

April 2015 
(C) 2015

Malori Comer

ALL RIGHTS RESERVED 
TITLE:

AUTHOR:

DATE SUBMITTED:

COMMITTEE CHAIR:

COMMITTEE MEMBER:

COMMITTEE MEMBER:
Consumer Evaluation: The Link between Body Mass Index, Reward Sensitivity, Product Liking and Emotion

Malori Comer

April 2015

Amy Lammert, Ph.D.

Assistant Professor of Food Science and Nutrition Department

Karen McGaughey, Ph.D.

Assistant Professor of Statistics Department

Robert Kravets, Ph.D.

Associate Professor of Food Science and Nutrition Department 


\begin{abstract}
Consumer Evaluation: The Link between Body Mass Index, Reward Sensitivity, Product Liking and Emotion

Malori Comer
\end{abstract}

The objectives of this study were: (1) to evaluate consumer acceptance of cheeses varying in fat and sodium levels, (2) to determine if sensitivity to reward and body mass index has an effect on product liking based on fat or salt content, (3) to evaluate the use of FaceReader technology during consumer evaluation and, (4) to determine if consumer's self-selected, conscious emotions matched with the expressed, subconscious emotions acquired by FaceReader.

Consumer acceptance testing $(n=108)$ was conducted on two medium cheddar cheeses with varying fat levels and two low-moisture part-skim mozzarella cheeses varying in sodium levels. Attributes were measured using a 9-point hedonic scale. In order to measure reward sensitivity, participants completed the BIS/BAS questionnaire and the SPSRQ prior to consumer acceptance testing. SIMS sensory software was used for data collection. The complete consumption experience was video recorded $(n=83)$. A chooseall-that-apply format was used so participants could indicate all emotional states before and after consumption. A total of 332 pairs of videos (83 subjects, four samples, before and after consumption) were used for FaceReader analysis.

Regular cheddar cheese scored significantly higher than the reduced fat cheddar cheese for mean overall liking, flavor, texture, creaminess, saltiness and aftertaste. The higher sodium mozzarella scored significantly higher than the lower sodium mozzarella for mean flavor, saltiness and aftertaste $(\mathrm{p}<0.05)$. The data indicated that men have a significantly higher sensitivity to reward than women $(\mathrm{p}=0.0183)$. There was no evidence to indicate that sensitivity to reward, gender or body mass index (BMI) had a significant effect on the product liking of the cheddar cheese. Gender and BMI did not have a significant effect on the overall liking based on salt content but the interaction between the two variables $(\mathrm{p}=0.0319)$ did have a significant effect on the overall liking of the mozzarella cheese.

FaceReader Results indicated:

(1) Neutral was the most accurately matched self-selected emotion (100\%) before and after consumption, followed by happy ( $82 \%$ and $63 \%$ respectively). FaceReader was unable to correctly match surprised/angry before consumption and angry/sad after consumption.

(2) FaceReader acquired 420 and 495 additional non-self-selected emotions before and after consumption, respectively. Neutral and angry were most commonly expressed when not self-selected. Disgusted and scared were rarely expressed when not self-selected. 
(3) FaceReader was not as successful matching the self-selected emotions after consumption. Surprised and happy were commonly missed both before and after consumption. Disgusted was missed primarily after consumption.

(4) "Happy" is self-selected and expressed more times for regular cheddar than the reduced fat cheddar. The mean overall liking score was also significantly higher for the regular cheddar than reduced fat cheddar. Similar results were found with mozzarella.

Although low fat and low sodium cheeses represent a healthier option, consumer acceptance indicated that the higher fat and higher sodium samples scored higher; changes in flavor and texture need to be made in order to produce a more liked product. There is a complex relationship between product liking, body mass index, gender and sensitivity to reward but further research needs to be conducted to investigate how the variables interact.

FaceReader technology did match some of the self-selected emotions identified by the subject. However, one question remains: which emotions, self-selected/conscious emotions or subconscious/expressed emotions, are a better predictor of liking?

Keywords: consumer evaluation, cheese, sensitivity to reward, body mass index, FaceReader, emotion 


\section{ACKNOWLEDGMENTS}

I would like to thank my committee chair and advisor, Dr. Amy Lammert, and my committee members, Dr. Robert Kravets and Dr. Karen McGaughey for their support, guidance, and knowledge over the last two years. To Dr. Lammert, a special thank you for the amazing opportunities you have provided me, I wouldn't be where I am without you.

Thank you to the faculty, students and staff in the Food Science and Nutrition Department. You have all made an impact on my experience here at Cal Poly and that is something I will always remember.

I am very grateful of the financial support provided by the California State University Agricultural Research Institute.

A big thank you to my research partner, Kristi Martinez. This research would not have been possible without all of your help!

To my family and friends, thank you for your unconditional support and encouragement. Words cannot express how grateful I am. 


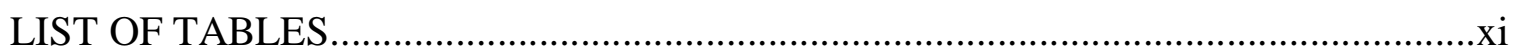

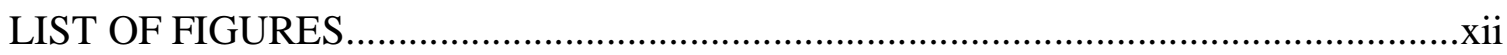

\section{CHAPTER}

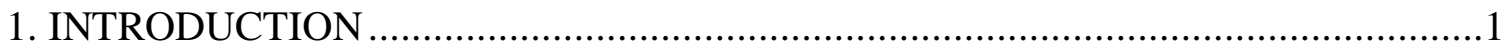

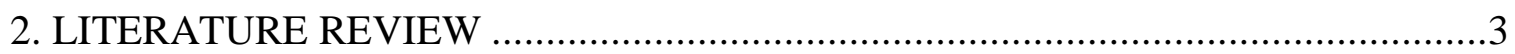

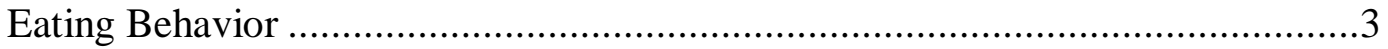

From the Homeostatic Model to the Non-Homeostatic Model ...........................3

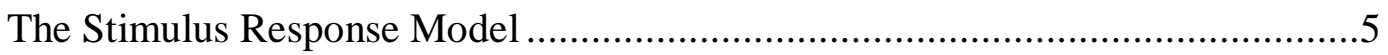

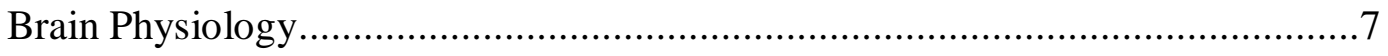

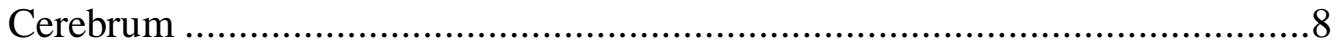

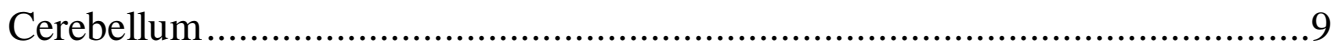

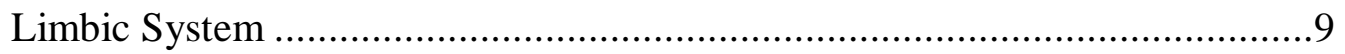

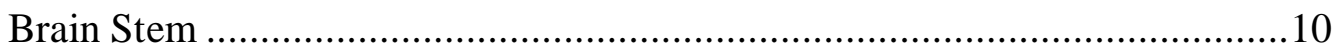

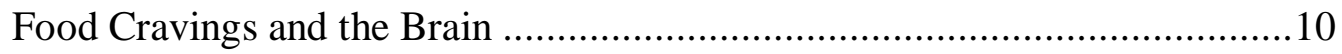

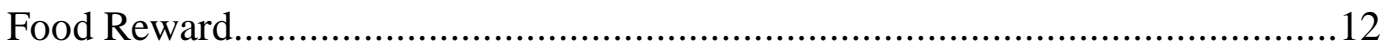

Gray's Theory of Brain Functions and Behavior ..........................................14

Sensitivity to Punishment and Sensitivity to Reward Questionnaire ................16

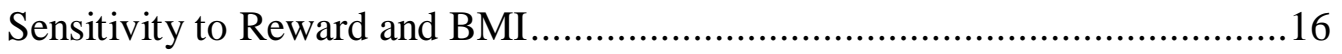

Food Preferences - Innate versus Learned .......................................................17 
Shift in Food Consumption Models

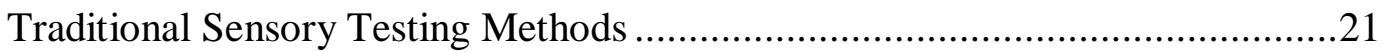

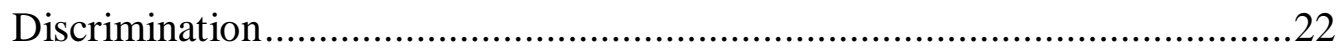

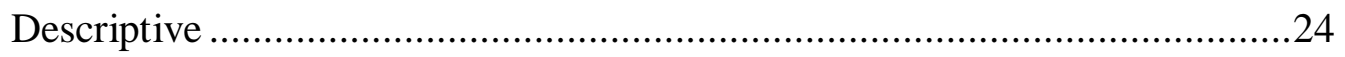

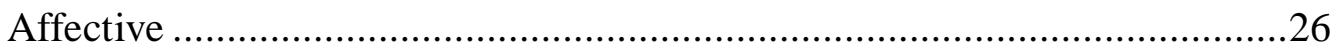

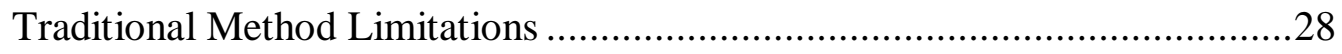

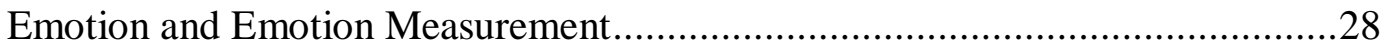

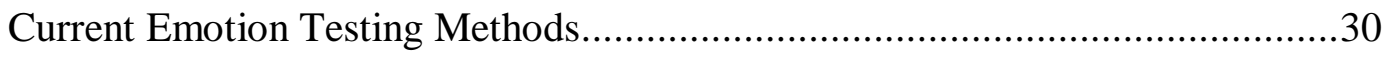

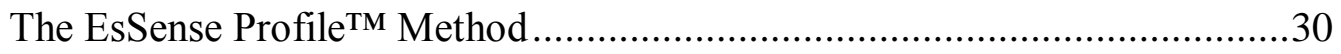

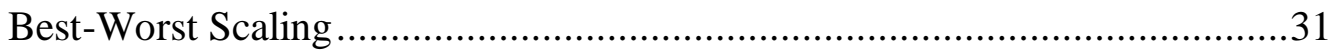

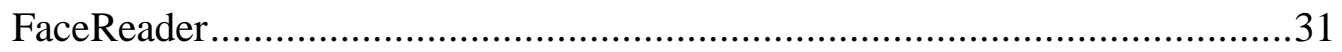

Theories about Emotion and Eating Behaviors in Obese Individuals ...............32

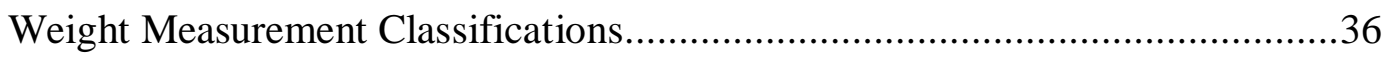

Health Complications Associated with Weight .................................................38

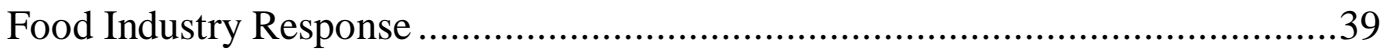

Drivers of Food Consumption.....................................................................

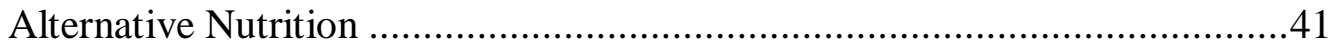

Cheese

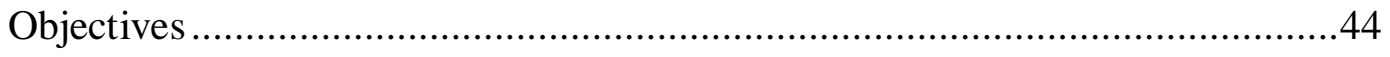

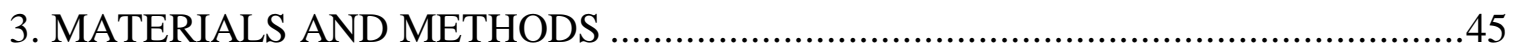


Participants

Samples and Sample Preparation ......................................................... 46

Questionnaires and "Emotion Poster" Homework ...........................................47

"Emotion Poster" Homework...................................................................47

BIS/BAS Questionnaire \& SPSRQ Questionnaire ..................................47

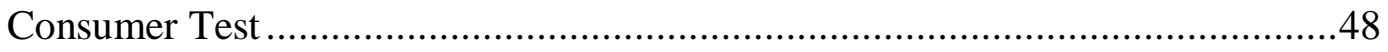

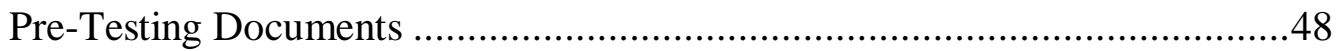

BMI Measurements .........................................................................4 48

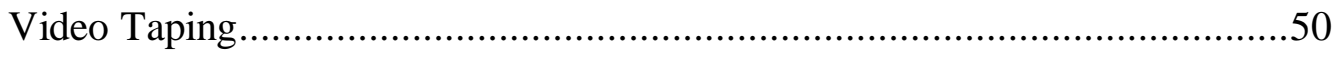

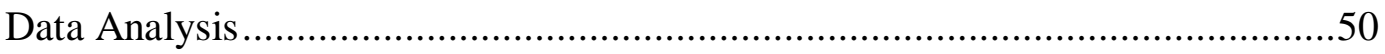

Consumer Acceptance of Cheeses Varying in Fat and Sodium Content .........50

Reward Sensitivity, Body Mass Index (BMI) and Gender ..........................51

Body Mass Index (BMI), Gender, Product Liking, and Fat/Salt Content of

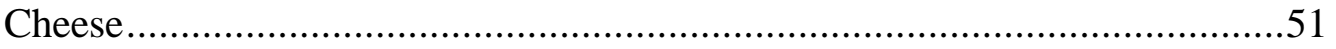

Reward Systems, Gender, and Product Liking .....................................52

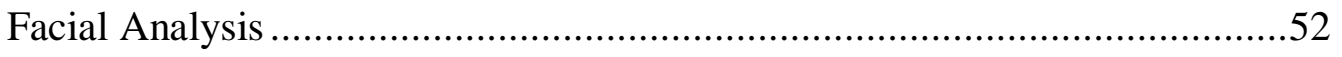

4. RESULTS AND DISCUSSION ................................................................... 53

Consumer Acceptance of Cheeses Varying in Fat and Sodium Content ..............53

Reward Sensitivity, Body Mass Index (BMI) and Gender ..............................55

Effects of Gender and Body Mass Index on Sensitivity to Reward................55 
Effects of Gender/Behavioral Activation System on Sensitivity to Reward ....57

Body Mass Index, Gender, Product Liking, and Fat/Salt Content of Cheese ........58

Effect of Sensitivity to Reward, Behavioral Activation System, and Gender on

Overall Liking based on Fat or Salt Content ..................................................6

Self-Selected Emotions and Emotions Captured by FaceReader ..........................61

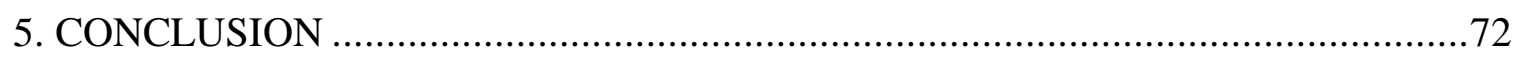

REFERENCES

APPENDICES

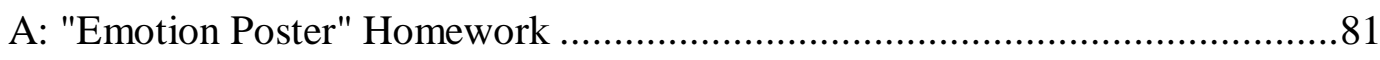

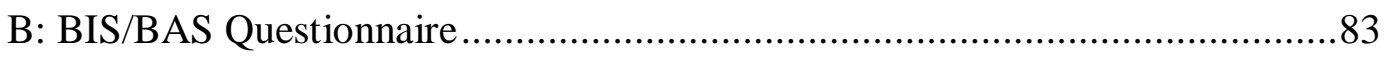

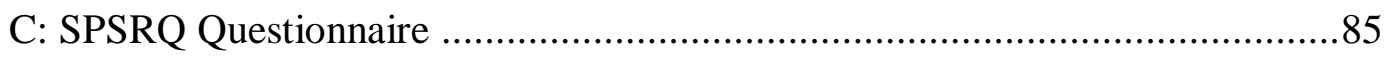

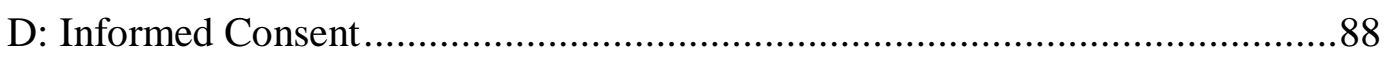

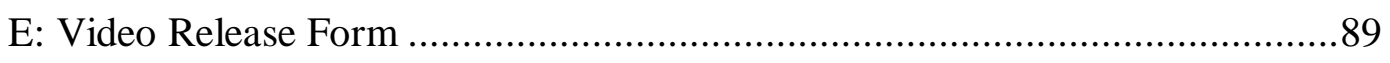

F: Consumer Acceptance - Testing Questionnaire ………..............................90 


\section{LIST OF TABLES}

Table

Page

Table 2.1 Standard Weight Categories with BMI Ranges 37

Table 3.1 Panelist cheese consumption in the past 3 months $(n=108)$

Table 3.2 Standard weight categories with body mass index (BMI) ranges .46

Table 3.3 Participants categorized by body weight and gender $(n=108)$ .46

Table 3.4 Cheese types and nutrition content .46

Table 4.1 Consumer acceptance scores for the cheddar cheese samples .53

Table 4.2 Consumer acceptance scores for the mozzarella cheese samples .54

Table 4.3 Effects test for gender and BMI on sensitivity to reward .55

Table 4.4 Distributions of sensitivity to reward by gender. .56

Table 4.5 Effects test for gender and behavioral activation system on SR .57

Table 4.6 Effects test for gender and body mass index on liking based on fat content ....59

Table 4.7 Effects test for gender and body mass index on liking based on salt content ...60

Table 4.8 Effects test for SR, BAS and gender on overall liking based on salt content ...61

Table 4.9 Number of panelists and videos per weight category .62

Table 4.10 Number of times/frequency emotion was selected and matched..... .66

Table 4.11 FaceReader and panelist agreement for each emotional state 67 


\section{LIST OF FIGURES}

Figure

Page

Figure 2.1 The stimulus-response relationship model..........................................

Figure 2.2 A simple illustration of the stimulus-response model ..............................6

Figure 2.3 Perception and conceptualization. .................................................

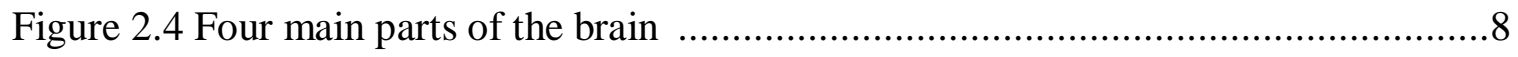

Figure 2.5 Four sections and functions of the cerebrum .....................................

Figure 2.6 The Limbic System in the brain .................................................... 10

Figure 2.7 Areas of the human brain activated in response to palatable food or food-

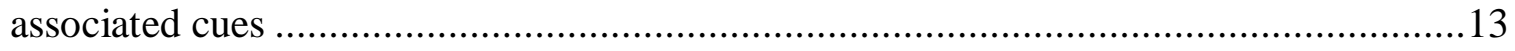

Figure 2.8 Traditional sensory evaluation methods ...........................................22

Figure 2.9 Example of a typical 9-point hedonic scale ........................................27

Figure 2.10 Example of a 7 -point facial scale ..................................................2

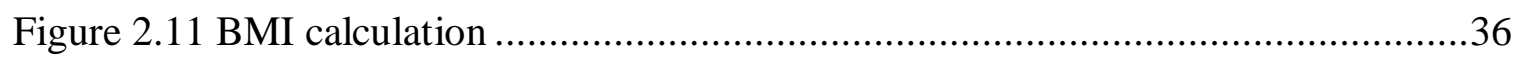

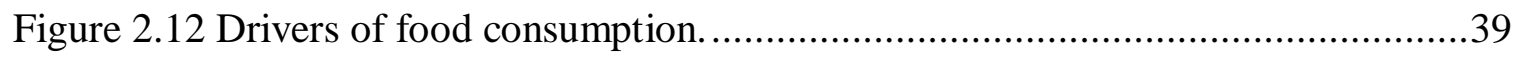

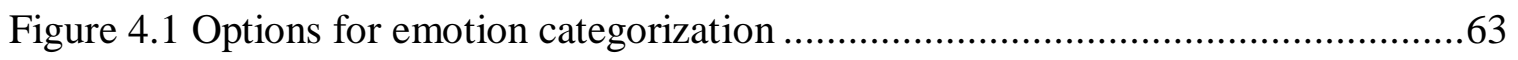

Figure 4.2 Self-selected emotions not captured by FaceReader ................................64

Figure 4.3 Frequency of self-selected emotions captured by FaceReader ....................65

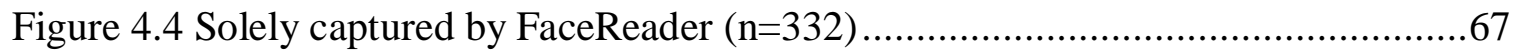

Figure 4.5 Relationship between occurrence of "Happy" and overall liking .................68

Figure 4.6 Relationship between frequency of "Happy" and overall liking by cheese and body mass index. 


\section{Chapter 1}

Introduction

Eating is the most fundamental of human behaviors; humans eat in order to survive. Modern evolutionary theory encompasses the same principle as natural selection in that organisms behave in a manner that ensures survival (Neal, 1978). Charles Darwin, the father of evolution, proposed survival was more than simply having a strong genetic makeup, survival depends on organisms behaving in ways that maintain overall health, which includes consuming adequate nutrients (Darwin, 1958). Still, in many countries today, obtaining food is a difficult daily task. However, in Western culture, food is abundant and generally easily accessible; which some attribute to the rise in obesity.

The United States incurs roughly $\$ 150$ billion a year in costs due to obesity, which account for almost $10 \%$ of the national medical budget (Centers for Disease Control and Prevention, 2011). Over the past three decades, national childhood and adult obesity rates have more than doubled. According to the National Health Nutrition and Examination Survey of 2009-2010, one in every three adults and one in every six children qualify as obese (Ogden, Carroll, Kit, \& Flegal, 2012). The drastic increase in obesity number over the past decades presents not only medical concerns, but social and psychological concerns as well.

In 2008, obesity ranked among the top ten health stories in the media (Blake et al., 2010). More recently, the Hunter Public Relations 2013 Food News Study revealed fighting childhood obesity as the top food story (Lukovitz, 2013). This epidemic will continue to grow unless appropriate measures are taken. 
First Lady Michelle Obama garnered extensive media coverage surrounding childhood obesity through her "Let's Move" campaign. "Let's Move", which launched in 2010 , is an initiative dedicated to solving the challenge of childhood obesity by providing not only health and wellness education but healthier food options in schools ("Let's Move - Learn the Facts,” 2010).

Researchers are trying to better understand the triggers, implications, and ramifications of food consumption. Research is currently focused on the relationship that exists between eating behavior and emotion. This complex relationship involves many scientific disciplines; physiology, biology, neurobiology, psychology, and sensory science are all involved in food consumption. Health professionals and food scientists are trying to better understand the relationship between body composition, eating behavior and emotion in both overweight and obese children/adults in order to decrease the obesity epidemic. 


\title{
Chapter 2
}

\author{
Literature Review
}

\section{Eating Behavior}

\section{From the Homeostatic Model to the Non-Homeostatic Model}

Early research of eating behavior focused on the physiological level as presented in the Homeostatic Model, which suggests the body is motivated to maintain homeostasis - a stable internal state. The model is based on traditional homeostatic principles including internal hunger cues. These hunger cues trigger eating and satiety cues halt food consumption. The basic principle is that the body takes action when food or hunger is necessary, yet takes no action when food is not necessary. The theory is based on the premise that eating is not a learned response but a response in reaction to hunger alone. The model does not include the effects of learning and experiences nor emotional influences on eating behavior (Shin et al., 2009).

In the 1960's, research demonstrated major fundamental flaws with the Homeostatic Model (Capaldi, 1996). Humans and animals do not solely eat due to hunger; oftentimes, animals actually eat in anticipation of hunger. In addition, the development of eating patterns, food preferences, and digestive responses are all subject to learning. For example, Pavlov (1927) demonstrated how animals salivate in response to anticipating food, rather than just in response to hunger cues. This challenges the premise of the Homeostatic Model, creating new opportunities to study and research eating behavior (Pavlov, 1927).

Food is not consumed solely for survival as the Homeostatic Model states. In fact, eating behavior is not usually driven by feelings of hunger or maintaining homeostasis 
(Franken and Muris, 2005); food is consumed for enjoyment and the positive emotions elicited, for the rewarding value. Non-homeostatic eating can be influenced by environmental factors, brain reward mechanisms, food sensory characteristics, and emotional states (Davis et al., 2007).

Researchers want to understand how learning and experience interact with biological predispositions to elicit specific behaviors. The development of food choice actually begins prenatally. Foods consumed during pregnancy can determine and influence a child's food preferences after birth (Prescott, 2012).

Eating is a way of initiating and maintaining human relationships. Breast milk, which is inherently sweet, is oftentimes the first liquid consumed by humans. Eating patterns and preferences imposed by parents influence the development of a child's food preferences (Barthomeuf et al., 2009; Prescott, 2012). In many cultures, food has symbolic meaning, relating to family traditions, social status, and even health. Although culturally acquired food preferences vary greatly, food provides a way for people to come together (Insel et al., 2007).

Environment can impact food choice, both positively and negatively (Lamichhane et al., 2012). Humans learn to avoid foods that make them sick, and learn to select foods that make them happy (Logue, 1998). Emotions can greatly influence these learned associations. Research demonstrates that experiencing emotions such as bored, depressed, or tired can lead to higher food consumption, while feeling fear, pain, or tension can lead to lower food consumption (Macht, 1999). Regardless of internal hunger cues, the environment in addition to emotion influences eating behavior. Stimulus from the 
environment in conjunction with previously learned connections gets processed by the brain triggering eating behavior (Macht, 2008).

\section{The Stimulus Response Model}

Psychophysics, the oldest branch of experimental psychology, explores the relationship between physical stimuli and the sensory experience. This relationship, between stimulus and response, provides the foundation for a sensory system. The stimulus from the environment in combination with previously learned associations gets processed by the brain, triggering a behavior or response (Figure 2.1). For example, consuming a specific food product (sensory stimulus), that is expected to elicit a positive response based on learned experiences (classical and operational conditioning), would then produce a specific behavior or response.

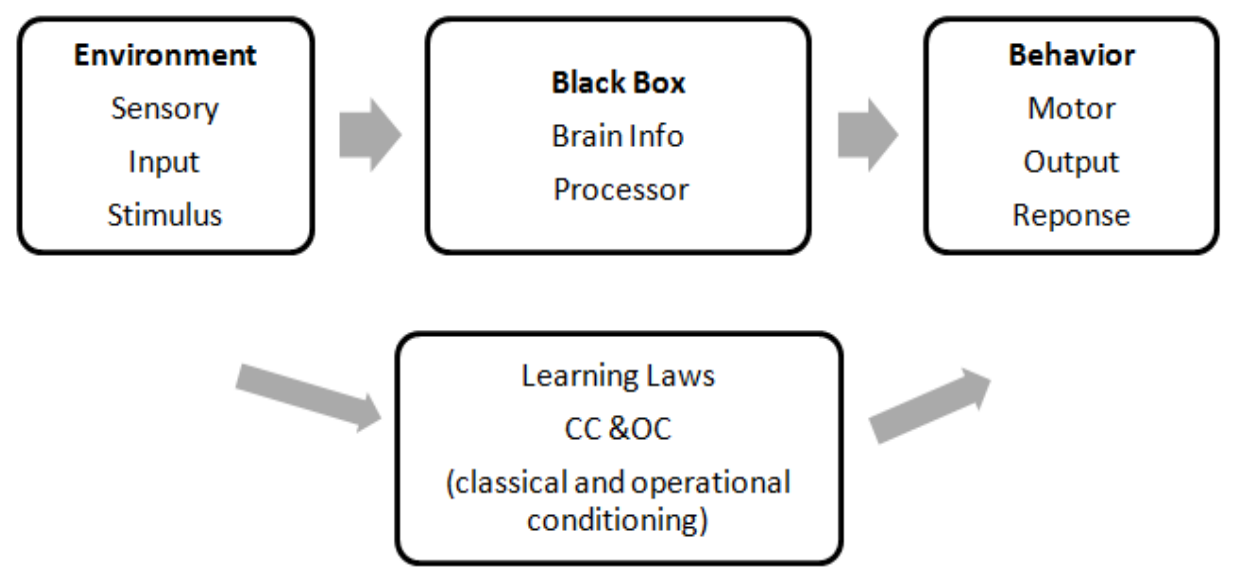

Figure 2.1 The stimulus-response relationship model.

In 1860, G.T. Fechner, philosopher and scientist, documented the psychophysical relationship between physical stimulus and sensory intensity. Fechner's ongoing research explained three important sensory methods: the method of limits, the method of constant 
stimuli, and the method of adjustment. The sensory evaluation toolbox used in today's food industry is based on these sensory methods (Lawless and Heymann, 1998).

Fechner established that there is a relationship between physical stimuli and sensory responses; however, the stimulus-response relationship is complex. The simplest conceptualization of sensory and hedonic measurement is a two stage process (Figure 2.2). When a stimulus is presented, a transduction and encoding process must take place; this is then followed by a cognitive process which elicits a behavior or response. An active cognitive decision-making process must be present in order for the model to function correctly. Traditional sensory methods may measure the response but they fail to account for contextual effects, emotion, or even learned experiences; these all highly influence eating behavior (Lim, 2011).

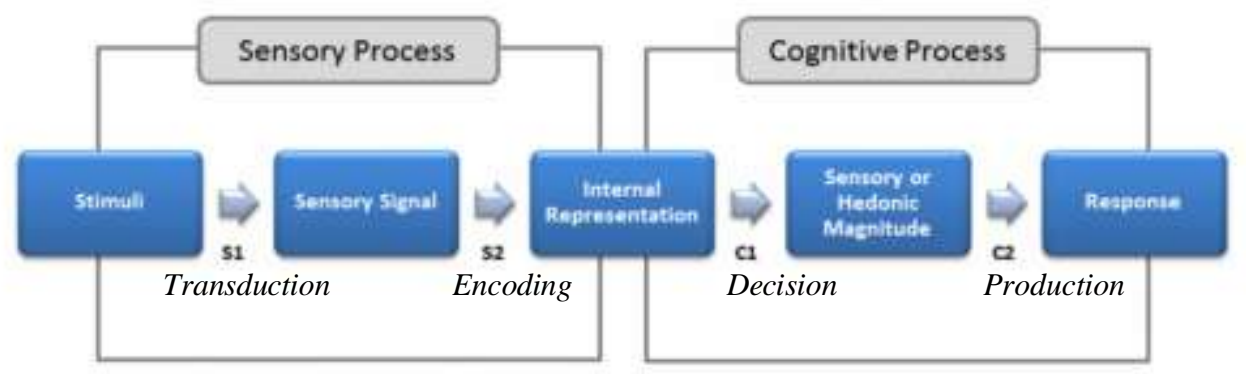

Figure 2.2 A simple illustration of the stimulus-response model (adapted from Lim, 2011).

As sensory information from the environment is introduced, the brain acts as a processor and assigns meaning to the given stimulus; it then produces a behavior or response. The brain uses classical conditioning and operational conditioning learning laws to elicit a response (Figure 2.1). The processing results in the creation of conceptualizations. Conceptualizations typically fall into three categories: function, emotional or abstract. The stimulus-response model fails to account for non-cognitive or 
subconscious processes that contribute to choice behavior. These subconscious processes are not easily accessed or measured by researchers, making it difficult to account for them. This inaccessibility can be challenging for the food industry, specifically when formulating new products for consumers. Methods must be investigated in order to gain a better understanding of how these learned associations and subconscious processes influence choice behaviors. Perception and conceptualization can affect behavior (Figure 2.3) (Thomson et al., 2010).

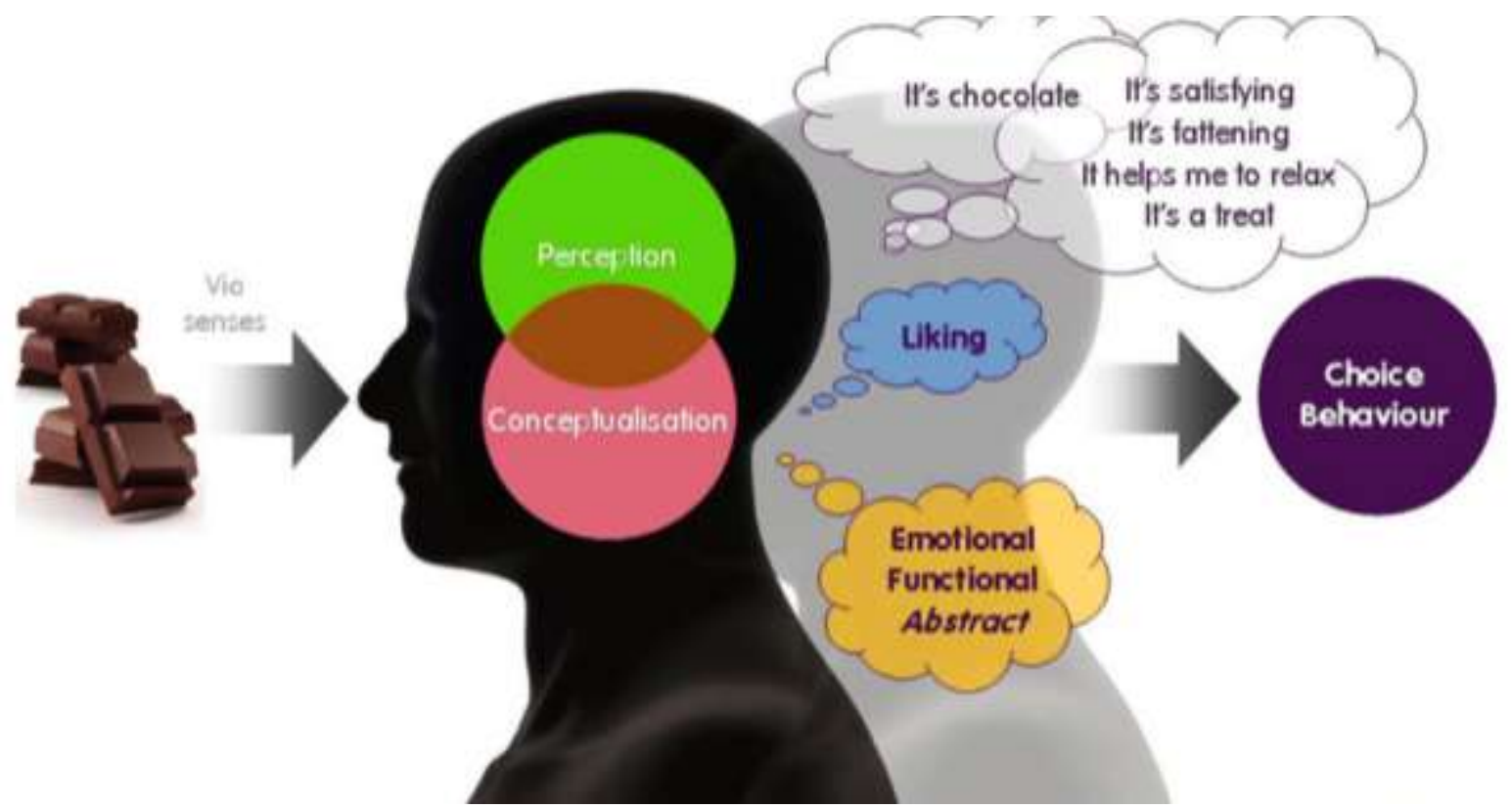

Figure 2.3 Perception and conceptualization (excerpted from Thomson et al., 2010).

\section{Brain Physiology}

The human brain is responsible for every thought and movement within the human body. It is composed of nerve cells and chemicals which help maintain homeostasis and ensure proper brain function. There are four main portions of the brain: the cerebrum, cerebellum, limbic system and brain stem (Figure 2.4). 


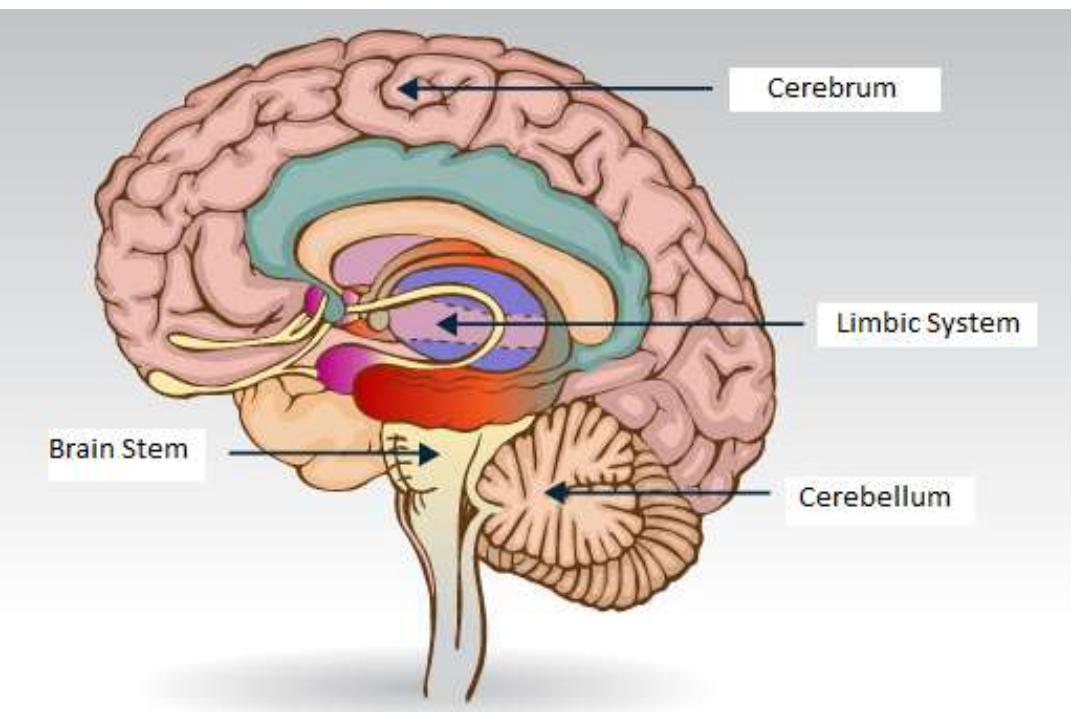

Figure 2.4 Four main parts of the brain (adapted from: google images)

\section{Cerebrum}

The cerebrum, which is the largest portion of the brain, is responsible for the majority of the brain's function. The cerebrum is divided into four sections or lobes: the frontal lobe, parietal lobe, temporal lobe and occipital lobe (Figure 2.5). Each lobe controls a specific and unique function. The frontal lobe controls reasoning skills including creative thought, problem solving, behavior, movements, smell and personality. The parietal lobe centers around comprehension; sensation and perception of stimuli take place in the parietal lobe. Both the sensory and motor cortexes are located in the parietal lobe. Next to the parietal lobe is the temporal lobe which is associated with perception of auditory stimuli, memory and speech. The fourth lobe, or occipital lobe, controls visual processing. 


\section{Cerebellum}

The cerebellum or 'little brain' controls body functions that help humans move properly including balance, posture, and coordination ("Parts of the Brain and Their Functions," 2015).

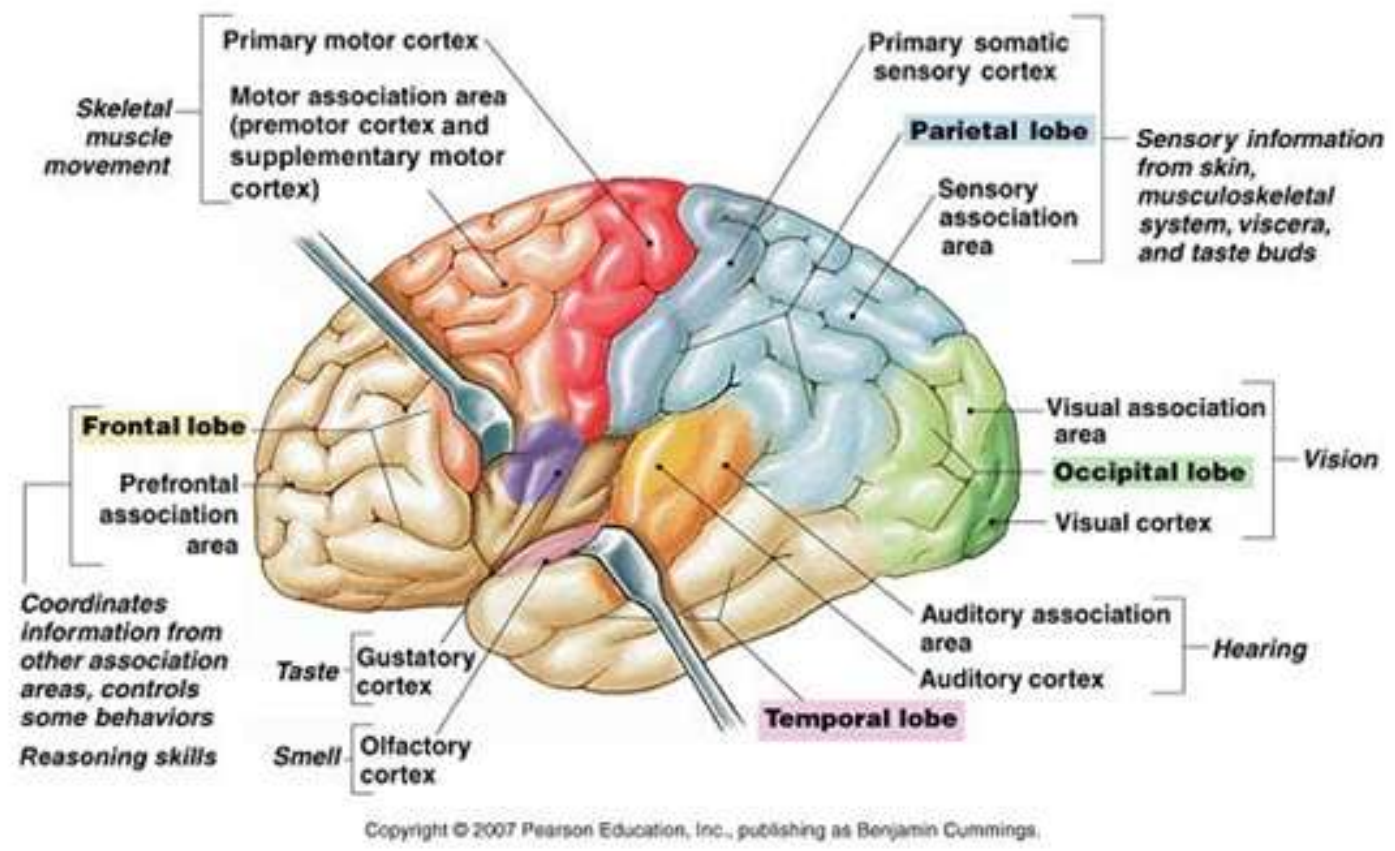

Figure 2.5 Four sections and functions of the cerebrum

\section{Limbic System}

The limbic system is often referred to as the "emotional brain". This area contains the thalamus, hypothalamus, amygdala and hippocampus (Figure 2.6). The thalamus has both sensory and motor functions. Sensory information enters the thalamus where neurons then send signals to the cortex. The hypothalamus is associated with functions related to homeostasis, emotion, thirst and hunger. The hypothalamus also controls the autonomic nervous system and hormonal processes in the body. Learning and memory, including converting short term memory, are both controlled in the hippocampus. The 
amygdala is involved in memory, emotion and fear ("Parts of the Brain and Their Functions," 2015).

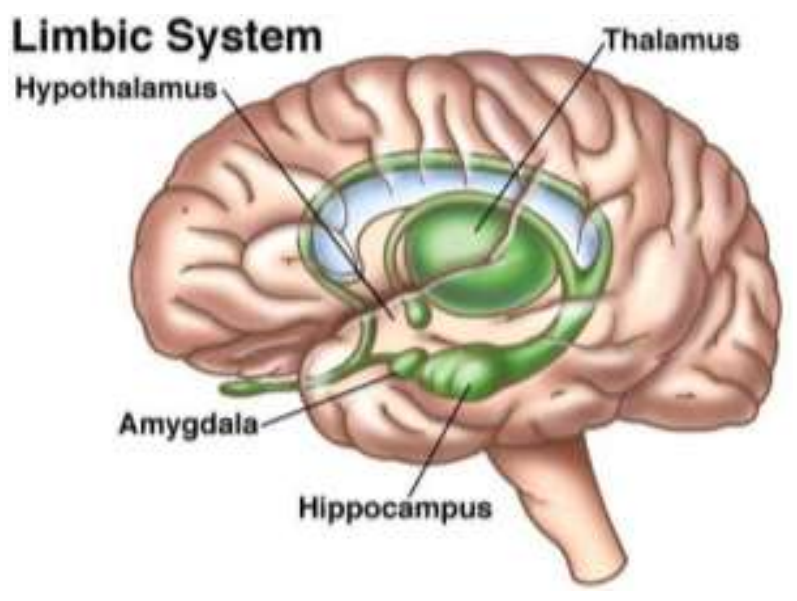

Figure 2.6 The Limbic System in the brain

\section{Brain Stem}

Beneath the limbic stem is the brain stem. The brain stem is responsible for vital life functions including breathing, heartbeat and blood pressure. In addition, the brain stem regulates sleeping and eating ("Parts of the Brain and Their Functions," 2015).

\section{Food Cravings and the Brain}

There are numerous neurotransmitters in the brain. These chemicals respond directly to various food elements. Sugar and fat when consumed in large quantities influences brain chemistry which in turn influences human behavior. In today's Western culture, high sugar/fat foods are easily accessible, readily available.

When high sugar foods are consumed, opiate receptors are engaged. Opiates help regulate pain, reward and euphoria; all positive reactions. However, when sugar is consumption ceases, individuals experience signs of withdrawal; these feelings of withdrawal can be directly compared to the feelings a drug addict may experience (Avena 
et al., 2009). Sugary foods are not necessarily addictive because of flavor; they are addictive because of the reward mechanisms in the brain, and the effects on the body's metabolism.

When more fat is consumed, the release of endorphins increases dramatically. The release of endorphins results in a natural 'high', offering pain relief and increased happiness. Galanin is a neurotransmitter that increases the desire for fatty foods. The more fat in a person's diet, the more galanin is produced; the more galanin that is produced, the more one prefers high-fat foods. The galanin production/fat craving cycle can be difficult to break. Consuming less fat for weeks can reduce the production of galanin in the brain and thus reduce the craving for fatty foods. The less an individual eats, the less high-fat food is desired (Howard, 2000).

Simple carbohydrates, including sugars, raise serotonin levels in the brain. Serotonin is a chemical that enhances calmness, improves mood, and lowers depression. High levels of serotonin can help control appetite, cravings, and provide a feeling of wellbeing. However, consuming refined sugars can cause a high-low blood sugar cycle which can easily cause sugar cravings (Howard, 2000).

The brain reward regions of the brain become activated with sugar consumption, reactions similar to the consumption of alcohol and drugs. The activation of the reward system can be extremely difficult to overcome which can result in compulsive eating behaviors. The brain regions, referred to as food-reward systems, control our desire for food; the more active these regions are, the greater the desire for food (Cheren et al., 2009). 


\section{Food Reward}

Food choice as well as eating behavior requires conscious decision making. Individuals choose different foods at varying quantities for a variety of reasons. The decision making process itself is influenced by brain reward mechanisms; mechanisms that generate "liking" and "wanting" for foods (Berridge et al., 2010). For most individuals, "reward" is desired due to the produced experience of pleasure. Foods higher in fat and sugar content are potential rewards, triggering learned connections between food and reward (Volkow et al., 2011). Reward can be separated into three main components: liking, wanting and learning: liking referring to the hedonic impact, wanting referring to the incentive salience component, and learning referring to predictive associations and cognitions (Berridge et al., 2009). In order to understand food choice and eating behavior, the psychological components of food reward must be studied, both separately and together.

The liking component, generated by the subcortical brain system, is generally defined as the hedonic reaction detected in behavior or neural signals. Many areas of the brain are activated by food pleasure including regions of the neocortex (orbitofrontal cortex, anterior cingulate cortex, anterior insula cortex), the subcortical forebrain structures (ventral pallidum, nucleus accumbens, and amygdala) and the lower brainstem systems (mesolimbic dopamine projections and parabranchial nucleus of the pons) (Figure 2.7) (Berridge et al., 2010). Although "liking" may be confused with "wanting", research has established the two are independent variables, both psychologically and neurobiologically (Berridge et al., 2009). 


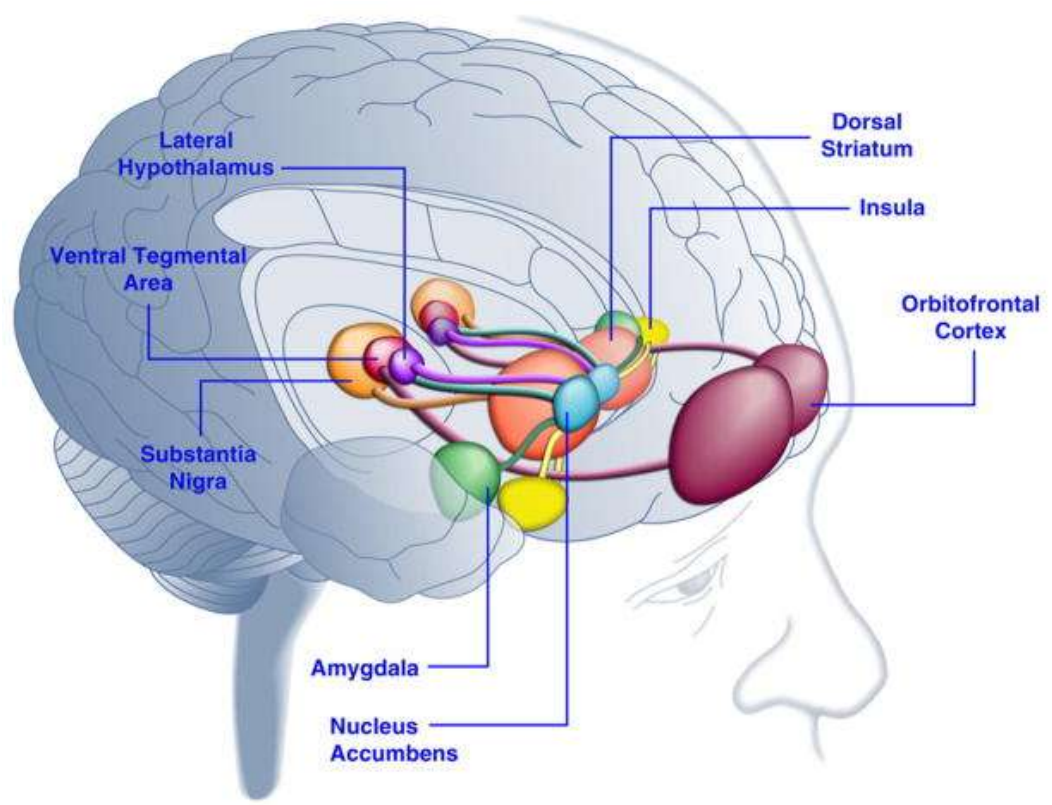

Figure 2.7 Areas of the human brain activated in response to palatable food or foodassociated cues (excerpted from Kenny, 2011)

Wanting is a fundamental type of incentive motivation that can be triggered by reward related cues. Typically defined as incentive salience, "wanting" can motivate an increase in consumption even if hedonic "liking" does not increase. "Wanting" most relevantly influences food intake; as individuals experience reward with certain foods, the motivational 'magnet' becomes stronger toward said stimulus due to the learned behavior. The mesolimbic dopamine system is the best known neural substrate to enhance "wanting" without "liking". Dopamine, which is a pleasure neurotransmitter, can be activated by pleasant foods, hedonic rewards, or reward cues (Berridge et al., 2010). Leptin and insulin are two nutritionally relevant hormones involved in modulating the "wanting" of food; both can act directly on mesolimbic dopamine neurons (Zheng and Berthoud, 2007).

The reward process is comprised of not only the physical taste stimulus, but the individual's psychological state as well as previous experiences (Berridge and Robinson, 
1998). The brain is hardwired to like certain tastes; however, the innate predispositions can be altered through experience. Hedonic biases are not fixed, but rather impressionable. Taste aversion learning is one way researchers have identified how learning impacts food reward. A once "liked" sweet taste can become disliked even though the flavor has stayed constant. A salty taste, which may be displeasing at first, can become pleasant during salt appetite, or when the body lacks sodium. Once cultural experience has altered the hedonic brain systems, typically unpleasant bitter flavors, such as beer and coffee, can become pleasant (Berridge et al., 2010).

Understanding the role of brain reward systems can offer insight into the growing rate of obesity. Temptations to eat, and to continue eating, are stronger today than in prior generations. Commonly consumed convenience foods are easier to obtain and contain higher amounts of sugar, fat and salt. In addition, portion sizes have increased and people tend to snack more in between the traditional three meals a day. The brain reward systems have become biased because of these factors and in turn, individuals give in to the cravings and consume more food. The reward system response may differ from person to person.

\section{Gray's Theory of Brain Functions and Behavior}

Gray's Model proposes two qualities of personality; anxiety and impulsivity, which represent individual differences to response sensitivity of two neurological systems to environmental cues. The two neurological systems are identified as the Behavioral Activation System (BAS) which regulates appetitive motivation, and the Behavioral Inhibition System (BIS) which regulates aversive motivation (Carver and White, 1994). 
These two motivational systems reflect brain structures that influence the sensitivity to reinforcing events and control the experience of emotion (Molto et al., 2001).

The BAS is responsible for approach behavior in response to incentives including: signals of reward, non-punishment, and escape from punishment (Molto et al., 2001). Activity in the behavioral activation system propels an individual toward goal oriented behavior; producing positive feelings such as hope, elation and happiness. A greater BAS sensitivity reflects a person's tendency to participate in goal directed efforts and experiences which would elicit positive feelings. The neural basis for BAS is less specified than BIS, but dopaminergic pathways are said to play a critical role (Carver and White, 1994).

The BIS, which controls aversive behavior, is sensitive to signals of punishment, non-reward, and novelty. The behavioral inhibition system is directly related to the personality quality of anxiety; individuals with a greater BIS sensitivity also have a greater propensity towards anxiety (Molto et al., 2001). The system minimizes behaviors that may lead to negative or painful outcomes; causing a decrease in goal oriented behavior. In addition, the BIS is responsible for experiencing negative feelings including fear, frustration and sadness (Carver and White, 1994).

The BAS and BIS, independent and orthogonal systems, represent distinct structures in the human nervous system. They are not only separated pharmalogically but by brain lesions as well (Carver and White, 1994).

Gray developed the BIS/BAS scales to assess individual differences in the sensitivity of the systems. The BAS system can be broken down into three separate scales: BAS drive, BAS fun seeking, and BAS reward responsiveness; each measure 
related to a non-specific concept of reward. The BIS system has only one measurement scale (Molto et al., 2001). The BIS/BAS questionnaire (Appendix B) is comprised of 24 agree/disagree statements using a 1-4 scale ( 1 = very true for me, $4=$ very false for me); with four questions related to both the BAS drive scale and BAS fun seeking scale, five questions related to the BAS reward responsiveness scale and seven questions related to BIS; four questions are used as fillers (Molto et al., 2001; University of Miami, 2007).

\section{Sensitivity to Punishment and Sensitivity to Reward Questionnaire}

The Sensitivity to Punishment and Sensitivity to Reward Questionnaire (SPSRQ) (Appendix C) serves as a tool to investigate Gray's model in normal populations. The Sensitivity to Punishment (SP) scale was designed to assess individual differences in the activity of the BIS. Published originally by Torrubía and Tobeña in 1984, the "Susceptibility to Punishment" scale was comprised of 36 yes-no questions about behaviors in response to cues of punishment, non-reward, and novel stimuli. The scale was later revised to contain 24 questions and was the title changed from "Susceptibility to Punishment" to "Sensitivity to Punishment". The Sensitivity to Reward (SR) scale, which contains 24 yes-no questions as well, was created to measure differences in the impulsivity dimension (BAS). The SPSRQ is used in conjunction with the BIS/BAS questionnaire as well as independently to assess reward mechanisms in individuals (Molto et al., 2001).

\section{Sensitivity to Reward and BMI}

Brain reward mechanisms play a significant role in the study of eating behavior and obesity; this research is important to multiple scientific disciplines including psychologists, nutritionists, neurobiologists, and food scientists. Eating behavior is driven 
by the rewarding value of food. Sensitivity to reward is significantly correlated with body mass index (BMI). Davis and Fox (2008) have found that individuals having a high sensitivity to reward (more sensitive BAS) have a greater propensity to notice signals of reward in the environment; these individuals also experience more positive emotions. Reward sensitive individuals typically consume more due to the hyper active dopamine system. In addition, there is evidence of a positive relationship between impulsivity and overeating (Franken and Muris, 2005).

\section{Food Preferences - Innate versus Learned}

With more than 10,000 taste buds located in the human mouth, it is no surprise that taste is the most important consideration in food choice. All humans experience basic tastes: salt, sweet, sour, and bitter. Although many studies focus on the major role that learning plays in eating behaviors, there is also research that focuses on human's innate tendencies in relation to food consumption (Berridge et al., 2009; Sijtsema et al., 2002). Humans are intrinsically drawn to salt and sweet but tend to avoid bitter and sour tastes. These predispositions are a direct response of natural selection. In nature, poisons are bitter, sour is not ripe, sweet indicates a ripe fruit, and a preference for salt produces ingestion of needed minerals (Prescott, 2012).

Fat. Humans and animals have adapted over time, learning which foods to consume because they are healthy and which to avoid because they contain illnesscausing elements. Throughout the human evolutionary process, adequate food supplies were not readily available. In order to survive, humans needed to learn which foods contained higher caloric values and which contained greater nutritional values. Calories provide energy and adequate calorie intake is necessary for the body to function properly. 
Knowledge of high calorie food sources is not innate; it is a learned behavior. After much exposure, animals and humans adapted; they learned to prefer food that contained substantial amounts of calories and nutritional value (Logue, 1998).

Booth et al. (1982) demonstrated that human adults can learn to consume smaller meals when the meals contained a disguised high calorie starch load associated with a distinctive taste. If the meals were consumed when the subjects were food deprived, their preferences for those meals increased. Conversely, preference for the meals decreased when the subjects were satiated (Booth et al., 1982).

Fat has twice the amount of calories per gram when compared to proteins and carbohydrates. The drastic caloric difference explains why humans have learned to prefer high-fat foods. High-fat foods were not available throughout the evolutionary process; however, high-fat foods are now readily available and inexpensive. In today's Western culture, preferences for high calorie foods make it difficult to keep fat consumption low, even with the knowledge that high calorie foods add to the obesity epidemic. Humans have adapted over time, yet more adaptation is necessary in order to maintain overall health and wellness in the today's Western culture.

Sweet. Although the preference for high-calorie foods is a learned behavior, the preference for sweet foods is innate. In nature, sweet tastes are associated with readily available sugar, hence readily available calories. The sweetness component in plants is a sign of vital nutrition in the presence of carbohydrates; carbohydrates, including sugars, being an excellent source of energy. Sweet fruit normally indicates ripeness, a quick source of sugar, and vitamins and minerals necessary for the body to function. Studies demonstrate humans of all ages pick sweet foods over non-sweet food options. Even 
infants indicate positive acceptance when they taste sweet for the first time, suggested by a slight smile (Logue, 1998; Prescott, 2012).

The taste of sweet is more important to the body than any other taste; biologically there is a genetic component favoring sweet. There are more receptors specific to the sweet taste on the surface of the tongue than any of the other basic tastes. Humans have evolved with an inherent preference for the taste of sweet; however, it today's culture sweet food and drinks may be more detrimental than beneficial. With so many sweet foods easily accessible and inexpensive, humans tend to overeat, ultimately resulting in the rise of obesity and adult onset diabetes.

Salt. Just as the body needs adequate nutrients and calories to properly function, salt is essential for survival. The concentration of salt in the blood must be kept at a specific level at all times. Small amounts of salt are lost continuously through sweat and kidney function. If the body does not have the proper amount of salt, it will excrete water in order to keep the salt level at an optimum concentration. The increase in salt and decrease in water ultimately results in death due to dehydration (Bloch, 1978).

Not only is salt not easily found in the wild; prior to industrialization humans struggled to find enough salt. Unlike sweet tastes, infants are not born preferring salt. Salt cannot be tasted until about 4 months of age. But by 24 months, humans learn which foods are typically salty and reject those foods when the salt levels are not high enough. The preference for salt, although developed later than the preference for sweet, still appears to be universal and genetic. Similar to sweet and fat, the preference for salt can also be influenced by experience. With the abundance of processed food and fast food chains, humans exceed the daily salt intake, contributing to the rise of hypertension. 
Taste is the most important consideration in food choice. Palatable foods promote eating; triggering learned connections between food and reward. Modern Evolutionary Theory, states that learned connections ensure food is consumed when available, allowing the body to store energy for future needs, protecting against times of food scarcity. In today's Western culture where food is widely available, this learned association has become a liability, contributing to the obesity epidemic (Volkow et al., 2011).

\section{Shift in Food Consumption Models}

The continuous shift away from the Homeostatic Model is significant to many scientific disciplines. If eating patterns and preferences are learned behaviors, then they can be modified. There is a predisposition to prefer fat, salt and sugar but if preferences are learned, then they can be altered, specifically through conditional training (Logue, 1998).

For example, if one dislikes a specific vegetable, then eating that vegetable repeatedly will eventually result in a 'learned' preference. Broccoli is often accompanied by a cheese sauce or cream based dip. Although these high fat sauces cover up the natural broccoli flavor, they also cause the body to become accustomed to the broccoli flavor in general. In time, dips and sauces can be reduced and eventually removed resulting in a positive learned preference. Studies have found that individuals can modify predispositions to fat, salt and sugar; focusing on unpleasant thoughts while eating those foods will result in reduced preferences. Levine et al. (2003) found that consuming less of certain foods will result in reduced cravings. 
Traditional learning theory states that any event could be associated equally with any other event; learning cannot occur if there are delays of more than a few seconds between the events and many trials are necessary for learning to occur (Schwartz, 1974). Taste aversion learning contradicts the assumptions associated with traditional learning. Generally, taste aversions do not form easily. The most easily acquired are when gastrointestinal distress, particularly nausea, occurs (Pelchat and Rozin, 1982). Time and repetition assumptions are also contradicted; taste aversion can be acquired in a single trial with delays up to 24 hours between consumption and illness. Food infection and intoxication both have different onset periods. Depending on the severity, some take minutes for illness to start, while others take hours, or even days.

The properties of conditioned and unconditioned stimuli involved in taste aversion learning vary when compared to stimuli involved in traditional learning. The unconditioned stimulus in taste aversion is the illness itself while the conditioned stimulus is the taste of the food. When illness occurs, that food is typically avoided whenever it is encountered again in the future. The hedonic value of the taste also changes when paired with an illness. Instead of the taste resulting in future illness, the taste becomes ultimately disliked. The liking of the conditioned stimulus changes (Garcia et al., 2014). Taste aversion learning has helped organisms avoid illness-causing food elements demonstrating how learning has been shaped by the evolutionary process.

\section{Traditional Sensory Testing Methods}

Current sensory evaluation principles stem from physiology, psychology, and psychophysics. The Sensory Evaluation Division of the Institute of Food Technologists defines sensory evaluation as: "a scientific discipline used to evoke, measure, analyze and 
interpret reactions to those characteristics of foods and materials as they are perceived by the senses of sight, smell, taste, touch, and hearing" (Stone et al., 2012). Traditional sensory methods are categorized as: discrimination, descriptive, and affective (Figure 2.8); each of these classifications is utilized in industry today.

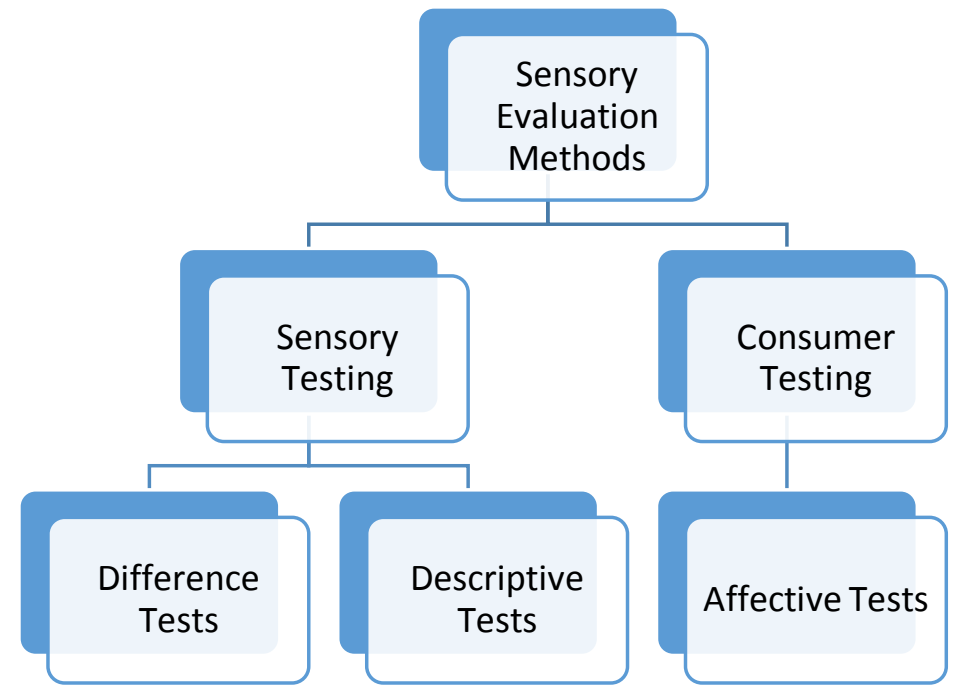

Figure 2.8 Traditional sensory evaluation methods

\section{Discrimination}

Discrimination tests, one of the two most useful analytical tools available, answer the basic question: "Are two products perceived as different?". Discrimination tests are commonly used to determine whether or not small changes in product ingredients, processing, or packaging have an effect on the sensory attributes of a given product. These tests are quick and simple to perform; however, they offer limited information. Researchers can only conclude if a perceived difference has been identified. There are three main types of discrimination tests: paired-comparison, triangle and duo-trio (Stone et al., 2012). 
Paired-Comparison. The paired-comparison test is the earliest example of a discrimination test used for food and beverage evaluation. Cover (1936) used the then 'paired eating' method to evaluate meat. The method was then adapted and used for beverage evaluation at the Carlsberg breweries (Helm and Trolle, 1946), Seagram and Sons quality Research laboratory (Peryam and Swartz, 1950) and utilized at the U.S. Army Quartermaster Food and Container Institute. This two sample test requires subjects to indicate which sample has more of a designated characteristic. A wide variety of characteristics/attributes can be tested including sweetness, tartness, or saltiness. The forced choice testing procedure requires subjects to make a decision, either selecting Product A or Product B, with a chance probability of $p=1 / 2$ (Stone et al., 2012).

Duo Trio. Peryam and Swartz (1950) developed the duo-trio test as an alternative to the triangle test while working with the Quartermaster Food and Container Institute. The duo-trio test, involving three unknown samples, is more complex psychologically. Subjects are presented with three samples; two labeled with 3-digit codes and the third used as the reference. Subjects are then instructed to indicate which sample is most similar to the reference. The duo-trio test is commonly used for products that have intense odors or flavors. The chance probability is the same as a paired-comparison or other two product test, $p=1 / 2$ (Stone et al., 2012).

Triangle. Triangle tests are considered more sensitive than the other two discrimination testing methods. The triangle test is the most well known and most commonly utilized. The method was developed at the Carlsberg Breweries for beer evaluation (Helm and Trolle, 1946). Subjects are presented with three samples, two of the same product and one of a different product. Subjects are asked to identify which sample 
is different. The probability of detecting the correct "different" sample is $p=1 / 3$. Triangle tests are not only the most sensitive, but can also be the most challenging because subjects must evaluate three different samples, remembering the sensory characteristics of each (Stone et al., 2012).

\section{Descriptive}

One of the most sophisticated methods available to sensory scientists is descriptive analysis; it is a tool for comparing products similarities, differences, and specific attributes impacting preferences. Descriptive analysis involves describing product attributes, both qualitatively and quantitatively, by using a small number of trained, qualified subjects, usually 10-12. Subjects are responsible for providing word descriptions for each product. After product evaluation and description of the sensory attributes, trained panelists quantify the perceived stimuli (Cássia et al., 2012). Researchers use the qualitative and/or quantitative information to determine which specific variables (i.e. processing or ingredient) have an impact on sensory attributes. Descriptive analysis is defined as: “... a sensory methodology that provides quantitative descriptions of products, obtained from the perceptions of a group of qualified subjects. It is a complete sensory description, taking into account all sensations that are perceivedvisual, auditory, olfactory, kinesthetic, etc.- when the product is evaluated...The evaluation is defined in part by the product characteristics as determined by the subjects and in part by the nature of the problem" (Stone et al., 2012).

In general, descriptive methods are designed to evaluate products with a high degree of consistency and precision (Stone et al., 2012). Today, there are several descriptive analysis methods used in industry including the: Flavor Profile Method, 
Texture Profile Method, Quantitative Descriptive Analysis® (QDA), Spectrum ${ }^{\mathrm{TM}}$ method, and Free-Choice Profiling. Each method serves a specific purpose making method selection essential in order to support the project objectives.

Flavor Profile. The Flavor Profile method, the first formal descriptive method, was developed as a tool to analyze differences in flavor based on individual character notes, degree of blending, and overall amplitude (Moskowitz, Beckley, \& Resurreccion, 2006). A panel of roughly six screened, trained and qualified subjects examine and discuss products as a group and report qualitative results (Stone et al., 2012). The Flavor Profile method is the most rigorous descriptive method; panelists are trained extensively to function as human analytical instruments (Moskowitz et al., 2006).

Texture Profile. The Texture Profile method, developed following the Flavor Profile method, defines textural properties of foods. The texture complex can be broken down and examined in terms of mechanical, geometric, fat, and moisture characteristics. Overall, the Texture Profile method eliminates problems with subject variability, compares results with known materials, and establishes a relationship with instrument measurements (Moskowitz et al., 2006).

Quantitative Descriptive Analysis ${ }^{\circledR}(Q D A)$. The QDA method relies on statistical analysis to determine appropriate terms, procedures, and subjects for product analysis. QDA is led by a moderator; ten to twelve panelists are trained extensively in order to develop terminology, definitions, and evaluation procedures. The products are then evaluated, using $15-\mathrm{cm}$ line scales, by panelists individually and independently of one another (Moskowitz et al., 2006). 
Spectrum $^{\mathrm{TM}}$ method. The Spectrum Method, designed to provide thorough, detailed, and accurate descriptive characteristics of a product's sensory attributes, gathers both qualitative and quantitative data. Similarly to the QDA method, a moderator leads twelve to fifteen trained panelists who develop terminology, definitions, and evaluation techniques used for product evaluation. The products are then evaluated, using 15-point or 150-mm line scales, individually in separate booths (Moskowitz et al., 2006).

\section{Affective}

Affective testing, also referred to as acceptance, preference or consumer testing, is another classification of sensory evaluation; the overall objective of an affective test is to measure the liking or preference of a product. Affective tests gather data about specific sensory properties of a product, such as overall liking, appearance, aroma, flavor, texture, and aftertaste (Moskowitz et al., 2006). Typically, 75-100 untrained consumers are selected for affective testing. Consumers act as a measuring device, assigning numbers or words from a scale.

The most frequently used method to determine product preference is the paired preference test, a type of affective testing. The paired preference test is similar to the paired-comparison discrimination test; however, for paired preference testing consumers are asked to select which product is preferred.

Acceptance testing utilizes scaled measurements to determine the degree of liking. Although there are a variety of scales used in acceptance tests, the 9-point hedonic scale is most common. Hedonic scales can be used to quantify product or attribute acceptance. Preference can be indirectly compared when testing two or more samples using an acceptance test. Researchers can also utilize the data to directly compare product 
attributes in order to determine which score higher or if significant differences are present (Stone et al., 2012).

Hedonic Scaling. The most commonly used scaling method, the hedonic scale, has been used for over 50 years. It was originally used for acceptance testing in the U.S. Army (Moskowitz et al., 2006). There are many variations of the hedonic scale including 3-, 5-, 7-, and 9- point scales. The 9-point hedonic scale (Figure 2.9) is most commonly used for consumer evaluation purposes; it is a balanced bipolar scale with a neutral center (Lim, 2011). Each point on the scale is labeled with a descriptive phrase; for example, 1 $=$ dislike extremely and $9=$ like extremely. Adaptations, such as the face scale, have been designed in order to work more effectively with younger consumers. Rather than having a box associated with each point, a facial expression is shown on the scale (Figure 2.10). The hedonic scale allows researchers to quantify consumer responses.

Overall, how much do you like or dislike sample 371?

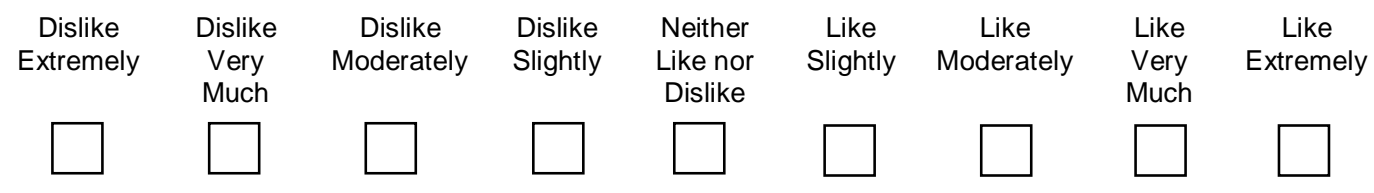

Figure 2.9 Example of a typical 9-point hedonic scale

Overall, how much do you like or dislike sample 598?
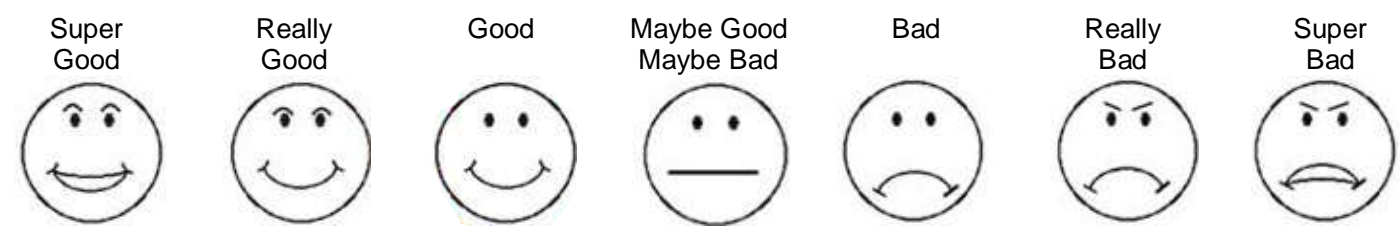

Figure 2.10 Example of a 7-point facial scale 


\section{Traditional Method Limitations}

Traditional sensory and consumer methods fail to guarantee accurate long-term product acceptance, as evidenced by the high failure rates of new products. Traditional methods reflect conscious processes, whereas consumer acceptance and product liking may be based on the unconscious processes as well. These unconscious processes may be measured using implicit physiological and behavioral measures (de Wijk et al., 2012). Traditional methods, a proven critical component in consumer research and sensory science, provide the framework necessary for the expansion of new methods and applications.

In recent years, there has been growing interest in using more sophisticated physiological and psychological approaches in measuring consumer behavior (Stone et al., 2012). The Sensory Evaluation Division of the Institute of Food Technologists defines sensory evaluation as: "a scientific discipline used to evoke, measure, analyze and interpret reactions to those characteristics of foods and materials as they are perceived by the senses of sight, smell, taste, touch, and hearing" (Stone et al., 2012).

Sensations and hedonic experiences are individualized experiences and cannot be shared directly with others. In order to produce products that appeal to consumers, physiological and psychological characteristics that affect food intake and eating behaviors must be examined. Traditional sensory methods may measure the response but they fail to account for emotion which highly influences eating behavior (Lim, 2011).

\section{Emotion and Emotion Measurement}

Research continues to focus on the complex relationship of eating behavior and emotion, ranging from the obvious connection to the more subtle, subconscious 
connection (Gibson, 2006). Sensory, physiological or psychological mechanisms are involved and can be studied from two perspectives: the effects of emotion on eating behavior and the effects of eating behavior on emotion (Schifferstein and Desmet, 2010). In order to properly utilize emotion measurement technology, researchers must first understand emotions in general.

Emotion theorists clearly distinguish emotions from moods; a mood lasts longer and is not focused on a reference while an emotion is a mental reaction focused specifically on a reference (Ferrarini et al., 2010). Emotions are unconscious physiological responses to meaningful external stimuli (de Wijk et al., 2012). At the most general level, emotions can be viewed as positive or negative, those of arousal or displeasure. Consumer emotions are typically categorized as positive or negative (King and Meiselman, 2010). Early emotion research indicated consumers use positive terminology more often than negative when describing food experiences or reactions to specific food products. However, in the list of "basic emotions" drawn from the literature, which encompasses 39 basic emotions, the number of negative emotions far exceed the number of positive emotions (Laros and Steenkamp, 2005). Desmet and Schifferstein (2010) denote the positive bias as "hedonic asymmetry", attributed to the positive experience of eating food and the fact that food products are designed to elicit positive responses.

Emotion plays a vital role in food consumption and eating behavior, compelling the food industry to use emotion testing alone and in conjunction with traditional consumer sensory evaluation methods (King and Meiselman, 2010). Consumer scientists hypothesize that eating behavior and food choice are driven not by product taste alone but 
by emotional responses as well, prompting the use of emotion testing methods (Seo et al., 2009). A variety of emotion testing methods have been researched and developed due to the promising future emotion measurement has in sensory evaluation (King and Meiselman, 2010; Thomson et al., 2010; Seo et al., 2009).

\section{Current Emotion Testing Methods}

Current emotion measurement methods are conducted in three distinct ways: selfreport questionnaires, autonomic measurements, and brain imaging techniques ( $\mathrm{Ng}$ et al., 2013). Self-report questionnaires are most commonly used in consumer testing.

\section{The EsSense Profile ${ }^{\mathrm{TM}}$ Method}

The EsSense Profile ${ }^{\mathrm{TM}}$ Method was developed in 2008 by King and Meiselman (2010) as a new emotion testing method. The purpose of the method was to gain a better understanding of the consumer's emotional response to a product, rather than a brand, and to measure emotions, rather than moods. Although the method was originally developed for commercial testing it provides information beyond acceptability. The emotion scores can be compared to traditional consumer testing scores, such as hedonics and acceptability. The EsSense Profile ${ }^{\mathrm{TM}}$ Method utilizes 39, mostly positive, emotions. A choose-all-that-apply (CATA) format was determined to be the most effective way to distinguish products with different flavor profiles, while scaling questionnaires were most effective at determining different flavors within the same product. Most effective when tested in a CLT or internet survey, the method provides a common emotion language that can be used to facilitate communication about emotions between sensory scientists, marketing, and product developers (King and Meiselman, 2010). 


\section{Best-Worst Scaling}

Best-Worst Scaling was developed in order to capture fundamental motivations and conceptualizations which influence choice. This emotion measurement method goes beyond the obvious factors that influence liking. The use of words in emotion research has been criticized; it is wrongly assumed that words require a type of measurement scale. The use of scaling leads consumers to think about the meaning of the words, resulting in cognitive, rational thinking. The purpose of best-worst scaling is to capture non-cognitive information about emotions. Best-worst scaling allows researchers to utilize words without requiring measurement scales (Hein et al., 2008). When implementing the best-worst scaling method, subjects are provided with the test product and four or five words, selected from a larger list of terms. The subject would select the words that are most and least related to their experience with the test product. This procedure is completed multiple times with the same product until a group of 16-30 words are selected. Upon completion, researchers have the most and least important terms for the given product (Thomson et al., 2010).

Emotion measurement methods are not limited to the EsSense Profile and BestWorst scaling. PrEmo, Facial scaling as well as Image Measurement of Emotions and Texture are three other methods currently being researched in industry settings. Although, verbal measurement techniques are the most commonly used the use of nonverbal measurement methods are increasing in popularity.

\section{FaceReader}

Non-verbal emotion measurement techniques utilize facial expressions. The link between facial expressions and emotions date back to Darwin (Darwin, 1958; de Wijk et 
al., 2012; Ekman, 2009). Facial expressions, elements of a synchronized response involving multiple biological response systems, are clearly visible, long-lasting, and universal across cultures. They are related to physiological responses in the autonomic nervous system which show different patterns for different expressions and their underlying emotion (Ekman, 1992). Micro expressions, the short-lasting facial expressions, may be even more useful in predicting food preferences (de Wijk et al., 2012).

FaceReader, a computer program, automatically analyzes facial expressions. This facial analysis software is one of the most advanced tools currently available, providing researchers with an objective evaluation of a person's emotion. The program classifies the seven basic or universal emotions, as described by Ekman: happy, sad, angry, surprised, scared, disgusted and neutral. Emotions can be broken down into three categories: positive (happy), negative (sad, angry, scared and disgusted) and neutral (neutral). FaceReader utilizes facial recognition technology that can eliminate inconsistencies commonly found within verbal emotion testing. Not only does FaceReader eliminate a language translation barrier that can occur when measuring across cultures, but it eliminates the subjective feelings of a consumer, creating a standard way to measure a consumer's subconscious emotion (Loijens and Krips, 2013).

\section{Theories about Emotion and Eating Behaviors in Obese Individuals}

Early theorists researched overeating in only obese individuals; current research focuses on overeating in normal, overweight, and obese populations (Canetti et al., 2002). The three dominant theoretical perspectives relating emotions and eating behaviors, psychosomatic, externality, and restraint, focus on obesity and the decision making 
process behind eating behavior. The psychosomatic theories focus on emotional influences, externality theory focuses on sensory influences, and restraint theory focuses on cognitive influences (Brogan and Hevey, 2012).

The psychosomatic theories states that obese individuals eat in response to emotional distress, particularly anxiety and depression (Kaplan and Kaplan, 1957; Allison and Heshka, 1993). Obesity is the direct result of pathological personality structures or processes. Obese individuals eat in response to negative emotional stimuli more than non-obese individuals (Allison and Heshka, 1993).

Kaplan and Kaplan psychosomatic theory of obesity (1957) suggests that obese individuals overeat when anxious and that eating reduces the anxiety. The biological mechanism involved is not fully understood; however, researchers propose the mechanism may involve the synthesis of brain neurotransmitters, specifically serotonin. The consumption of protein and carbohydrates may affect the synthesis of the neurotransmitters. In addition, learning factors are involved; for example individuals have learned associations between happy times and eating. The basis of learned habits cannot solely explain the anxiety reducing effects of eating. A psychological factor must play a role; researchers hypothesized that the emotions of intense fear or anxiety are temporarily reduced during the act of eating. Obese individuals are unable to differentiate hunger and anxiety, learning to eat in response to hunger as well as anxiety. Therefore, eating in response to anxiety may lead to compulsive eating and obesity (Kaplan and Kaplan, 1957) (Canetti et al., 2002).

Bruch's Theory, another psychosomatic theory, proposes the feeling of "hunger" is not innate but learned. A normal response to emotional stress is loss of appetite 
because emotional stress inhibits gastric motility, leading to the release of sugar from the liver into the bloodstream; this response is similar to the feeling of satiety (Brogan and Hevey, 2012). Bruch linked overeating to a damaged understanding of hunger. Since "hunger" is a learned feeling, Bruch believed that obese individuals never learned the correct feeling of "hunger", developing a faulty hunger sensor. Early experiences contribute to the inability to distinguish between hunger and other signals of discomfort or emotional distress. Individuals do not recognize hunger or satiety, nor can they tell the difference between the need for food from other uncomfortable feelings; emotional distress and the need to eat are equivalent. The inner awareness of food intake has been wired incorrectly; individuals need external signals in order to make "normal" food choices. According to Bruch's Theory, individuals overeat in response to "emotional tension" and "uncomfortable sensations and feelings" (Canetti et al., 2002).

While the psychosomatic theories focus on how emotions influence eating behaviors, the externality theory focuses on how external stimuli influence eating behaviors. "External eating" refers to eating that is independent of an individual's internal state. External factors, which may affect food intake but are unrelated to nutrition, include cognitive and sensory cues such as taste, aroma, social environment, and habit. In external eating, there is insensitivity to internal hunger and satiety cues; the choice to overeat is driven by a heightened sensitivity to food cues. Psychosomatic and externality theories state that obesity can be caused by an individual's inability to comprehend the internal state prior to eating. However, the trigger for overeating differs in each perspective; psychosomatic theories focus on the psychic states and the externality theory focuses on external food related stimuli (Brogan and Hevey, 2012). 
Eating behaviors are influenced by not only emotional and sensory factors, but cognitive factors as well. The restraint theory focuses on cognitive influences impacting eating behaviors. Restraint theory was initially envisioned based on Nisbett's set-point theory. Set-point theory hypothesized that individuals, both normal and obese, have a predetermined weight based on the number of fat cells in the body; individuals eat in order to align their weight with this biologically determined set-point. Some researchers oppose the biological set-point premise, stating that individuals are pressured by cultural and social demands. Today's cultural and social message to be slim and fit results in restrictive eating. The theory proposes that cognitive efforts to chronically and consciously restrict food intake lead individuals to a physiological deprivation which results in a predisposition to counterregulatory eating (Brogan and Hevey, 2012; Polivy et al., 1988).

Counterregulation, the breakdown of restrictive control, results in excessive food intake. Counterregulation can occur when self-control processes are weakened; contributing factors are alcohol, high calorie food, anxiety and depression. The restraint theory examines both "external" and "emotional eating" as the consequence of intense dieting; the cycle of restraint eating and counter regulation can lead to an inability to differentiate feelings of hunger and satiety (Van Strien et al., 1995).

As obesity continues to rise, researchers and health professionals are examining eating behaviors in order to understand food consumption. The psychosomatic, externality, and restraint theories offer a framework as to how emotional, sensory, and cognitive influences contribute to eating behavior (Brogan and Hevey, 2012). 


\section{Weight Measurement Classifications}

There are three main methods used to classify weight: body mass index (BMI), body fat percentage, and body fat distribution. According to the Centers for Disease Control and Prevention, calculating body mass index is one of the best methods for determining overweight and obesity statistics. BMI is used to identify body weight ranges; it is a measurement based on an individual's height and weight. BMI is calculated by dividing the individual's weight (in kilograms) by the individual's height squared (in meters) (Whitney et al., 2008) (Figure 2.11).

$$
B M I=\frac{(\text { weight }(\mathrm{lb}) \times 703)}{\text { height }(\mathrm{in})^{2}} \text { or } B M I=\frac{\text { weight }(\mathrm{kg})}{\text { height }^{2}(\mathrm{~m})}
$$

Figure 2.11 BMI calculation (adapted from Centers for Disease Control and Prevention, 2011)

Although BMI does not measure body fat directly, it remains a reliable indicator of body fatness for most individuals. Research has shown that BMI correlates directly to an individual's body fat. BMI is a quick, inexpensive and easy-to-perform method of screening for weight categories and considered a reliable alternative for direct measures of body fat (Centers for Disease Control and Prevention, 2011).

Weight classifications based on BMI fall into five distinct categories (Table 2.1): underweight with a BMI below 18.5, normal weight with a BMI range of 18.5 to 24.9, overweight with a BMI range of 25 to 29.9 , obese with a BMI range of 30 to 39.9 , and severe obesity with a BMI range of 40+ (Blake et al., 2010). Obesity-related diseases are more likely to affect those with a BMI greater than 25 . 
Table 2.1 Standard Weight Categories with BMI Ranges (adapted from Centers for Disease Control and Prevention, 2011)

\begin{tabular}{ll}
\hline BMI & Weight Status \\
\hline Below 18.5 & Underweight \\
$18.5-24.9$ & Normal \\
$25.0-29.9$ & Overweight \\
30.0 and Above & Obese \\
\hline
\end{tabular}

BMI reflects a calculation based strictly upon height and weight; body composition is not taken into account. Some individuals, such as professional athletes or bodybuilders, may be classified as "overweight" according the BMI calculations, yet be perfectly healthy due to increased muscle mass; muscle mass and bone density needs to be taking into account for individuals who may fall into an improper category (Turocy et al., 2011).

Body mass index may be inexpensive, easy-to-take and highly accurate; however, the readings lack important information that may be helpful when assessing disease risk, specifically fat content and fat location. Body fat percentage and body fat distribution are also effective methods used to calculate obesity.

Women must have more than $32 \%$ body fat and men must have more than $25 \%$ body fat to be classified as obese. An individual's body fat distribution can be categorized as well. Android obesity and gynoid obesity are two classifications regarding distribution of body fat. Android obesity refers to excess subcutaneous and visceral fat stored in the upper body. Gynoid obesity refers to excess subcutaneous fat stored in the lower body (Blake et al., 2010). Body fat can be measured using a variety of methods including: skinfold measures, hydrodensitometry, bioelectrical impedance, or dual energy X-ray absorptiometry (DEXA). Eating behavior directly correlates to weight and weight is directly linked to disease risks and potential health complications. 


\section{Health Complications Associated with Weight}

There are significant health complications with being both overweight and underweight. Being overweight can increase the risk of numerous diseases including hypertension, stroke, heart disease, type 2 diabetes, inflammation and arthritis (Blake et al., 2010).

Hypertension, commonly referred to as high blood pressure, is the most common cardiovascular disease, affecting more than $30 \%$ of American adults. Blood pressure tends to increase with weight gain and age, making it more problematic in overweight individuals. In addition to weight and age, the consumption of sodium can increase hypertension. High blood pressure, the leading cause of stroke and heart attacks, is the primary cause of death among Americans older than 25 (Blackwell et al., 2014).

Heart disease is a general term used to describe a variety of ailments that affect the heart. Obesity is a primary cause of heart disease. (Roger et al., 2012). The treatments for heart disease vary, but lifestyle changes and medications may be necessary.

Type 2 diabetes is a chronic condition that affects the way the body metabolizes glucose; the body either resists the effects of insulin or produces insufficient insulin to maintain normal glucose levels. Insulin, the hormone that regulates the movement of sugar, is the main source of energy into the body's cellular system. Many individuals, children and adults, with type 2 diabetes are overweight or obese; an obese person is three times more likely to develop type 2 diabetes that a non-obese person. Adolescents who develop type 2 diabetes are at a greater risk for developing cardiovascular diseases (Lamichhane et al., 2012). There is no cure for this disease; however, it can be managed through proper diet, exercise and maintenance of a healthy body weight. 


\section{Food Industry Response}

In order to respond to the obesity epidemic within the American population, food scientists' research is focused on ways to support and enhance the food supply. Sensory and consumer researchers study what drives food consumption in order to produce healthy food products consumers will purchase and consume.

\section{Drivers of Food Consumption}

What really drives food consumption? Research indicates that taste is the primary factor when making food choices however, cost, nutrition, convenience, environment, weight concern, advertising, habits and emotions also influence food choice (Figure 2.12) (Glanz et al., 1998). In reality, food choice is the result of a complex combination of the drivers listed above.

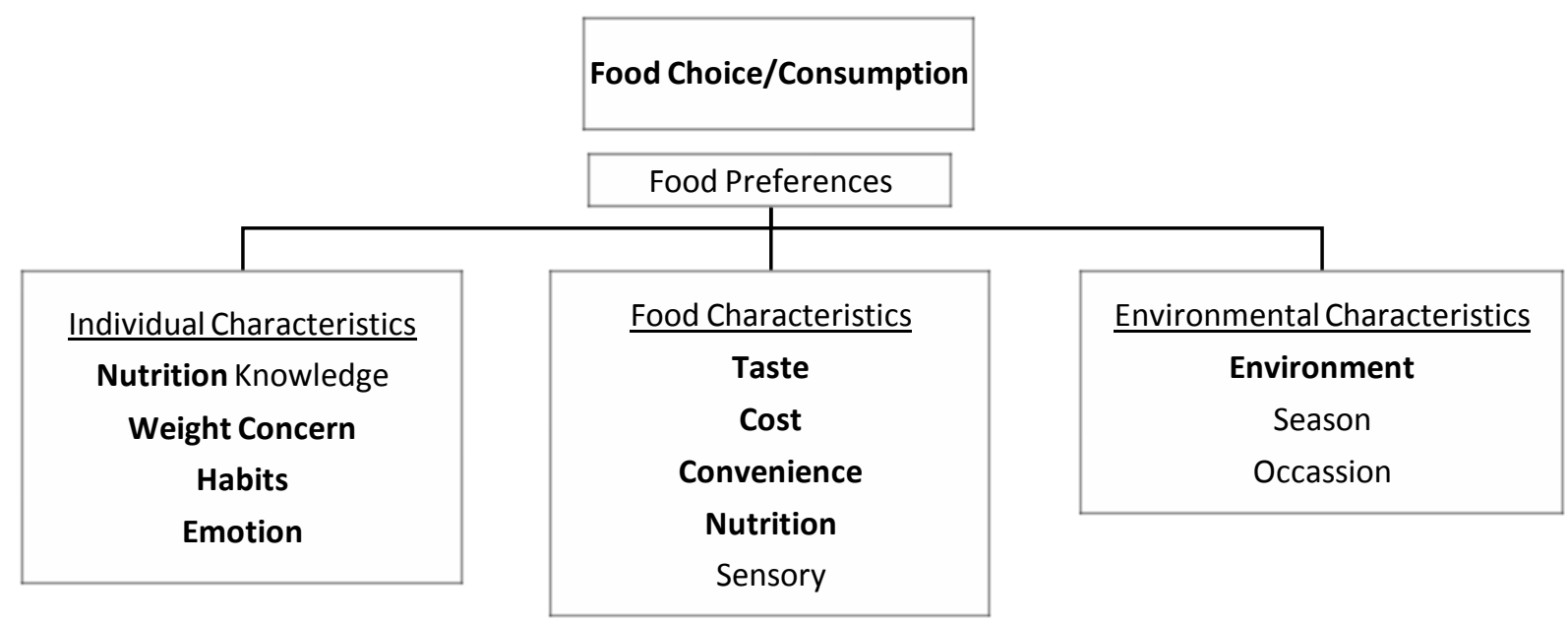

Figure 2.12 Drivers of food consumption. (adapted from Randall and Sanjur, 1981 and Glanz et al., 1998)

Sensory characteristics, including taste and texture, play an important role in food choice. The five basic tastes identified within the food industry are sweet, salty, sour, bitter, and umami. It is the integration of the sensory attributes of foods including taste, 
texture, aroma, and appearance, that impact the ability to recognize and enjoy food (Prescott, 2012). Genetics and age may alter the degree to which we enjoy foods, specifically sweet or salty foods. Research has shown that preferences for sweetness, high fat, and specific textures are hardwired and difficult to alter (Mennella, 2007).

According to a 1998 consumer study, cost is the secondary consideration in food choice (Glanz et al., 1998). People eat foods that are affordable, accessible and easy to prepare. Limited finances produce a shift from more expensive fruits and vegetables to cheaper high-fat and high-sugar prepackaged foods.

Consumers are willing to spend more money for products that are quick and easy to prepare, however, the health value of convenience products can vary greatly. The food industry has responded by focusing on manufacturing and producing quality, convenient food items. (Brunner et al., 2010).

As health information becomes more available and accessible, Americans are becoming more health conscious with a focus on eating behavior and food choice (Kearney, 2010). Consumers are looking more closely at the nutritional content of food, buying functional foods that provide greater health benefits. Foods are also being modified to provide greater health benefits; food companies fortify foods by adding nutrients or phytochemicals. Decisions based on nutritional and fitness information can be beneficial but can also be detrimental if based on inadequate information or the latest fad diet (Whitney et al., 2008).

Food companies spend $\$ 10$ to $\$ 15$ billion annually on food advertising (Linn and Novosat, 2008). Exposure to television and social media advertising is one of the largest 
factors responsible for the obesity epidemic among children in the United States (Kearney, 2010).

Habits are one of the most powerful predictors of eating behavior (van't Riet et al., 2011),developing through learned associations between stimuli and response (Wood and Neal, 2007). Repetition is key in habit formation; eating behaviors that are rewarding are often repeated, resulting in a habit (Wood and Neal, 2009).

Emotion plays a critical role in food selection, directly correlating to food choice and eating behavior. Research indicates that consumption of specific foods can increase feelings of joy and decrease negative feelings such as helplessness, depression, loss of control, distress, and stress. Specific food items do not merely represent a means to satiety but can also signify comfort or reward (Hamburg et al., 2014). In addition, feeling happy or sad trigger specific eating behaviors; for many individuals food is used as emotional support during times of stress, depression, or joy (Blake et al., 2010).

By focusing on the drivers of food consumption, the food industry can respond by producing tasty, affordable, convenient, healthy food options that satisfy the needs of the consumer.

\section{Alternative Nutrition}

Obesity is directly linked to high fat content, high sodium content, and over consumption; the food industry must work diligently to produce and provide alternative nutritional products that people will not only purchase but consume as well (Pray and Pillsbury, 2011). Now that food scientists understand what drives food consumption, new technologies can be utilized to provide healthier alternatives. Fiber is being used as a fat replacement in food production, multi-grain dough is being incorporated into baked 
products, reduced calorie beverages are produced and low and zero calorie sweeteners are available. Food scientists are responding to the obesity epidemic by reducing the energy density of foods, providing ready-to-eat portion-controlled fresh and frozen meals, producing fruit and vegetable based products, and enhancing nutrient dense foods.

\section{Cheese}

Cheese, one of the most ancient forms of food, dates back to $7000 \mathrm{BC}$ (Cruz et al., 2011). Today, cheese is consumed throughout the world, supplying essential nutrients in a convenient, economical, and flavorful food form. Cheese contains a substantial amount of protein, bioactive peptides, amino acids, fat, fatty acids, vitamins, minerals, and bioavailable calcium (providing one-third to one-half the recommended daily intake (1200mg)) (Walther et al., 2008). Regular intake of cheese has been shown to have antiobesity effects, anti-hypertensive properties and bone health benefits (Walther et al., 2008).

Human consumption of salt and fat has continued to increase, leaving Americans consuming too much sodium and too many calories from solid fats. The recommended daily sodium intake, set by the American Heart Association, is 1,500 milligrams. The average American consumes more than twice that amount, approximately 3,400 milligrams of sodium per day (American Heart Association, 2010). The average consumption of added fats has increased by two-thirds in the past 50 years. Today, roughly $40 \%$ of total calories are consumed from fat; while the Dietary Guidelines for Americans 2010 recommend $20 \%-35 \%$ of total calories from fat, and less than $10 \%$ of calories from saturated fat (American Heart Association, 2010). 
Cheese consumption has increased by more than $12 \%$ in the past decade; in 2012 alone, Americans consumed 33 pounds per capita (United States Department of Agriculture, 2014). The sodium levels in cheese vary widely. For example, a $60 \mathrm{~g}$ serving of mozzarella cheese provides approximately $20 \%$ of the recommended daily intake of sodium (Cruz et al., 2011). On average, one 50g serving of cheese can provide two-thirds of the recommended daily intake of fat (Walther et al., 2008).

Cheese has many health benefits; however, with the rise in obesity and hypertension cheese has a negative image due to the fat and sodium content. With nearly $75 \%$ of the sodium coming from processed foods, food manufacturers are presented with the opportunity to make a positive change through product innovation and development (American Heart Association, 2010). With cheese consumption dramatically increasing worldwide, the food and dairy industries are working to reduce the fat and sodium content without compromising flavor or sensory characteristics (Cruz et al., 2011). 


\section{Objectives}

The objectives of this study were:

1) To evaluate consumer acceptance of cheeses varying in fat and sodium levels

2) To examine the relationship between reward sensitivity, BMI, and gender

3) To determine if body mass index and gender have an effect on product liking based on fat/salt content

4) To determine if sensitivity to reward and gender have an effect on product liking based on fat/salt content

5) To evaluate the use of FaceReader technology during consumer evaluation

6) To determine if consumers self-selected, conscious emotions matched with the expressed, subconscious emotions acquired by FaceReader 


\section{Chapter 3}

Materials and Methods

\section{Participants}

Participant recruitment was done via email. The selection process was based upon the following criteria: frequent consumption (2-4 times a month or more) of both cheddar and mozzarella cheese (Table 3.1), being a non-user of Crest-Pro Health products, having no known food allergies, and a willingness to complete two online questionnaires and an "emotion poster" prior to the testing session. Crest Pro-Health products contain the active ingredient cetylpyridinium chloride, which has been shown to alter taste perception (Food and Drug Administration, 2003; DeSimone \& Heck, 1991; St John \& Hallagan, 2005).

Participants were also recruited based on body mass indices (BMI) which were calculated using self-reported height and weight measurements. The self-reported measurements were used to calculate body mass index (BMI) using the following equation:

$$
B M I=\frac{\text { weight }(l b) \times 703}{\text { height }{ }^{2}\left(\text { in }^{2}\right)}
$$

Participants were then categorized based on BMI, as determined by the Centers for Disease Control and Prevention (Table 3.2). Normal, overweight, and obese individuals were selected to participate in the study. Underweight individuals were excluded based on the available participant pool and the experimental objectives. Subjects were informed that body composition measurements would be taken on the test day to confirm the self-reported measurements. Subjects including Cal Poly and Cuesta College students, Cal Poly staff and community members totaled 108 (Table 3.3). 
Table 3.1 Panelist cheese consumption in the past 3 months $(n=108)$

\begin{tabular}{lll}
\hline Frequency of Consumption (Past 3 Month) & n & \% \\
\hline Daily & 26 & $24 \%$ \\
2 or more times a week & 72 & $67 \%$ \\
2 - 4 times a month & 10 & $9 \%$ \\
Once a month & 0 & $0 \%$ \\
Less than once a month & 0 & $0 \%$ \\
Never & 0 & $0 \%$ \\
\hline
\end{tabular}

Table 3.2 Standard weight categories with body mass index (BMI) ranges

\begin{tabular}{cc}
\hline BMI & Weight Status \\
\hline Below 18.5 & Underweight \\
$18.5-24.9$ & Normal \\
$25.0-29.9$ & Overweight \\
30.0 and Above & Obese \\
\hline
\end{tabular}

Table 3.3 Participants categorized by body weight and gender $(n=108)$

\begin{tabular}{ccccc}
\hline & Normal & Overweight & Obese & Total \\
\hline Male & 21 & 18 & 10 & $\mathbf{4 9}$ \\
Female & 28 & 24 & 7 & $\mathbf{5 9}$ \\
Total & $\mathbf{4 9}$ & $\mathbf{4 2}$ & $\mathbf{1 7}$ & $\mathbf{1 0 8}$ \\
\hline
\end{tabular}

\section{Samples and Sample Preparation}

Four commercially available cheeses, two medium cheddar and two low-moisture part-skim mozzarella, were selected for consumer evaluation based upon fat and sodium contents (Table 3.4). The cheddar samples contained the same sodium levels but varied in fat content, while the mozzarella samples had the same fat content but varied in sodium levels. The cheeses were selected in order to analyze product liking based on sodium levels or fat content, while keeping the other variable constant.

Table 3.4 Cheese types and nutrition content

\begin{tabular}{llccc}
\hline Type & Brand & $\begin{array}{c}\text { Total Fat } \\
(\mathbf{g})\end{array}$ & $\begin{array}{c}\text { Sodium } \\
(\mathbf{m g})\end{array}$ & $\begin{array}{c}\text { \% } \\
\text { Reduction }\end{array}$ \\
\hline Medium Cheddar - Regular & Tillamook & 9 & 170 & $33 \%$ \\
Medium Cheddar - Reduced Fat & Tillamook & 6 & 170 & \\
& & & & \\
LMPS Mozzarella - Block & Lucerne & 6 & 170 & $19 \%$ \\
LMPS Mozzarella - Round & Lucerne & 6 & 210 & \\
\hline
\end{tabular}


Samples were cut into 3/4-in cubes using a metal cheese cuber (Model N55300A, Nemco Inc., Hicksville, Ohio) and placed in labeled 2oz Solo® brand cups with lids and stored at refrigerated temperatures $\left(42^{\circ} \mathrm{F}\right)$ one day prior to testing. Ten minutes prior to serving, samples were removed from the refrigerator and held at room temperature $\left(72^{\circ} \mathrm{F}\right)$.

\section{Questionnaires and "Emotion Poster" Homework}

Subjects who qualified were instructed to complete the "emotion poster" homework and two online questionnaires prior to testing.

\section{"Emotion Poster" Homework}

Each subject was given an $8.5 " x 11 "$ sheet of paper divided into seven sections; each section labeled with a specific emotion (Appendix A): happy, sad, neutral, angry, scared, disgusted, and surprised. The emotions were selected to match with the seven emotions the FaceReader software recognizes and analyzes. Subjects were asked to find one image they felt represented each of the given emotions; the "emotion poster" was used during the tasting portion of the study.

\section{BIS/BAS Questionnaire \& SPSRQ Questionnaire}

Subjects were required to complete the Behavioral Inhibition System (BIS)/Behavioral Activation System (BAS) questionnaire (Carver \&White, 1994), and the Sensitivity to Punishment and Sensitivity to Reward Questionnaire (SPSRQ) (Avila, Caseras, Molto \& Torrubia, 2000), both of which were programmed using SurveyMonkey (SurveyMonkey Inc., Palo Alto, California, USA), an online surveying tool. (Appendix B and C). 
The BIS/BAS questionnaire is comprised of 24 agree/disagree statements using a $1-4$ scale $(1=$ very true for me, 4 = very false for me $)$; four questions related to both the BAS drive scale and BAS fun seeking scale, five questions related to the BAS reward responsiveness scale and seven questions related to BIS; four questions are used as fillers.

The SPSRQ contains two scales: Sensitivity to Punishment and Sensitivity to Reward. Each scale includes 24 yes-no questions, for a total of 48 questions. All 48 questions were asked in a random order in one survey. Scores for each scale were calculated by adding all the "yes" answers. "Yes" answers are given a "1" and "No" answers are scored as a "0".

\section{Consumer Test}

\section{Pre-Testing Documents}

On the day of, but prior to participation in the sensory evaluation portion, participants signed an informed consent form (Appendix D) and video release form (Appendix E).

\section{BMI Measurements}

A standard measuring tape (Kreg 12 Foot Measuring Tape, Kreg Tool Company., Huxley, Iowa) and bathroom scale (Eat Smart Precision Digital Bathroom Scale, Health Tools LLC, Mahwah, NJ) were used to measure and verify the height and weight of all participants.

\section{Testing Protocol}

Prior to acceptability testing, human subject approval for the testing was obtained by the Cal Poly Human Subjects Committee. Consumer evaluation for the mozzarella and cheddar cheese was carried out in two independent testing sessions. The test ( $\mathrm{n}=108)$ was 
conducted using prescreened consumers; individuals who purchase and consume mozzarella and cheddar cheese two to four times per month or more qualified for testing. Crest-Pro Health users were disqualified based on prior research and those with known food allergies were immediately disqualified based on traditional sensory practices. Consumer evaluation was conducted at California Polytechnic State University, San Luis Obispo on May 9th and May 10th, 2014. Demographic questions were asked again at the end of the testing sessions to validate that panelists were true consumers and representative of the target market. All of the panelists were true consumers.

The four samples of cheese were served to panelists in $2 \mathrm{oz}$ cups, labeled with randomized 3-digit codes, using a randomized complete block design. The entire questionnaire took approximately 30 minutes to complete.

The testing questionnaire was composed of two choose-all-that-apply (CATA) questions and hedonic questions. A CATA format was used so participants could indicate all emotional states before and after consuming each sample. Each panelist used their "emotion posters" as a reference when selecting the emotions. A 9-point hedonic scale (1 $=$ dislike extremely, $9=$ like extremely) was implemented to evaluate overall liking, appearance, aroma, flavor, texture, creaminess, saltiness, and aftertaste. The hedonic questions were asked in between the initial emotion question and final emotion question (Appendix F). Consumers were instructed to eat unsalted crackers (Premium Brand, Nabisco, New Jersey, USA) and rinse with room temperature bottled water (Crystal Geyser) in between samples. SIMS sensory software (SIMS Software, Version 6.0) was used for data collection. Prior to the testing session, participants were informed they would received an incentive upon completing the sensory evaluation portion of the study. 


\section{Video Taping}

Video cameras (930C JVC Hard Drive Camcorder) were arranged in the testing room, one directed at each of the panelist stations. The cameras were angled to capture the participant's facial expressions in the center of the viewing screen. Participants were videotaped throughout the sensory evaluation portion of the study. Using the "Emotion Poster", subjects selected which emotions were being experienced before and after consuming each sample. The videos were uploaded into the FaceReader software (FaceReader Version 5, Noldus Information Technology, Wageningen, Netherlands) to analyze facial expressions exhibited during the sensory evaluation portion.

\section{Data Analysis}

Data analyses were performed using JMP® Pro statistical software (JMP, Version 10. SAS Institute Inc., Cary, NC, 1989-2007). Analysis of Variance (ANOVA) was used for consumer data followed by means separation using Tukey's HSD. The ANOVA procedure was used to determine significant differences between samples and attribute means $(\mathrm{p}<0.05$ significance level).

\section{Consumer Acceptance of Cheeses Varying in Fat and Sodium Content}

The four samples of cheese were compared within their respective categories; the two cheddar cheese samples and two mozzarella cheese samples were compared independently. An Analysis of Variance (ANOVA) was performed on the hedonic scores to determine if the scores differed significantly between samples $(\alpha=0.05)$. Significant differences were found using Tukey's tests to compare the mean scores. 


\section{Reward Sensitivity, Body Mass Index (BMI) and Gender}

A one way Analysis of Variance (ANOVA) was performed to determine if sensitivity to reward differed significantly between genders. Significant differences were found when using Tukey's test to compare the mean scores

\section{Body Mass Index (BMI), Gender, Product Liking, and Fat/Salt Content of Cheese}

In order to determine if there was a relationship between a consumer's body mass index (BMI) and their overall liking of a product based on fat content, a new response variable was derived by subtracting the overall liking score of the reduced fat cheddar cheese from the overall liking score of the regular cheddar cheese. The new response variable modeled the difference in liking. A simple regression model was run using the new overall liking score as the response variable and BMI as the explanatory variable.

BMI was treated as a continuous variable to be consistent with other research in this area (Davis \& Fox, 2008). The same method was used to analyze the data, but creaminess liking was used in place of overall liking. An Analysis of Covariance (ANCOVA) was run to determine if gender and BMI had an effect on the overall liking or creaminess liking.

In order to determine if there was a relationship between a consumer's body mass index (BMI) and their overall liking of a product based on salt content, a new response variable was derived by subtracting the overall liking score of the lower sodium mozzarella cheese from the overall liking score of the higher sodium mozzarella cheese. The new response variable modeled the difference in liking. A simple regression model was run using the new overall liking score as the response variable and BMI as the explanatory variable. BMI was treated as a continuous variable to be consistent with 
other research in this area (Davis \& Fox, 2008). Using the same method of analysis, saltiness liking was used in place of overall liking. An Analysis of Covariance (ANCOVA) was run to determine if gender and BMI had an effect on the overall liking or saltiness liking.

Reward Systems, Gender, and Product Liking

An Analysis of Variance (ANOVA) was run to determine if gender, BAS, and SR had an effect on the overall liking.

\section{Facial Analysis}

The raw videos were spliced into useable segments using Windows Media Player (Version 11, Microsoft Corporation). The segments consisted of the time before consumption and after consumption. Each spliced video clip was imported into the FaceReader software.

FaceReader software was used to analyze the subjects facial expressions in the before and after consumption videos. The analyzed emotions were compared to the selfselected emotions in order to determine consistency between the emotions captured by FaceReader and self-selected emotions. 


\section{Chapter 4}

Results and Discussion

\section{Consumer Acceptance of Cheeses Varying in Fat and Sodium Content}

Consumer acceptance testing indicated that the regular cheddar cheese scored significantly higher than the reduced fat cheddar cheese in mean overall liking, flavor, texture, creaminess, saltiness and aftertaste (Table 4.1). In addition, the full fat cheddar cheese scored higher for appearance and aroma. Overall, the full fat cheddar cheese trended higher for all of the tested attributes.

These results supported research conducted by Childs and Drake (2009) in which full fat cheddar cheese scored highest in each hedonic category when tested against reduced fat cheddar cheese samples. Although low fat cheeses represent a healthier option, consumer acceptance was below the acceptable target score of seven (Peryam, 1998). Changes in flavor and texture need to be made in order to produce a more liked product.

Table 4.1 Consumer acceptance scores for the cheddar cheese samples $(n=108)($ mean \pm standard deviation)

\begin{tabular}{lcc}
\hline Attribute & Regular Cheddar & Reduced Fat Cheddar \\
\hline Appearance & $6.889 \pm 1.518^{\mathrm{a}}$ & $6.731 \pm 1.243^{\mathrm{a}}$ \\
Aroma & $6.861 \pm 1.488^{\mathrm{a}}$ & $6.759 \pm 1.427^{\mathrm{a}}$ \\
Overall Liking & $7.287 \pm 1.618^{\mathrm{a}}$ & $6.278 \pm 1.734^{\mathrm{b}}$ \\
Flavor & $7.287 \pm 1.708^{\mathrm{a}}$ & $6.269 \pm 1.863^{\mathrm{b}}$ \\
Texture & $7.139 \pm 1.655^{\mathrm{a}}$ & $5.898 \pm 1.957^{\mathrm{b}}$ \\
Creaminess & $6.991 \pm 1.574^{\mathrm{a}}$ & $6.065 \pm 1.752^{\mathrm{b}}$ \\
Saltiness & $6.630 \pm 1.812^{\mathrm{a}}$ & $6.167 \pm 1.507^{\mathrm{b}}$ \\
Aftertaste & $6.444 \pm 2.075^{\mathrm{a}}$ & $5.639 \pm 1.872^{\mathrm{b}}$ \\
\hline
\end{tabular}

Different letters in the same row indicate significant differences between samples as evaluated by Tukey HSD ( $\mathrm{p}<0.05)$. Attributes were evaluated on a 9-pt hedonic scale with $1=$ dislike extremely and $9=$ like extremely. 
Consumer acceptance testing indicated that the higher sodium mozzarella scored significantly higher than the lower sodium mozzarella for mean flavor, saltiness and aftertaste. The higher sodium mozzarella trended higher for aroma, overall liking and creaminess. Although not significant, the lower sodium mozzarella scored higher for appearance and texture (Table 4.2).

Table 4.2 Consumer acceptance scores for the mozzarella cheese samples ( $\mathrm{n}=108)$ (mean \pm standard deviation)

\begin{tabular}{lcc}
\hline Attribute & Higher Na Mozzarella & Lower Na Mozzarella \\
\hline Appearance & $6.370 \pm 1.538^{\mathrm{a}}$ & $6.556 \pm 1.506^{\mathrm{a}}$ \\
Aroma & $6.324 \pm 1.634^{\mathrm{a}}$ & $6.074 \pm 1.639^{\mathrm{a}}$ \\
Overall Liking & $6.380 \pm 1.999^{\mathrm{a}}$ & $6.093 \pm 1.785^{\mathrm{a}}$ \\
Flavor & $6.870 \pm 1.708^{\mathrm{a}}$ & $6.139 \pm 1.748^{\mathrm{b}}$ \\
Texture & $5.639 \pm 2.563^{\mathrm{a}}$ & $5.898 \pm 2.082^{\mathrm{a}}$ \\
Creaminess & $6.574 \pm 2.210^{\mathrm{a}}$ & $6.028 \pm 1.926^{\mathrm{a}}$ \\
Saltiness & $6.472 \pm 1.469^{\mathrm{a}}$ & $5.907 \pm 1.700^{\mathrm{b}}$ \\
Aftertaste & $6.231 \pm 1.817^{\mathrm{a}}$ & $5.694 \pm 1.774^{\mathrm{b}}$ \\
\hline
\end{tabular}

Different letters in the same row indicate significant differences between samples as evaluated by Tukey HSD $(\mathrm{p}<0.05)$. Attributes were evaluated on a 9-pt hedonic scale with $1=$ dislike extremely and $9=$ like extremely.

Consumer liking decreased when the salt content decreased. These results supported research found by Ganesan et al. (2014). Overall, consumers were very capable of detecting salt reductions in cheese as indicated by the hedonic scores (Drake et al., 2011; Ganesan et al., 2014).

The hedonic data indicated that significant differences do exist between the cheddar cheese samples and between the mozzarella cheese samples. There were fewer significant differences between the mozzarella samples as compared to the cheddar samples (Childs \& Drake, 2009). Both mozzarella samples and the reduced fat cheddar cheese received scores lower than expected. Because the four samples used were commercially produced and readily available for consumer purchase, researchers 
expected hedonic scores to be at least six or higher. Traditionally, a score of seven or higher on a 9-pt hedonic scale is reflective of a well-liked product (Peryam, 1998). The reduced fat cheddar, higher sodium mozzarella and lower sodium mozzarella failed to score a seven or higher for any of the tested attributes. Both the cheddar cheese samples as well as the mozzarella cheese samples were received from their respective manufacturer in order to reduce variability between brands and production techniques.

\section{Reward Sensitivity, Body Mass Index (BMI) and Gender}

\section{Effects of Gender and Body Mass Index (BMI) on Sensitivity to Reward (SR)}

Interactions between gender and body mass index (BMI) were not found to be significant $(\mathrm{p}=0.4000)($ Table 4.3$)$. There was evidence of a gender effect on sensitivity to reward $(\mathrm{p}=0.0291)$; however, there was no evidence of an effect of BMI on sensitivity to reward ( $\mathrm{p}=0.4006)$ which contradicts results by Davis and Fox (2008).

Table 4.3 Effects test for gender and BMI on sensitivity to reward

\begin{tabular}{ll}
\hline Source & $\mathrm{p}$ value \\
\hline Gender & $0.0291 *$ \\
BMI & 0.4006 \\
Gender * BMI & 0.4000 \\
\hline$* \mathrm{p}<0.05$ is considered statistically significant
\end{tabular}

Sensitivity to reward differed significantly between genders when using Tukey's test to compare the mean scores (Table 4). With a p-value of 0.0183 , male subjects had a statistically significant higher average sensitivity to reward (SR) than females; the variability in SR was also slightly larger for males than females. The descriptive statistics for sensitivity to reward (Table 4.4), broken up by gender (males and females, $\mathrm{n}=49$ and $\mathrm{n}=59$, respectively). 
Table 4.4 Distributions of sensitivity to reward by gender

\begin{tabular}{lcccc}
\hline & Mean \pm St. Dev & Minimum & Median & Maximum \\
\hline Male & $12.06 \pm 4.10^{\mathrm{a}}$ & 4 & 12 & 21 \\
Female & $10.41 \pm 3.97^{\mathrm{b}}$ & 2 & 11 & 19 \\
\hline
\end{tabular}

Different letters in the same column indicate significant differences between means as evaluated by Tukey HSD $(\mathrm{p}<0.05)$

Researchers are continuing to examine the role of brain reward mechanisms on eating behaviors and obesity. The data indicated that men have a significantly higher reward sensitivity than women (Davis and Fox, 2008). Although there are many factors that influence obesity, individuals with a high sensitivity to reward have a stronger appetitive drive. A stronger appetitive drive may lead to a more difficult time resisting food temptations.

Although BMI was not found to have a significant effect on reward sensitivity (measured using SR scale of SPSRQ) in this study, BMI has been found to be positively associated with reward sensitivity by Franken and Muris (2005) and Davis and Fox (2008). Franken and Muris found that sensitivity to reward but positively associated with food craving and relative body weight ( $\mathrm{n}=99$ female subjects, $83.4 \%$ normal BMI). Davis and Fox found that among normal and overweight participants, the relationship between sensitivity to reward and body mass index was in the positive direction; the relationship then turned into a negative association with obese subjects $(n=369)$. The present study had a slightly larger sample size than the study conducted by Franken and Muris, but subjects had a much wider range of body mass indices. In this study, both male and females (45\% and 55\%, respectively) participated and were categorized by body mass index (normal - 45\%, overweight - 39\% and obese - 16\%). Future studies 
should further investigate reward sensitivity and body mass index using male and female participants with a wider range of body mass index.

BMI reflects a calculation based strictly upon height and weight; body composition is not taken into account. Some individuals, such as professional athletes or bodybuilders, may be classified as "overweight" according the BMI calculations, yet be perfectly healthy due to increased muscle mass (Turocy et al., 2011). In the present study, several individuals fell into the overweight category, although visually appearing to fall into a normal category. In reality, these individuals may be physiologically healthy, simple athletic, but overweight according to the body mass index calculation. Future studies should investigate how body fat percentage effects sensitivity to reward, rather than body mass index.

\section{Effects of Gender and Behavioral Activation System (BAS) on Sensitivity to Reward}

The interactions between gender and the behavioral activation system (BAS) score were not found to have a significant effect on sensitivity to reward $(p=0.7004)$. There was evidence of a gender effect on sensitivity to reward $(p=0.0050)$ and evidence of an effect of BAS on sensitivity to reward $(\mathrm{p}<0.0001)$. When evaluating males and females independently, the effect of gender was significant for both but varied slightly ( $p$ $=0.0009$ and $\mathrm{p}<0.0001$, respectively) (Table 4.5).

Table 4.5 Effects test for gender and behavioral activation system on sensitivity to reward

\begin{tabular}{ll} 
Source & $\mathrm{p}$ value \\
\hline Gender & $0.0050^{*}$ \\
Male & $0.0009^{*}$ \\
$\quad$ Female & $<0.0001^{*}$ \\
BAS & $<0.0001^{*}$ \\
Gender * BAS & 0.7004 \\
\hline$* \mathrm{p}<0.05$ is considered statistically significant
\end{tabular}


Gray's (1987) reinforcement sensitivity theory describes a character dimension based on individual differences in the activation threshold of brain reward regions or the behavioral activation system (BAS). Those with a high reward sensitivity have a more sensitive BAS. Activity in the behavioral activation system propels an individual toward goal oriented behavior, producing positive feelings such as hope, elation and happiness. A greater BAS sensitivity reflects a person's tendency to participate in goal directed efforts and experiences which would elicit positive feelings (Carver \& White, 1994; Davis \& Fox, 2008).

The Sensitivity to Punishment and Sensitivity to Reward Questionnaire (SPSRQ) serves as a tool to investigate Gray's model. The Sensitivity to Reward (SR) scale was created to measure differences in the impulsivity dimension (BAS). The SPSRQ is used in conjunction with the BIS/BAS questionnaire as well as independently to assess reward mechanisms in individuals (Molto et al., 2001).

This present study implemented both the BIS/BAS questionnaire and SPSRQ. As expected the BAS had a significant effect on SR. This result was expected due to the inherent nature of the questionnaires; both scales measure the same activation system in the brain.

\section{Body Mass Index (BMI), Gender, Product Liking, and Fat/Salt Content of Cheese \\ With a p-value of 0.6799 , there was not enough evidence to indicate that BMI had an effect on the overall liking of a product based on fat content. Similar to overall liking, there was not enough evidence to indicate that BMI (continuous variable) had an effect on the creaminess liking of a product based on fat content $(\mathrm{p}=0.6785)$.}


An Analysis of Covariance (ANCOVA) was run to determine if gender and BMI had an effect on the overall liking or creaminess liking (Table 4.6). After fitting a model no significant differences were found.

Table 4.6 Effects test for gender and body mass index on product liking based on fat content

\begin{tabular}{lcc}
\hline Source & Overall Liking & Creaminess Liking \\
\hline Gender & 0.7900 & 0.5098 \\
BMI & 0.7844 & 0.7183 \\
Gender*BMI & 0.1073 & 0.2194 \\
\hline
\end{tabular}

$* \mathrm{p}<0.05$ is considered statistically significant

There was no evidence to indicate that gender or body mass index had a significant effect on the overall liking or creaminess liking of a product based on fat content. Keskitalo et al. (2008) conducted a study using the Three-Factor Eating Questionnaire and reported the liking and use-frequency of 4 sweet-and-fatty and saltyand-fatty food items. Keskitalo et al. (2008) observed no significant correlations between BMI and the liking or use of fatty foods.

The population tested in the present study were cheese consumers and both of the tested products were commercially available, these two factors could have played a role in why body mass index and gender did not have a significant effect on product liking. Because the cheese products tested were commercially available, one can assume that typical cheese consumers would like the samples. The general liking could have caused there to be no difference between product liking based on body mass index and gender.

With a p-value of 0.6974 , there was not enough evidence to indicate that BMI has an effect on the overall liking of a product based on salt content. Similar to overall liking, there was not enough evidence to indicate that BMI (continuous variable) had an effect on the saltiness liking of a product based on salt content $(\mathrm{p}=0.9006)$. 
An Analysis of Covariance (ANCOVA) was run to determine if gender and BMI had an effect on the overall liking or saltiness liking (Table 4.7). After fitting a model no differences were found for saltiness liking. Interactions between gender and BMI were found to have a significant effect $(\mathrm{p}=0.0319)$ on the overall liking of the mozzarella cheese. The gender and BMI main effects were not found to be significant.

Table 4.7 Effects test for gender and body mass index on product liking based on salt content

\begin{tabular}{lcc}
\hline Source & Overall Liking & Saltiness Liking \\
\hline Gender & 0.0716 & 0.9944 \\
BMI & 0.8751 & 0.9095 \\
Gender*BMI & $0.0319^{*}$ & 0.3142 \\
\hline
\end{tabular}

$* \mathrm{p}<0.05$ is considered statistically significant

Keskitalo et al. (2008) observed significant differences in the liking or use of salty-and-fatty foods between males and females. There was no correlation between BMI and salty food use or liking. In the present study, gender and BMI did not have a significant effect on the overall liking of the samples but the interaction between the two variables did have a significant effect on the overall liking of a product based on salt content. There is a complex relationship between product liking, body mass index, and gender but further research needs to be conducted to investigate how the three variables interact.

\section{Effect of Sensitivity to Reward (SR), Behavioral Activation System (BAS), and Gender on Overall Liking based on Fat or Salt Content}

After fitting a model to determine if gender, BAS, and SR had an effect on the overall liking no differences were found (Table 4.8). There was not enough evidence to indicate that the interaction between gender and BAS scores or gender and SR scores had an effect on the overall liking based on fat or salt content. 
Table 4.8 Effects test for SR, BAS and gender on overall liking based on salt content

\begin{tabular}{lcc}
\hline Source & Fat Content & Salt Content \\
\hline SR & 0.5613 & 0.1322 \\
BAS & 0.9940 & 0.5340 \\
Gender & 0.7066 & 0.1939 \\
Gender*BAS & 0.0722 & 0.3717 \\
Gender*SR & 0.5892 & 0.6632 \\
\hline
\end{tabular}

$* p<0.05$ is considered statistically significant

The product selection may have been too limited to notice a significant difference. Only two products with varying fat contents were tested, and only two products with varying salt contents were tested. The difference in fat content between the two cheddar cheese samples was $33 \%$ while the difference in sodium between the two mozzarella cheese samples was $19 \%$.

\section{Self-Selected Emotions and Emotions Captured by FaceReader}

Each panelist, categorized by body mass index, received four samples of cheese. Video segments were spliced so that each panelist had a video clip before and after consuming each cheese sample. In total, each panelist had eight videos: before and after consuming the regular cheddar, before and after consuming the reduced fat cheddar, before and after consuming the higher sodium mozzarella, and before and after consuming the lower sodium mozzarella.

Cheese sample and body mass index were not factored into the analysis when comparing the self-selected emotions to the emotions captured by the FaceReader software. Each video represented an individual unit independent of the other videos. In total, 332 pairs of videos (332 before consumption and 332 videos after consumption) were used for analysis (Table 4.9). 
Table 4.9 Number of panelists and videos per weight category

\begin{tabular}{lccc}
\hline Weight Category & $\begin{array}{c}\text { Number of } \\
\text { Panelists }\end{array}$ & $\begin{array}{c}\text { Number of Videos } \\
\text { Before Consumption }\end{array}$ & $\begin{array}{c}\text { Number of Videos } \\
\text { After Consumption }\end{array}$ \\
\hline Normal & 37 & 148 & 148 \\
Overweight & 33 & 132 & 132 \\
Obese & 13 & 52 & 52 \\
Total & $\mathbf{8 3}$ & $\mathbf{3 3 2}$ & $\mathbf{3 3 2}$ \\
\hline
\end{tabular}

FaceReader is a computer program that automatically analyzes facial expressions.

This facial analysis software is one of the most advanced tools currently available, providing researchers with an objective evaluation of a person's emotion. Emotions can be broken down into categories: positive (happy), negative (sad, angry, scared and disgusted), neutral (neutral), and other (surprised). FaceReader software utilizes facial recognition technology to eliminate inconsistencies commonly found within verbal emotion testing. Not only does FaceReader software eliminate a language translation barrier that can occur when measuring emotions across cultures, but it eliminates the subjective feelings of a consumer, creating a standard way to measure a consumer's subconscious emotion (Loijens and Krips, 2013).

The question remains, can consumer acceptance testing benefit from utilizing FaceReader technology? Is FaceReader capable of capturing self-selected emotions? In the present study, the use of FaceReader was investigated. Panelists' self-selected emotions were compared to the emotions FaceReader captured, before and after the consumption of the samples. 


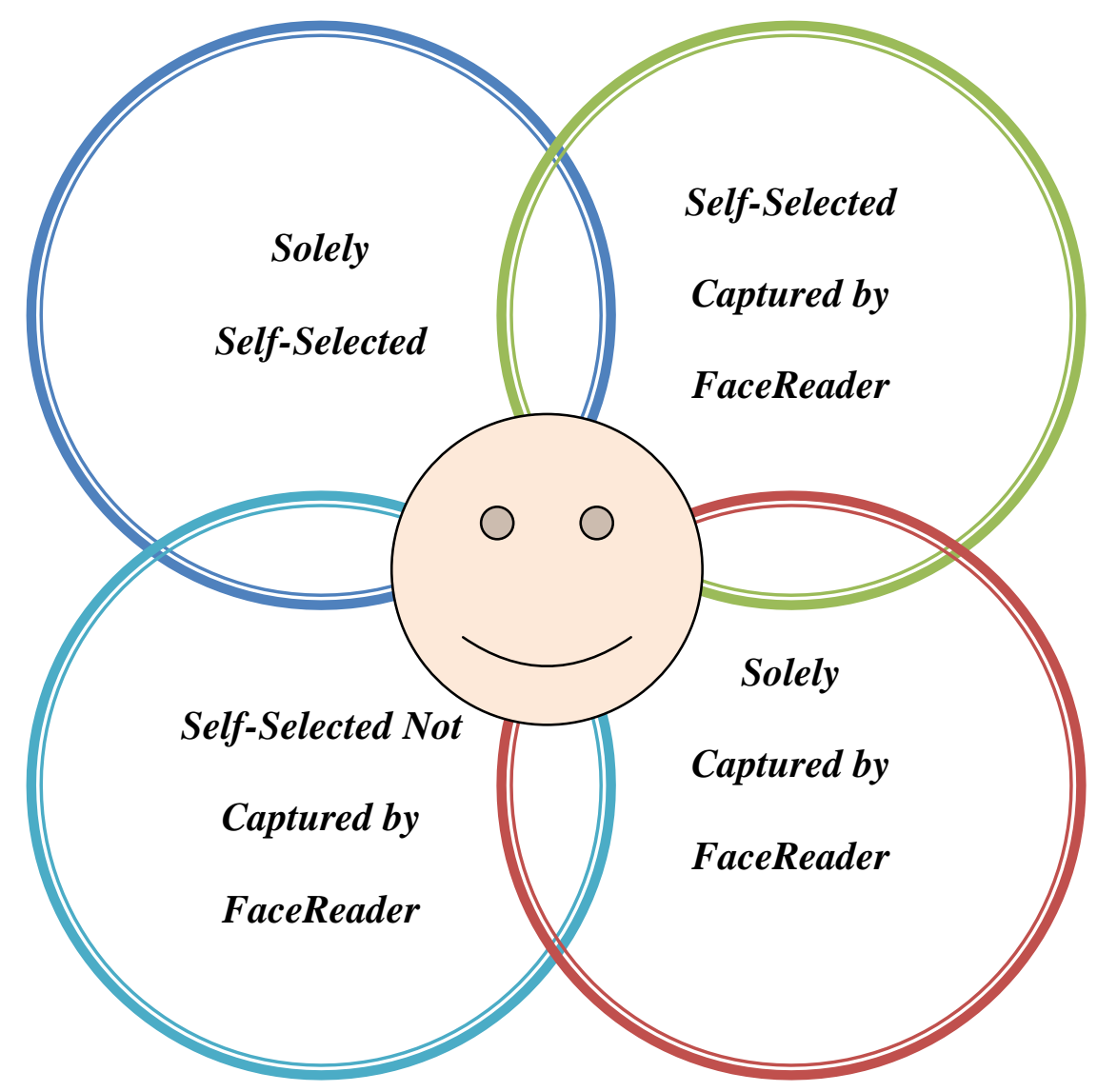

Figure 4.1 Options for emotion categorization

There were four main categories for emotion categorization (Figure 4.1):

1. Self-Selected: panelist self-selected emotion(s) using a CATA style question

2. Self-Selected and Captured by FaceReader: panelist self-selected emotion(s) that matched with the emotion(s) FaceReader captured

3. Self-Selected but Not Captured by FaceReader: panelist self-selected emotion(s) that were not captured by FaceReader

4. Captured by FaceReader: emotion(s) solely captured by FaceReader but not self-selected by a panelist 


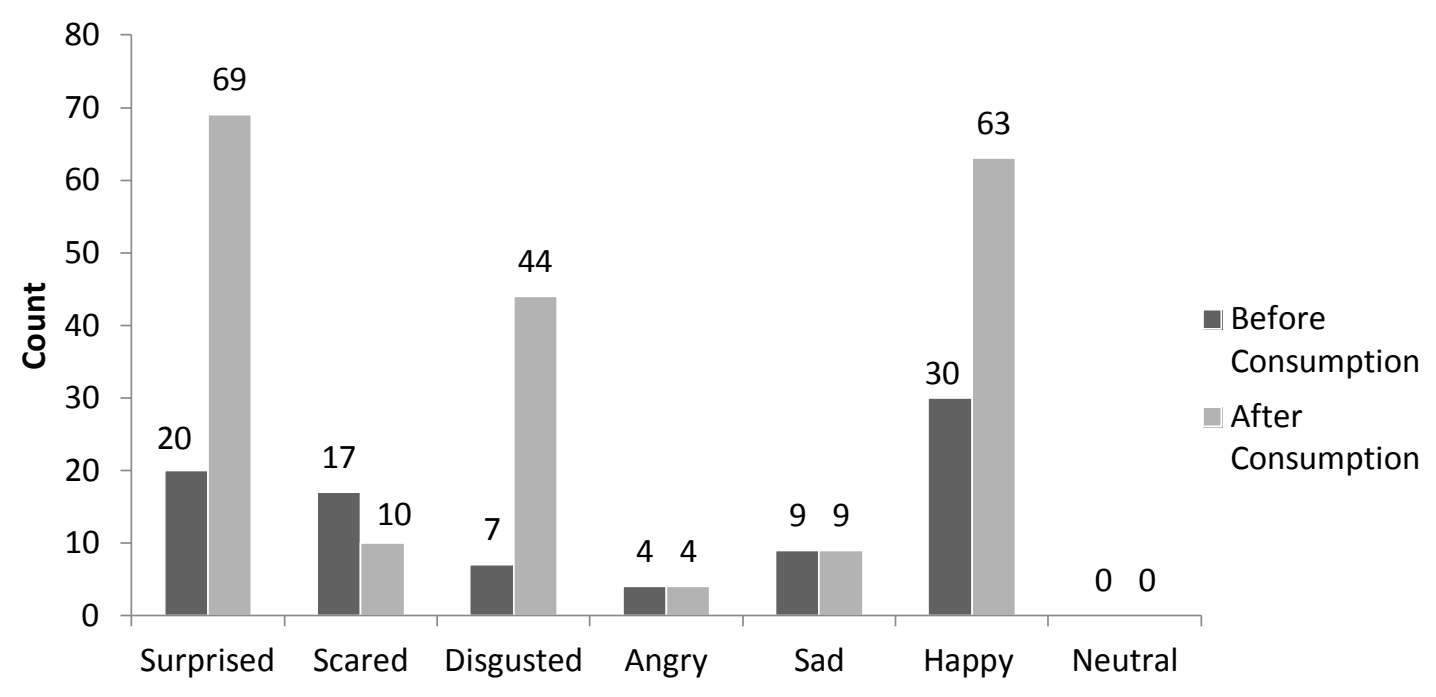

Figure 4.2 Self-selected emotions not captured by FaceReader

Counts of each self-selected emotion not captured by FaceReader were tallied

(Figure 4.2). Overall, FaceReader was not as successful analyzing emotions after consumption. FaceReader failed to capture 87 emotions before consumption and 199 emotions after consumption. Surprised and happy were the two emotions most commonly missed both before and after consumption. Disgusted was missed primarily after consumption. Neutral was never missed, due to the fact that FaceReader analyzed neutral in all of the video clips. 


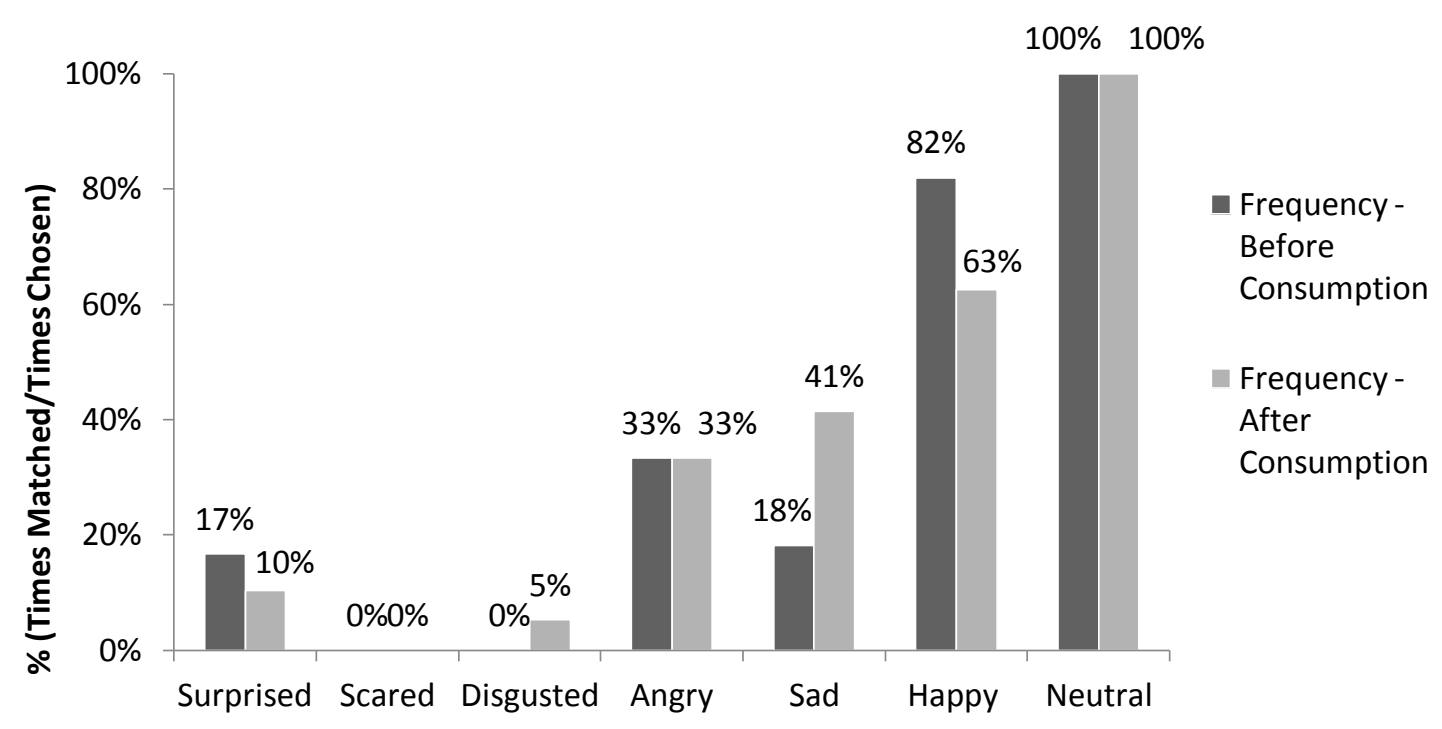

Figure 4.3 Frequency of self-selected emotions captured by FaceReader

In order to determine the frequency when FaceReader correctly matched the selfselected emotions, the following formula was used:

Frequency $=\frac{\text { number of times emotion was self-selected by the panelist and matched with FaceReader }}{\text { the number of times the emotion was strictly self-selected }}$

Overall, for both before and after consumption, FaceReader most accurately matched neutral, followed by happy (Table 4.10). FaceReader was not able to correctly match surprised/angry before consumption and angry/sad after consumption (Figure 4.3). 
Table 4.10 Number of times/frequency emotion was selected by subject and matched with FaceReader

\begin{tabular}{lccc|ccc}
\hline & \multicolumn{3}{c|}{ Before Consumption } & \multicolumn{3}{c}{ After Consumption } \\
Emotion & $\begin{array}{c}\text { FaceReader } \\
\text { Matched }\end{array}$ & $\begin{array}{c}\text { Self- } \\
\text { Selected }\end{array}$ & Frequency & $\begin{array}{c}\text { FaceReader } \\
\text { Matched }\end{array}$ & $\begin{array}{c}\text { Self- } \\
\text { Selected }\end{array}$ & Frequency \\
\hline Surprised & 4 & 24 & $\mathbf{1 7 \%}$ & 8 & 77 & $\mathbf{1 0 \%}$ \\
Scared & 0 & 17 & $\mathbf{0 \%}$ & 0 & 10 & $\mathbf{0 \%}$ \\
Disgusted & 0 & 7 & $\mathbf{0 \%}$ & 2 & 38 & $\mathbf{5 \%}$ \\
Angry & 2 & 6 & $\mathbf{3 3 \%}$ & 2 & 6 & $\mathbf{3 3 \%}$ \\
Sad & 2 & 11 & $\mathbf{1 8 \%}$ & 12 & 29 & $\mathbf{4 1 \%}$ \\
Happy & 136 & 166 & $\mathbf{8 2 \%}$ & 105 & 168 & $\mathbf{6 3 \%}$ \\
Neutral & 224 & 224 & $\mathbf{1 0 0 \%}$ & 175 & 175 & $\mathbf{1 0 0 \%}$ \\
Total & 368 & 455 & $\mathbf{8 1 \%}$ & 304 & 503 & $\mathbf{6 0 \%}$ \\
\hline
\end{tabular}

FaceReader has been used in a variety of ways, however there is little research that examines FaceReader and self-selected emotions. Terzis et al. (2010) examined the use of FaceReader during a self-assessment test, specifically, the FaceReader results were compared to researchers estimations of the subjects emotions. The present study compared the subjects self-selected emotions to FaceReader. The present study found that FaceReader and the panelists had a high agreement for happy and neutral (Table 4.11). Terzis et al. (2010) also found that researchers and FaceReader had a high agreement for happy (90\%) and neutral (99\%), however the percentages were much higher. When looking at disgusted, angry and sad, the agreement was much lower when looking at selfselected emotions. For all seven emotions, Terzis et al. (2010) had at least 70\% agreement between the researchers and FaceReader when examining the subjects emotional states during a self-assessment exam. When subjects are asked to self-select their emotional states, the agreement with FaceReader appears to be much lower which may be due to the fact that subjects are unaware of their subconscious emotional states. 
Overall disgusted and angry were the two emotions that FaceReader recognized less

effectively (Terzis et al., 2010).

Table 4.11 FaceReader and panelist agreement for each emotional state

\begin{tabular}{lcccccc}
\hline & \multicolumn{3}{c}{ Before Consumption } & \multicolumn{3}{c}{ After Consumption } \\
\hline & $\begin{array}{c}\text { FaceReader } \\
\text { and } \\
\text { Panelist } \\
\text { Agreement }\end{array}$ & $\begin{array}{c}\text { Records for } \\
\text { Each } \\
\text { Emotion - }\end{array}$ & $\%$ & $\begin{array}{c}\text { FaceReader } \\
\text { and } \\
\text { Panelist } \\
\text { FaceReader }\end{array}$ & $\begin{array}{c}\text { Records for } \\
\text { Each } \\
\text { Emotion- }\end{array}$ & $\%$ \\
\hline Surprised & 4 & 26 & $15 \%$ & 8 & 29 & $28 \%$ \\
Scared & 0 & 0 & -- & 0 & 0 & -- \\
Disgusted & 0 & 2 & $0 \%$ & 2 & 9 & $22 \%$ \\
Angry & 2 & 112 & $2 \%$ & 2 & 127 & $2 \%$ \\
Sad & 2 & 74 & $3 \%$ & 12 & 101 & $12 \%$ \\
Happy & 136 & 241 & $56 \%$ & 105 & 204 & $51 \%$ \\
Neutral & 224 & 332 & $67 \%$ & 175 & 332 & $53 \%$ \\
Total & 368 & 787 & $47 \%$ & 304 & 802 & $38 \%$ \\
\hline
\end{tabular}

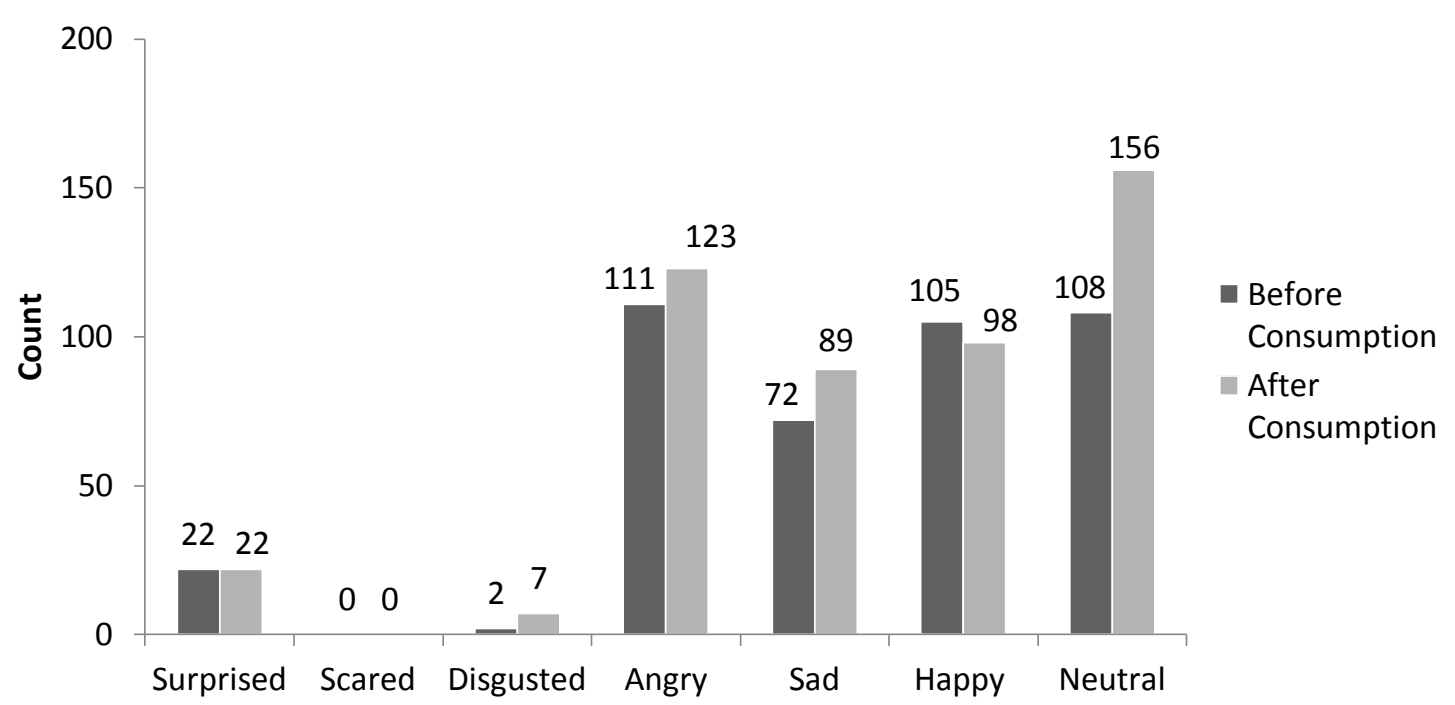

Figure 4.4 Solely captured by FaceReader (n=332)

Counts of each emotion captured by FaceReader but not self-selected were tallied (Figure 4.4). Overall, FaceReader analyzed a large number of emotions that panelists did not self-select. FaceReader analyzed 420 additional emotions before consumption and 495 additional emotions after consumption. Neutral and angry were the two emotions 
most commonly captured when not self-selected. Disgusted was rarely analyzed when not self-selected and scared was never analyzed when not self-selected. FaceReader analyzed neutral in all of the video clips.

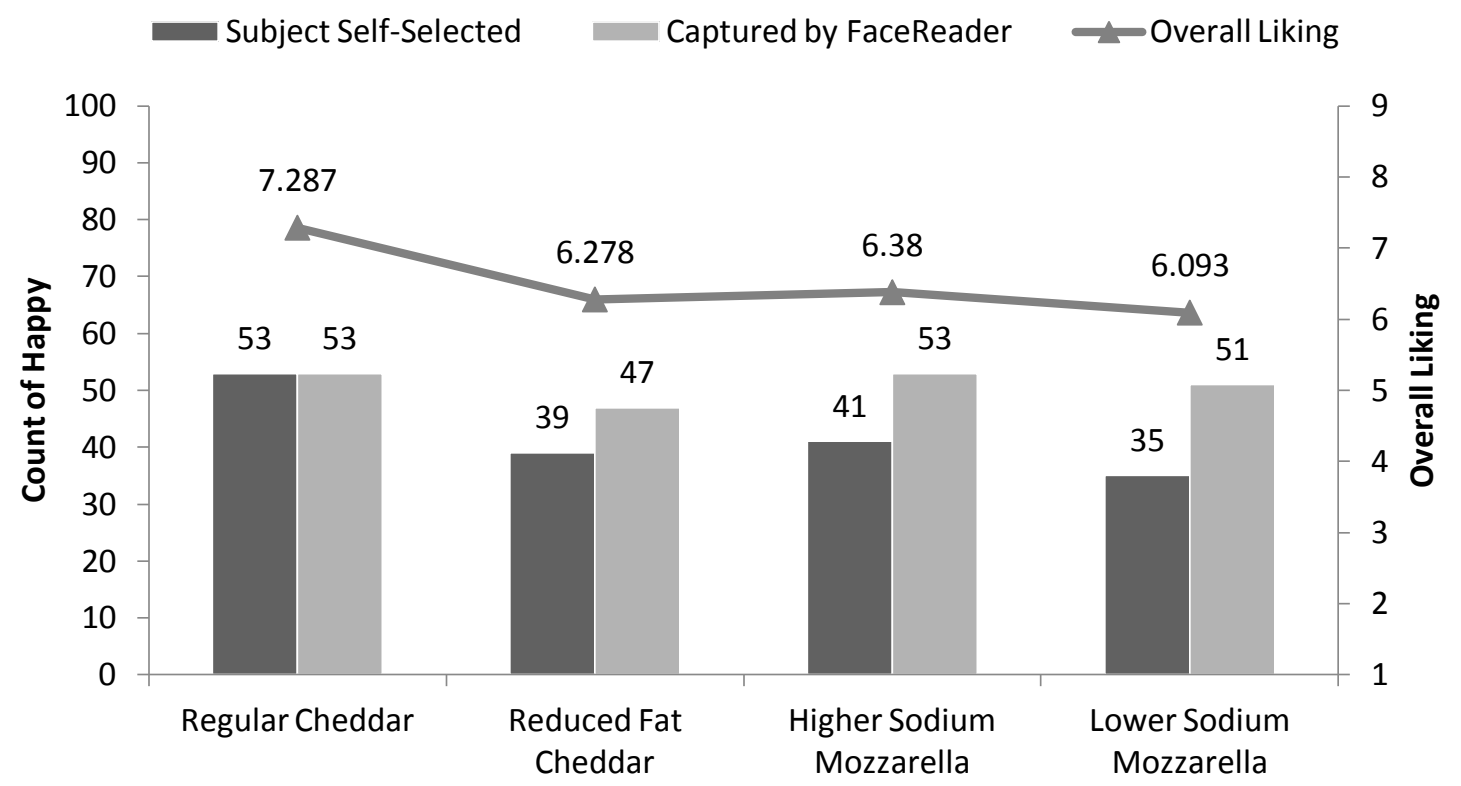

Figure 4.5 Relationship between occurrence of "Happy" emotion (after consumption) and overall liking by cheese sample

Overall liking is a common attribute used in sensory testing to measure a consumers perception of a product as a whole. One would assume that the "happy" emotion is related to the overall liking score a product receives. The relationship between the number of times "happy" was selected for each sample of cheese and the overall liking is shown in Figure 4. When looking at the cheddar cheese samples, "happy" is self-selected and captured by FaceReader more times for the regular cheddar cheese than the reduced fat cheddar (53/53 vs. 39/47, respectively). The mean overall liking score is also significantly higher for the regular cheddar cheese when compared to the reduced fat cheddar cheese $(\mathrm{p}<0.05)($ Table 4.1$)$. Similarly, when comparing the mozzarella cheese 
samples, the higher sodium sample received more "happy" selections and a higher mean overall liking. The overall liking scores for mozzarella cheese were not significantly different, but the higher sodium sample trended higher. The "happy" counts were also closer in relation than those for the cheddar cheese samples (Figure 4.5). 


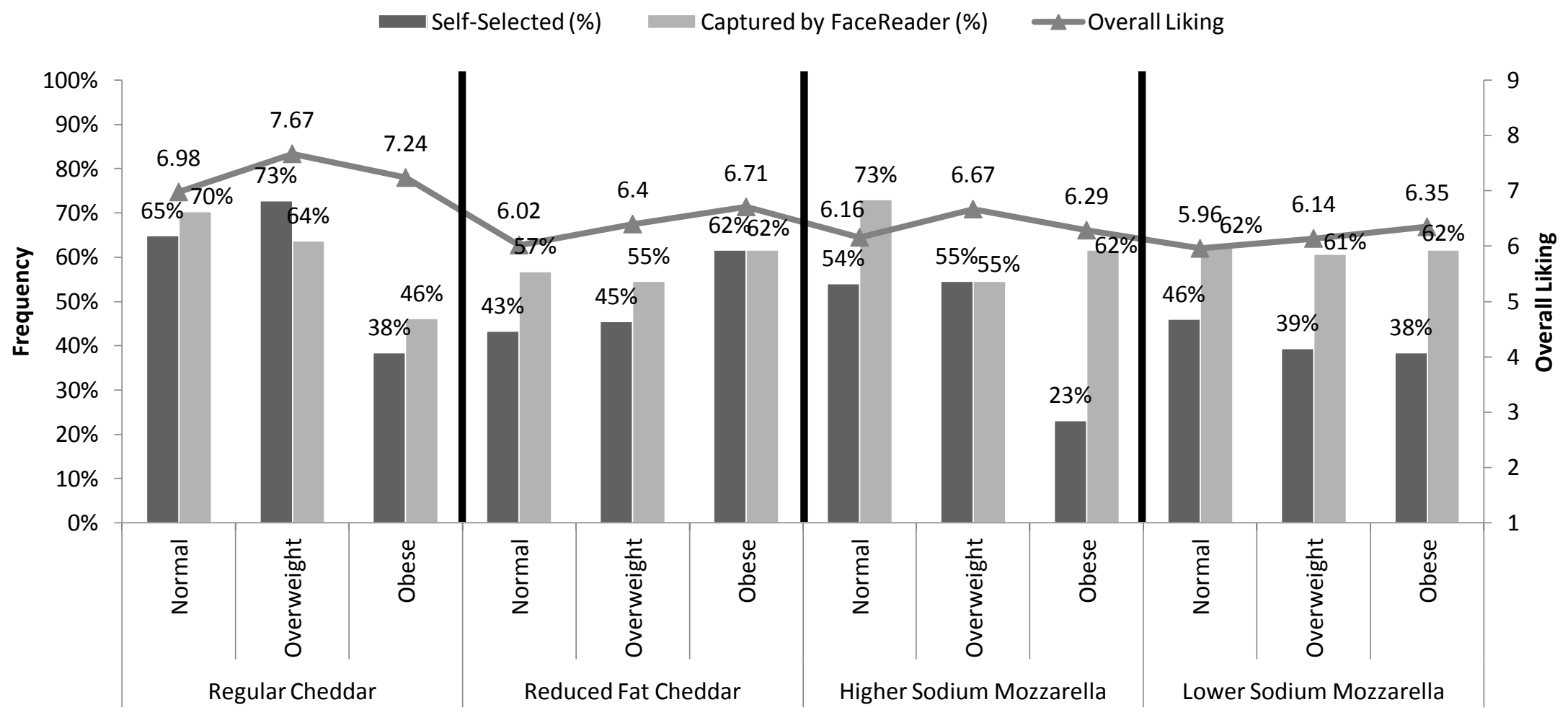

Figure 4.6 Relationship between frequency of "Happy" emotion (after consumption) and overall liking by cheese sample and body mass index 
The relationship between the number of times "happy" was selected for each sample of cheese and the overall liking score based on body mass index category was examined (Figure 4.6). Although there were no significant differences in overall liking of the cheese sample when looking at body mass index, there were trends. For the regular samples (regular cheddar and higher sodium mozzarella), the mean overall liking score was highest for the overweight participants, followed by the obese and then normal weight groups. For the reduced fat and lower sodium samples, the mean overall liking score was highest for the obese participants, followed by the overweight and then normal weight groups.

Emotion plays a vital role in food consumption and eating behavior, compelling the food industry to use emotion testing alone and in conjunction with traditional consumer sensory evaluation methods (King and Meiselman, 2010). Consumer scientists hypothesize that eating behavior and food choice are driven not by product taste alone but by emotional responses as well, prompting the use of emotion testing methods (Seo et al., 2009). A variety of emotion testing methods have been researched and developed due to the promising future emotion measurement has in sensory evaluation (King and Meiselman, 2010; Thomson et al., 2010; Seo et al., 2009).

FaceReader technology eliminates the subjective feelings of a consumer, creating a standard way to measure a consumer's subconscious emotion (Loijens and Krips, 2013), but is the subconscious emotion more important than the subjective feelings of a consumer? The current study evaluated the use of FaceReader technology in comparison to a subjective emotion measurement. FaceReader captured the negative self-selected emotions less frequently than self-selected positive emotions (Table 4.10). 


\section{Chapter 5}

\section{Conclusion}

Although low fat and low sodium cheeses represent a healthier option, consumer acceptance revealed that the higher fat and higher sodium samples scored higher; changes in flavor and texture need to be made in order to produce a more liked product. There is a complex relationship between product liking, body mass index, and gender but further research needs to be conducted to investigate how the three variables interact.

FaceReader technology eliminates the subjective feelings of a consumer, creating a standard way to measure a consumer's subconscious emotion, but is the subconscious emotion more important than the subjective feelings of a consumer? The question remains, can consumer acceptance testing benefit from utilizing FaceReader technology? The current study provides preliminary research to future work as to how FaceReader can be incorporated into consumer evaluation. 


\section{REFERENCES}

Allison, D. B., \& Heshka, S. (1993). Emotion and eating in obesity? A critical analysis. The International Journal of Eating Disorders, 13(3), 289-95. Retrieved from http://www.ncbi.nlm.nih.gov/pubmed/8477301

American Heart Association. (2010). 2010 Dietary Guidelines (pp. 2009-2010).

Avena, N. M., Rada, P., \& Hoebel, B. G. (2009). Evidence for sugar addiction: Behavioral and neurochemical effects of intermittent, excessive sugar intake. Neuroscience and Biobehavioral Reviews, 32(1), 20-39. doi:10.1016/j.neubiorev.2007.04.019

Barthomeuf, L., Rousset, S., \& Droit-Volet, S. (2009). Emotion and food. Do the emotions expressed on other people's faces affect the desire to eat liked and disliked food products? Appetite, 52(1), 27-33. doi:10.1016/j.appet.2008.07.002

Berridge, K. C., \& Robinson, T. E. (1998). What is the role of dopamine in reward: hedonic impact, reward learning, or incentive salience ? Brain Research, 28(3), 309-369. doi: 10.1016/S0165-0173(98)00019-8

Berridge, K. C., Ho, C.-Y., Richard, J. M., \& DiFeliceantonio, A. G. (2010). The tempted brain eats: pleasure and desire circuits in obesity and eating disorders. Brain Research, 1350, 43-64. doi:10.1016/j.brainres.2010.04.003

Berridge, K. C., Robinson, T. E., \& Aldridge, J. W. (2009). Dissecting components of reward: "liking", "wanting", and learning. Current Opinion in Pharmacology, 9(1), 65-73. doi:10.1016/j.coph.2008.12.014

Blackwell, D. L., Lucas, J. W., \& Clarke, T. C. (2014). Summary health statistics for u.s. Adults: national health interview survey, 2012. Vital and Health Statistics. Series 10, Data from the National Health Survey, (260), 1-171. Retrieved from http://www.ncbi.nlm.nih.gov/pubmed/24819891

Blake, Joan Salge, Munoz, Kathy D., Volpe, S. (2010). Nutrition: From Science to You. San Francisco: Pearson Education, Inc.

Bloch, M. R. (1978). The social influence of salt. In Human Nutrition (pp. 120-129). San Francisco: W.H. Freeman and Company.

Booth, D. A., Mather, P., \& Fuller, J. (1982). Starch content of ordinary foods associatively conditions human appetite and satiation, indexed by intake and eating pleasantness of starch-paired flavours. Appetite, 3(2), 163-184. doi:10.1016/S01956663(82)80009-3 
Brogan, A., \& Hevey, D. (2012). A review of affective and cognitive approaches to assessing decision making in overweight and obesity. Handbook on Psychology of Decision Making Nova Science Publishers, Inc. 1-25.

Brunner, T. A., van der Horst, K., \& Siegrist, M. (2010). Convenience food products. Drivers for consumption. Appetite, 55(3), 498-506. doi:10.1016/j.appet.2010.08.017

Canetti, L., Bachar, E., \& Berry, E. M. (2002). Food and emotion. Behavioural Processes, 60(2), 157-164. Retrieved from http://www.ncbi.nlm.nih.gov/pubmed/12426067

Capaldi, E. D. (1996). Why we eat what we eat - The Psychology of Eating. (E. D. Capaldi, Ed.). Washington, DC: American Psychological Association.

Carver, C. S., \& White, T. L. (1994). Behavioral Inhibition, Behavioral Activation , and Affective Responses to Impending Reward and Punishment : The BIS / BAS Scales. Journal of Personality and Social Psychology. 67(2), 319-333. doi: 10.1037/00223514.67.2.319

Cássia, R. De, Paula, V., Minim, R., Simiqueli, A. A., Elen, L., Gomide, A. I., \& Minim, L. A. (2012). Optimized Descriptive Profile: A rapid methodology for sensory description. Food Quality and Preference. 24, 190-200. doi:10.1016/j.foodqual.2011.10.014

Centers for Disease Control and Prevention. (2011). Health Matters: The Obesity Epidemic. Centers for Disease Control and Prevention. Retrieved from http://www.cdc.gov/CDCTV/ObesityEpidemic/Transcripts/ObesityEpidemic.pdf.

Cheren, M., Foushi, M., Gudmundsdotter, E. H., Hillock, C., Lerner, M., Rice, M., ... Werdell, P. (2009). Physical Craving and Food Addiction, 1-51.

Childs, J. L., \& Drake, M. (2009). Consumer Perception of Fat Reduction in Cheese. Journal of Sensory Studies, 24(6), 902-921. doi:10.1111/j.1745-459X.2009.00243

Cover, S. (1936). A new subjective method of testing tenderness in meat - The pairedeating method. Journal of Food Science, 1(3), 287-295. doi: 10.1111/j.13652621.1936.tb17790.x

Cruz, A. G., Faria, J. A. F., Pollonio, M. A. R., Bolini, H. M. A., Celeghini, R. M. S., Granato, D., \& Shah, N. P. (2011). Cheeses with reduced sodium content: Effects on functionality, public health benefits and sensory properties. Trends in Food Science \& Technology, 22(6), 276-291. doi:10.1016/j.tifs.2011.02.003

Darwin, C. (1958). The origin of species (original). New York: The New American Library of World Literature. 
Davis, C., \& Fox, J. (2008). Sensitivity to reward and body mass index (BMI): evidence for a non-linear relationship. Appetite, 50(1), 43-9. doi:10.1016/j.appet.2007.05.007

Davis, C., Patte, K., Levitan, R., Reid, C., Tweed, S., \& Curtis, C. (2007). From motivation to behaviour: a model of reward sensitivity, overeating, and food preferences in the risk profile for obesity. Appetite, 48(1), 12-9. doi:10.1016/j.appet.2006.05.016

De Wijk, R. A., Kooijman, V., Verhoeven, R. H. G., Holthuysen, N. T. E., \& de Graaf, C. (2012). Autonomic nervous system responses on and facial expressions to the sight, smell, and taste of liked and disliked foods. Food Quality and Preference, 26(2), 196-203. doi:10.1016/j.foodqual.2012.04.015

DeSimone, J. A., \& Heck, G. L. (1991). Salt Taste Enhancer. United States.

Drake, S. L., Lopetcharat, K., \& Drake, M. A. (2011). Salty taste in dairy foods: can we reduce the salt? Journal of Dairy Science, 94(2), 636-45. doi:10.3168/jds.2010-3509

Ekman, P. (1992). Facial expressions of emotion: an old controversy and new findings. Philosophical Transactions of the Royal Society of London. Series B, Biological Sciences, 335(1273), 63-9. doi:10.1098/rstb.1992.0008

Ekman, P. (2009). Darwin's contributions to our understanding of emotional expressions. Philosophical Transactions of the Royal Society of London. Series B, Biological Sciences, 364(1535), 3449-51. doi:10.1098/rstb.2009.0189

Ferrarini, R., Carbognin, C., Casarotti, E. M., Nicolis, E., Nencini, A., \& Meneghini, A. M. (2010). The emotional response to wine consumption. Food Quality and Preference, 21(7), 720-725. doi:10.1016/j.foodqual.2010.06.004

Food and Drug Administration. (2003). Oral Health Care Drug Products for Over- theCounter Human Use; Antigingivitis/ Antiplaque Drug Products; Establishment of a Monograph; Proposed Rules (pp. 1-57).

Franken, I. H. A, \& Muris, P. (2005). Individual differences in reward sensitivity are related to food craving and relative body weight in healthy women. Appetite, 45(2), 198-201. doi:10.1016/j.appet.2005.04.004

Ganesan, B., Brown, K., Irish, D. A., Brothersen, C., \& McMahon, D. J. (2014). Manufacture and sensory analysis of reduced- and low-sodium Cheddar and Mozzarella cheeses. Journal of Dairy Science. 97(4), 1970-82. doi:10.3168/jds.2013-7443

Garcia, J., Hankins, W. G., \& Rusiniak, K. W. (1974). Behavioral regulation of the milieu interne in man and rat. Science. 185(4154), 824-831. 
Gibson, E. L. (2006). Emotional influences on food choice: sensory, physiological and psychological pathways. Physiology \& Behavior, 89(1), 53-61.

doi:10.1016/j.physbeh.2006.01.024

Glanz, K., Basil, M., Maibach, E., Goldberg, J., \& Snyder, D. (1998). Why Americans eat what they do: taste, nutrition, cost, convenience, and weight control concerns as influences on food consumption. Journal of the American Dietetic Association, 98(10), 1118-1126. doi:10.1016/S0002-8223(98)00260-0

Hamburg, M. E., Finkenauer, C., \& Schuengel, C. (2014). Food for love: the role of food offering in empathic emotion regulation. Frontiers in Psychology, 5(32), 1-9. doi:10.3389/fpsyg.2014.00032

Hein, K. A., Jaeger, S. R., Tom Carr, B., \& Delahunty, C. M. (2008). Comparison of five common acceptance and preference methods. Food Quality and Preference, 19(7), 651-661. doi:10.1016/j.foodqual.2008.06.001

Helm, E., \& Trolle, B. (1946). Selection of a taste panel. Wallerstein Lab. Commun., 9(28), 181-194.

Howard, P. J. (2000). The Owner's Manual For The Brain - Everyday Applications from Mind-Brain Research (Second.). Austin: Bard Press.

Insel, Paul, Turner, R. Elaine, Ross, D. (2007). Nutrition (third.). Sudbury: Jones and Bartlett Publishers, Inc.

Kaplan, H. I., \& Kaplan, H. S. (1957). The psychosomatic concept of obesity. Journal of Nervous and Mental Disease, 125, 181-201.

Kearney, J. (2010). Food consumption trends and drivers. Philosophical Transactions of the Royal Society of London. Series B, Biological Sciences, 365(1554), 2793-807. doi:10.1098/rstb.2010.0149

Kenny, P. J. (2011). Reward mechanisms in obesity: new insights and future directions. Neuron, 69(4), 664-79. doi:10.1016/j.neuron.2011.02.016

Keskitalo, K., Tuorila, H., Spector, T. D., Cherkas, L. F., Knaapila, A., Kaprio, J., ... Perola, M. (2008). The Three-Factor Eating Questionnaire, body mass index, and responses to sweet and salty fatty foods: a twin study of genetic and environmental associations. The American Journal of Clinical Nutrition, 88(2), 263-71. Retrieved from http://www.ncbi.nlm.nih.gov/pubmed/18689360

King, S. C., \& Meiselman, H. L. (2010). Development of a method to measure consumer emotions associated with foods. Food Quality and Preference, 21, 168-177. Retrieved from http://www.sciencedirect.com/science/article/B6T6T-4VP4TJX1/2/c1cd584d452452ac375c376f21ee3bf5 
Lamichhane, A. P., Puett, R., Porter, D. E., Bottai, M., Mayer-Davis, E. J., \& Liese, A. D. (2012). Associations of built food environment with body mass index and waist circumference among youth with diabetes. The International Journal of Behavioral Nutrition and Physical Activity, 9(1), 81. doi:10.1186/1479-5868-9-81

Laros, F. J. M., \& Steenkamp, J.-B. E. M. (2005). Emotions in consumer behavior: a hierarchical approach. Journal of Business Research, 58(10), 1437-1445. doi:10.1016/j.jbusres.2003.09.013

Lawless, H. T., \& Heymann, H. (1998). Sensory Evaluation of Food Principles and Practices. New York: Chapman and Hall.

Let's Move - Learn the Facts. (2010). Retrieved January 01, 2015, from http://www.letsmove.gov/learn-facts/epidemic-childhood-obesity

Levine, A. S., Kotz, C. M., \& Gosnell, B. A. (2003). Sugar and fat: the neurobiology of preference The Journal of Nutrition. 133(3), 831S-834S

Lim, J. (2011). Hedonic scaling: A review of methods and theory. Food Quality and Preference, 22(8), 733-747. doi:10.1016/j.foodqual.2011.05.008

Linn, S., \& Novosat, C. L. (2008). Calories for sale: food marketing to children in the twenty-first century. The ANNALS of the American Academy of Political and Social Science, 615(1), 133-155. doi:10.1177/0002716207308487

Logue, A. W. (1998). Evolutionary Theory and the Psychology of Eating. Baruch College, City University of New York. Retrieved from http://faculty.baruch.cuny.edu/naturalscience/biology/darwin/faculty/LogueA.html\# definitions

Loijens, L., \& Krips, O. (2013). FaceReader methodology.

Lukovitz, K. (2013, December 17). Childhood Obesity Tops 2013's Food News Stories. Marketing Daily.

Macht, M. (1999). Characteristics of eating in anger, fear, sadness and joy. Appetite 33(1), 129-139. doi: 10.1006/appe.1999.0236

Macht, M. (2008). How emotions affect eating: a five-way model. Appetite 50(1), 1-11. Retrieved from http://www.ncbi.nlm.nih.gov/pubmed/17707947

Mennella, J. A. (2007). Sweet Taste and Development. In E. Smith, G, Firestein, D.S., Firestein, S. (Ed.), Handbook os the Senses: Olfaction and Taste. San Diego: Elsevier. 
Molto, J., Torrubia, R., Avila, C., \& Caseras, X. (2001). The Sensitivity to Punishment and Sensitivity to Reward Questionnaire ( SPSRQ) as a measure of Gray' s anxiety and impulsivity dimensions. Personality and Individual Differences. 31(6), 837-862. doi: 10.1016/S0191-8869(00)00183-5

Moskowitz, H. R., Beckley, J. H., \& Resurreccion, A. V. A. (2006). Sensory and consumer research in food product design and development (First.). Ames: Blackwell Publishing Professional.

Neal, M. A., (1978). Sociobiology and Behavior by David P . Barash Review by : Marie Augusta Neal. Sociology Analysis, 39(2), 185-187.

Ng, M., Hort, J., \& Chaya, C. (2013). Beyond liking: Comparing the measurement of emotional response using EsSense Profile and consumer defined check-all-thatapply methodologies. Food Quality and Preference, 28(1), 193-205. doi:10.1016/j.foodqual.2012.08.012

Ogden, C. L., Carroll, M. D., Kit, B. K., \& Flegal, K. M. (2012). Prevalence of obesity in the United States, 2009-2010. NCHS Data Brief, (82), 1-8. Retrieved from http://www.ncbi.nlm.nih.gov/pubmed/22617494

Parts of the Brain and Their Functions. (2015). Retrieved from http://www.mdhealth.com/Parts-Of-The-Brain-And-Function.html

Paryam, D. R., \& Swartz, V. W. (1950). Measurement of sensory differences. Food Technology, 4, 390-395.

Pavlov, I. P. (1927). Conditioned Reflexes. Oxford, England: Oxford University Press.

Pelchat, M. L., \& Rozin, P. (1982). The special role of nausea in the acquisition of food dislikes by humans. Appetite, 3(4), 341-351. doi:10.1016/S0195-6663(82)80052-4

Peryam, D. R. (1998). The 9-Point Hedonic Scale. Peryam \& Kroll Research Corporation. Retrieved from http://www.pkresearch.com/services/media/paperandpublications/theninepointhedonicscalepapers.pdf

Peryam, D. R., \& Swartz, V. W. (1950). Measurement of sensory differences. Food Technology, 4, 390-395.

Polivy, J., Heatherton, T. F., \& Herman, C. P. (1988). Self-esteem, restraint, and eating behavior. Journal of Abnormal Psychology, 97(3), 354-6. Retrieved from http://www.ncbi.nlm.nih.gov/pubmed/3192831 
Pray, Leslie, Pillsbury, L. (2011). Leveraging Food Technology for Obesity Prevention and Reduction Efforts. In Institute of Medicine. Washington, DC: The National Academies Press.

Prescott, J. (2012). Taste Matters (p. 27). London: MPG Books Group.

Randall, E., \& Sanjur, D. (1981). Food preferences - their conceptualization and relationship to consumption. Ecology of Food Nutrition, 11(3), 151-161. doi: 10.1080/03670244.1981.9990671

Roger, V. L., Go, A. S., Lloyd-Jones, D. M., Benjamin, E. J., Berry, J. D., Borden, W. B., ... Turner, M. B. (2012). Heart disease and stroke statistics--2012 update: A report from the American Heart Association. Circulation, 125(1), e2-e220. doi:10.1161/CIR.0b013e31823ac046

Schifferstein, H. N. J., \& Desmet, P. M. A. (2010). Hedonic asymmetry in emotional responses to consumer products. Food Quality and Preference, 21(8), 1100-1104. doi:10.1016/j.foodqual.2010.07.004

Schwartz, B. (1974). On going back to nature: a review of Seligman and Hager's Biological boundaries of learning. Journal of the Experimental Analysis of Behavior, 21(1), 183-198. doi: 10.1901/jeab.1974.21-183

Seo, H.-S., Lee, Y., Yoon, N.-R., Song, J. M., Shin, J.-M., Lee, S.-Y., \& Hwang, I. (2009). Impacts of sensory attributes and emotional responses on the hedonic ratings of odors in dairy products. Appetite, 53(1), 50-55. doi:10.1016/j.appet.2009.05.010

Shin, A. C., Zheng, H., \& Berthoud, H.R. (2009). An expanded view of energy homeostasis: neural integration of metabolic, cognitive, and emotional drives to eat. Physiology \& Behavior, 97(5), 572-80. doi:10.1016/j.physbeh.2009.02.010

Sijtsema, S., Linnemann, A., Gaasbeek, T. Van, \& Dagevos, H. (2002). for ConsumerOriented Product Development. Critical Reviews in Food Science and Nutrition, 42(6), 565-581. doi: 1040-8398/02/\$.50

St John, S. J., \& Hallagan, L. D. (2005). Psychophysical investigations of cetylpyridinium chloride in rats: its inherent taste and modifying effects on salt taste. Behavioral Neuroscience, 119(1), 265-79. doi:10.1037/0735-7044.119.1.265

Stone, H., Bleibaum, R. N., \& Thomas, H. A. (2012). Sensory Evaluation Practices (Fourth). San Diego, CA: Elsevier Inc.

Terzis, V., Moridis, C. N., \& Economides, A. a. (2010). Measuring instant emotions during a self-assessment test: the use of FaceReader. Proceedings of the 7th International Conference on Methods and Techniques in Behavioral Research - MB '10, 1-4. doi:10.1145/1931344.1931362 
Thomson, D. M. H., Crocker, C., \& Marketo, C. G. (2010). Linking sensory characteristics to emotions: An example using dark chocolate. Food Quality and Preference, 21(8), 1117-1125. doi:10.1016/j.foodqual.2010.04.011

Turocy, P. S., DePalma, B. F., Horswill, C. a., Laquale, K. M., Martin, T. J., Perry, A. C., ... Utter, A. C. (2011). National athletic trainers' association position statement: Safe weight loss and maintenance practices in sport and exercise. Journal of Athletic Training, 46(3), 322-336.

United States Department of Agriculture. (2014). Per capita consumption of selected cheese varieties (Annual).

University of Miami, D. of P. (2007). BIS/BAS Scale.

Van Strien, T., Schippers, G. M., \& Cox, W. M. (1995). On the relationship between emotional and external eating behavior. Addictive Behaviors, 20(5), 585-94. Retrieved from http://www.ncbi.nlm.nih.gov/pubmed/8712056

van't Riet, J., Sijtsema, S. J., Dagevos, H., \& De Bruijn, G.-J. (2011). The importance of habits in eating behaviour. An overview and recommendations for future research. Appetite, 57(3), 585-96. doi:10.1016/j.appet.2011.07.010

Volkow, N. D., Wang, G.-J., \& Baler, R. D. (2011). Reward, dopamine and the control of food intake: implications for obesity. Trends in Cognitive Sciences, 15(1), 37-46. doi:10.1016/j.tics.2010.11.001

Walther, B., Schmid, A., Sieber, R., \& Wehrmüller, K. (2008). Cheese in nutrition and health. Dairy Science and Technology, 88(4-5), 389-405. doi:10.1051/dst:2008012

Whitney, Ellie, Rolfes, S. R. (2008). Understanding Nutrition (Eleventh., pp. 259-266). Belmont: Thomas Wadsworth.

Wood, W., \& Neal, D. T. (2007). A new look at habits and the habit-goal interface. Psychological Review, 114(4), 843-63. doi:10.1037/0033-295X.114.4.843

Wood, W., \& Neal, D. T. (2009). The habitual consumer. Journal of Consumer Psychology, 19(4), 579-592. doi:10.1016/j.jcps.2009.08.003

Zheng, H., \& Berthoud, H.-R. (2007). Eating for pleasure or calories. Current Opinion in Pharmacology, 7(6), 607-12. doi:10.1016/j.coph.2007.10.011 


\title{
APPENDICES
}

\author{
A: "Emotion Poster" Homework
}

\section{Cheese Homework for May Sensory Test}

Thank you for agreeing to participate in our cheese sensory test!!! You will have $\underline{\mathbf{3}}$ pieces of homework to complete *before* the product tasting.

First, we would like you to attach a total of 7 images (on the paper provided) that represent the different emotions below. These images should be meaningful to you. They can be images from magazines, the internet, your personal photos or a mixture of these; however they will not be returned to you.

1. Happy including energetic, excited, overjoyed

2. Sad including nostalgic, regretful, depressed, discontent

3. Scared including afraid, fearful, terrified, panicked

4. Angry including mad, annoyed, bitter, furious

5. Disgusted including appalled, offended, sickened, outraged

6. Surprised including startled, shocked, stunned

7. Neutral including impartial, unbiased, indifferent

Your images are part of the test and will not be returned to you when completed.

Please remember: because you will be participating in a research study on food, it is *VERY* important that you follow the following guidelines:

- Bring a valid picture ID to validate your name and age. Those that arrive without a valid ID will be asked to leave without payment.

- Refrain from drinking coffee or eating at least 30 minutes before your scheduled test time.

- Do NOT use any mouthwash within 1 day of testing.

- Do not wear any fragrances. Those that arrive with fragrances will be asked to leave without payment.

- No children will be allowed to wait alone at the facility. (WHY: To eliminate distractions and because we cannot provide supervision.)

- To allow for the check-in process, give yourself enough time to get here approximately 15 minutes before your scheduled testing time. The test will take approximately 20 minutes to complete.

- If you need glasses to read, please bring them as you will be reading and completing an online questionnaire.

ALSO, prior to the testing day please go to the following link and complete the online questionnaires:

1. BAS Questionnaire - https://www.surveymonkey.com/s/cheesehomework1

2. SPSRQ Questionnaire - https://www.surveymonkey.com/s/SPSRQ 


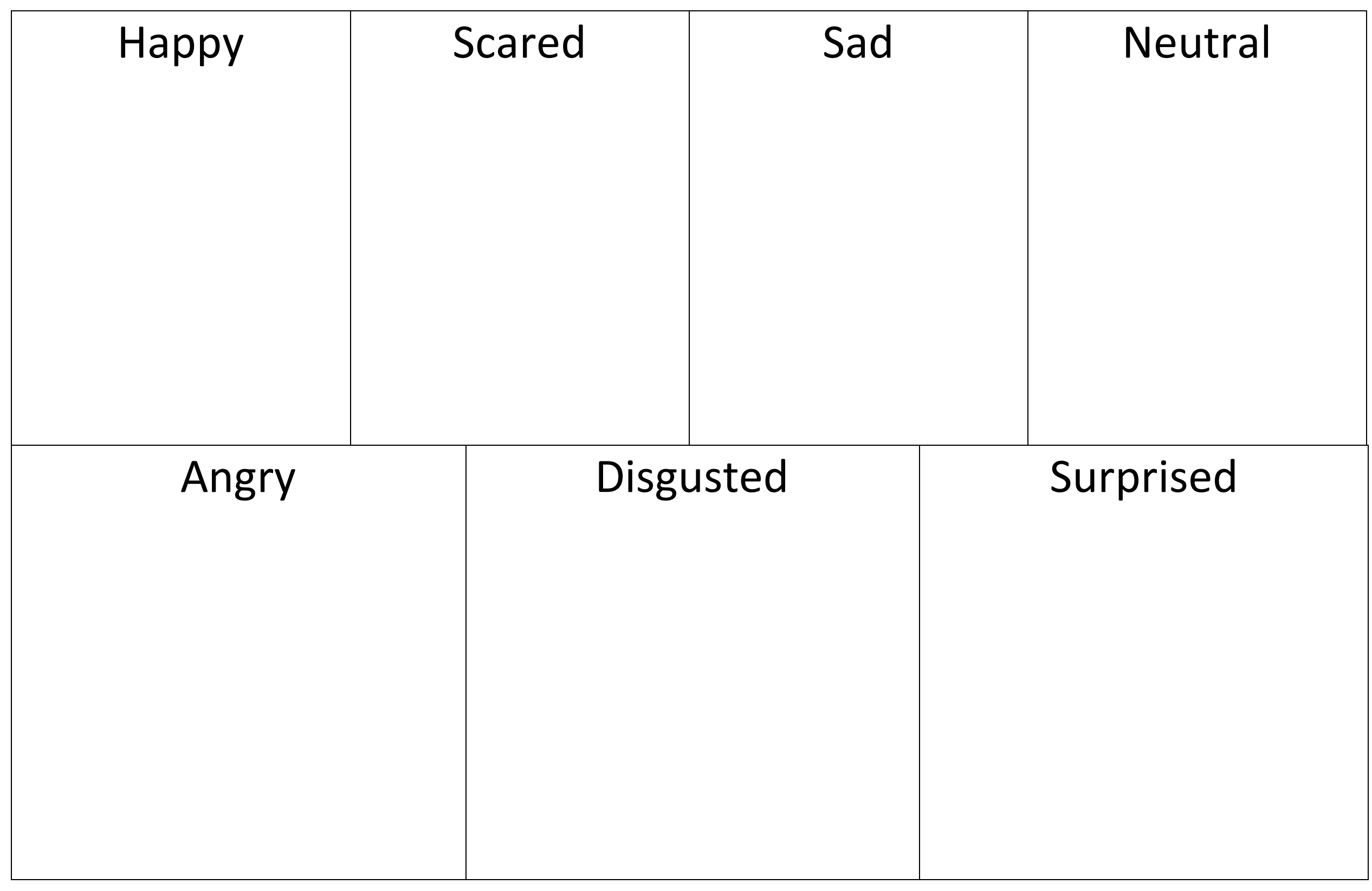




\section{B: BIS/BAS Questionnaire}

\section{Directions:}

Each item of this questionnaire is a statement that a person may either agree with or disagree with. For each item, indicate how much you agree or disagree with what the item says. Please respond to all the items; do not leave any blank. Choose only one response to each statement. Please be as accurate and honest as you can be.

Respond to each item as if it were the only item. That is, don't worry about being "consistent" in your responses.

Choose from the following four response options:

$1=$ very true for me

2 = somewhat true for me

$3=$ somewhat false for me

$4=$ very false for me

\begin{tabular}{|c|c|c|c|c|c|}
\hline & & $\begin{array}{l}\text { Very } \\
\text { true }\end{array}$ & $\begin{array}{c}\text { Somewhat } \\
\text { true }\end{array}$ & $\begin{array}{l}\text { Somewhat } \\
\text { false }\end{array}$ & $\begin{array}{l}\text { Very } \\
\text { false }\end{array}$ \\
\hline 1) & $\begin{array}{l}\text { A person's family is the most important } \\
\text { thing in life. }\end{array}$ & 1 & 2 & 3 & 4 \\
\hline 2) & $\begin{array}{l}\text { Even if something bad is about to happen } \\
\text { to me, I rarely experience fear or } \\
\text { nervousness. }\end{array}$ & 1 & 2 & 3 & 4 \\
\hline 3) & I go out of my way to get things I want. & 1 & 2 & 3 & 4 \\
\hline 4) & $\begin{array}{l}\text { When I'm doing well at something I love } \\
\text { to keep at it. }\end{array}$ & 1 & 2 & 3 & 4 \\
\hline 5) & $\begin{array}{l}\text { I'm always willing to try something new if } \\
\text { I think it will be fun. }\end{array}$ & 1 & 2 & 3 & 4 \\
\hline 6) & How I dress is important to me. & 1 & 2 & 3 & 4 \\
\hline 7) & $\begin{array}{l}\text { When I get something I want, I feel } \\
\text { excited and energized. }\end{array}$ & 1 & 2 & 3 & 4 \\
\hline 8) & Criticism or scolding hurts me quite a bit. & 1 & 2 & 3 & 4 \\
\hline
\end{tabular}




\begin{tabular}{|c|c|c|c|c|c|}
\hline & & $\begin{array}{l}\text { Very } \\
\text { true }\end{array}$ & $\begin{array}{c}\text { Somewhat } \\
\text { true }\end{array}$ & $\begin{array}{l}\text { Somewhat } \\
\text { false }\end{array}$ & $\begin{array}{l}\text { Very } \\
\text { false }\end{array}$ \\
\hline 9) & $\begin{array}{l}\text { When I want something I usually go all- } \\
\text { out to get it. }\end{array}$ & 1 & 2 & 3 & 4 \\
\hline 10) & $\begin{array}{l}\text { I will often do things for no other reason } \\
\text { than that they might be fun. }\end{array}$ & 1 & 2 & 3 & 4 \\
\hline 11) & $\begin{array}{l}\text { It's hard for me to find the time to do } \\
\text { things such as get a haircut. }\end{array}$ & 1 & 2 & 3 & 4 \\
\hline 12) & $\begin{array}{l}\text { If I see a chance to get something I want I } \\
\text { move on it right away. }\end{array}$ & 1 & 2 & 3 & 4 \\
\hline 13) & $\begin{array}{l}\text { I feel pretty worried or upset when I think } \\
\text { or know somebody is angry at me. }\end{array}$ & 1 & 2 & 3 & 4 \\
\hline 14) & $\begin{array}{l}\text { When I see an opportunity for something I } \\
\text { like I get excited right away. }\end{array}$ & 1 & 2 & 3 & 4 \\
\hline 15) & I often act on the spur of the moment. & 1 & 2 & 3 & 4 \\
\hline 16) & $\begin{array}{l}\text { If I think something unpleasant is going to } \\
\text { happen I usually get pretty "worked up". }\end{array}$ & 1 & 2 & 3 & 4 \\
\hline 17) & $\begin{array}{l}\text { I often wonder why people act the way } \\
\text { they do. }\end{array}$ & 1 & 2 & 3 & 4 \\
\hline 18) & $\begin{array}{l}\text { When good things happen to me, it affects } \\
\text { me strongly. }\end{array}$ & 1 & 2 & 3 & 4 \\
\hline 19) & $\begin{array}{l}\text { I feel worried when I think I have done } \\
\text { poorly at something important. }\end{array}$ & 1 & 2 & 3 & 4 \\
\hline 20) & I crave excitement and new sensations. & 1 & 2 & 3 & 4 \\
\hline 21) & $\begin{array}{l}\text { When I go after something I use a "no } \\
\text { holds barred" approach. }\end{array}$ & 1 & 2 & 3 & 4 \\
\hline 22) & $\begin{array}{l}\text { I have very few fears compared to my } \\
\text { friends. }\end{array}$ & 1 & 2 & 3 & 4 \\
\hline 23) & It would excite me to win a contest. & 1 & 2 & 3 & 4 \\
\hline 24) & I worry about making mistakes. & 1 & 2 & 3 & 4 \\
\hline
\end{tabular}




\section{C: SPSRQ Questionnaire}

\section{Directions:}

Answer "Yes" or "No" for each item. There are no right or wrong answers or trick questions. Work quickly and don't think too much about the exact meaning of the questions.

\begin{tabular}{|c|c|c|c|}
\hline & & Yes & No \\
\hline & $\begin{array}{l}\text { Do you often refrain from doing something because you are afraid of it } \\
\text { being illegal? }\end{array}$ & Yes & No \\
\hline 2) & $\begin{array}{l}\text { Does the good prospect of obtaining money motivate you strongly to do } \\
\text { some things? }\end{array}$ & Yes & No \\
\hline 3) & $\begin{array}{l}\text { Do you prefer not to ask for something when you are not sure you will } \\
\text { obtain it? }\end{array}$ & Yes & No \\
\hline 4) & $\begin{array}{l}\text { Are you frequently encouraged to act by the possibility of being valued in } \\
\text { your work, in your studies, with your friends or with your family? }\end{array}$ & Yes & No \\
\hline 5) & Are you often afraid of new or unexpected situations? & Yes & No \\
\hline 6) & Do you often meet people that you find physically attractive? & Yes & No \\
\hline 7) & Is it difficult for you telephone someone you do not know? & Yes & No \\
\hline 8) & $\begin{array}{l}\text { Do you like to take some drugs because of the pleasure you get from } \\
\text { them? }\end{array}$ & Yes & No \\
\hline 9) & $\begin{array}{l}\text { Do you often renounce your rights when you know you can avoid a } \\
\text { quarrel with a person or organization? }\end{array}$ & Yes & No \\
\hline & Do you often do things to be praised? & Yes & No \\
\hline 11) & As a child, were you troubled by punishments at home or in school? & Yes & No \\
\hline 12) & Do you like being the center of attention at a party or a social meeting? & Yes & No \\
\hline & $\begin{array}{l}\text { In tasks that you are not prepared for, do you attach great importance to } \\
\text { the possibility of failure? }\end{array}$ & Yes & No \\
\hline 14) & Do you spend a lot of your time on obtaining a good image? & Yes & No \\
\hline 15) & Are you easily discouraged in difficult situations? & Yes & No \\
\hline
\end{tabular}


16) Do you need people to show their affection for you all the time? Yes No

17) Are you a shy person? $\quad$ Yes No

18) When you are in a group, do you try to make your opinions the most $\quad$ Yes $\quad$ No intelligent or the funniest?

19) Whenever possible, do you avoid demonstrating your skills for fear of $\quad$ Yes $\quad$ No being embarrassed?

20) Do you often take the opportunity to pick up people you find attractive? Yes No

21) When you are with a group, do you have difficulty selecting a good topic $\quad$ Yes No to talk about?

22) As a child, did you do a lot of things to get people's approval? $\quad$ Yes No

23) Is it often difficult for you to fall asleep when you think about things you $\quad$ Yes $\quad$ No have done or must do?

24) Does the possibility of social advancement move you to action, even if $\quad$ Yes No this involves not playing fair?

25) Do you think a lot before complaining in a restaurant if your meal is not $\quad$ Yes No well prepared?

26) Do you generally give preference to those activities that imply an $\quad$ Yes No immediate gain?

27) Would you be bothered if you had to return to a store when you noticed Yes No you were given the wrong change?

28) Do you often have trouble resisting the temptation of doing forbidden $\quad$ Yes No things?

29) Whenever you can, do you avoid going to unknown places?

30) Do you like to compete and do everything you can to win? Yes No

31) Are you often worried by things you said or did? $\quad$ Yes No

32) Is it easy for you to associate taste and smells to very pleasant events? Yes No

33) Would it be difficult for you to ask your boss for a raise (salary increase)? Yes No

34) Are there a large number of objects or sensations that remind you of $\quad$ Yes $\quad$ No pleasant events?

35) Do you generally try to avoid speaking in public? $\quad$ Yes No 
36) When you start to play with a slot machine, is it often difficult for you to Yes No stop?

37) Do you, on a regular basis, think that you could do more things if it was Yes No not for your insecurity or fear?

38) Do you sometimes do things for quick gains? $\quad$ Yes $\quad$ No

39) Comparing yourself to people you know, are you afraid of many things? Yes No

40) Does your attention easily stray away from your work in the presence of Yes No an attractive stranger?

41) Do you often find yourself worrying about things to the extent that performance in intellectual abilities is impaired?

42) Are you interested in money to the point of being able to do risky jobs? Yes No

43) Do you often refrain from doing something you like in order not to be Yes No rejected or disapproved of by others?

44) Do you like to put competitive ingredients in all of your activities? $? \quad$ Yes No

45) Generally do you pay more attention to threats than to pleasant events? Yes No

46) Would you like to be a socially powerful person? $\quad$ Yes No

47) Do you often refrain from doing something because of your fear of being Yes No embarrassed?

48) Do you like displaying your physical abilities even though this may $\quad$ Yes No involve danger? 


\section{D: Informed Consent}

\section{INFORMED CONSENT TO PARTICIPATE IN A RESEARCH PROJECT: Consumer Evaluation of Commercially Available Cheeses based on BMI and Emotion}

A research project on cheese is being conducted by Malori Comer, graduate student in the Food Science and Nutrition Department at Cal Poly, San Luis Obispo, under the supervision of Dr. Amy Lammert. The purpose of the study is to measure the emotional responses of consumers as they relate to foods; more specifically, differences in full fat vs. reduced fat cheddar cheese and full sodium vs. reduced sodium mozzarella cheese. In addition, the study will determine if there is a relationship between an individual's sensitivity to reward, body mass index, and their liking of a product based on salt/fat content.

Prior to the experiment, your Body Mass Index and body fat percentage will be estimated using a hand-held device which will introduce a small, imperceptible amount of electric current through your body. You are being asked to put together a visual for emotions (the homework), answer a learning style questionnaire in order to determine sensitivity to reward, and evaluate your emotional response to commercially available cheese by completing a questionnaire and agreeing to have your image recorded during the taste testing. Your participation will take approximately 2 hours, approximately one hour for the homework and one 45 minute tasting session. Please be aware that you are not required to participate in this research and you may discontinue your participation at any time without penalty. You also do not have to answer any questions you choose not to answer.

The possible risks associated with participation in this study include potential discomfort if you are lactose-intolerant or suffer from other gastric distress. Do not participate in this project if you are allergic or intolerant to dairy products, or if you have a pacemaker, insulin pump, or other susceptibility to small electrical currents. If you should experience food allergy, please be aware that you may contact Dr. Amy Lammert at (805) 439-1612. If you are a Cal Poly student you may contact the Cal Poly Health Center, located in Building 27, at (805)756-1211 for assistance. If you are not a Cal Poly student, you may contact an off campus health care provider, but you will be responsible for any costs associated with medical treatment.

Your confidentiality will be protected as your results will remain anonymous. Your name and image will not be used in reports of this research, unless you complete the Image Release Waiver, in which case your image may be used. Potential benefits associated with the study include helping the researchers understand the influence of fat and sodium on the emotional response to various cheeses and you will receive $\$ 40$ upon completion.

If you have questions regarding this study or would like to be informed of the results when the study is completed, please feel free to contact Dr. Amy Lammert at 805.756.6108 or alammert@calpoly.edu. If you have concerns regarding the manner in which the study is conducted, you may contact Dr. Steve Davis, Chair of the Cal Poly Human Subjects Committee, at 805-756-2754, sdavis@calpoly.edu, or Dr. Dean Wendt, Interim Dean of Research, at (805) 756-1508, dwendt@calpoly.edu.

If you agree to voluntarily participate in this research project as described, please indicate your agreement by signing below. Please keep one copy of this form for your reference, and thank you for your participation in this research.

Name (Print)

Signature of Volunteer

\section{Date}




\section{E: Video Release Form}

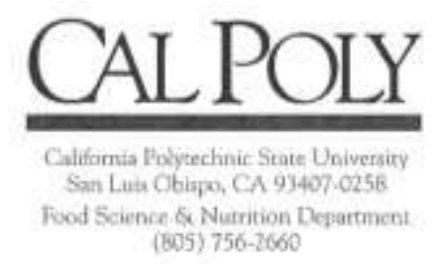

\section{Photographic Image and Video Recording Release Agreement - Personal Image}

I. hereby release to California Polytechnic State University San Luis Obispo (University), for use and reproduction by the University for representation, publicity, and/or promotional purposes which may include, but are not limited to: print and video recording materials: assessment for research purposes,

Such release is made without consideration beyond acknowledgement by the University of this Release Agreement.

This Release Agreement is intended to discharge the State of California, Trustees of the California State University, California Polytechnic State University, officers, employees, students and volunteers of each from and against any and all liability arising out of or connected in any way with my release of photographic image even though that liability may arise out of the negligence or carelessness on the part of persons or agencies mentioned above.

I understand that institutional data (including photographic image(s) may be protected under state and/or federal privacy acts (including but not limited to the Family Educational Rights and Privacy Act), nevertheless, I agree to assume the risks of authorizing the University to use my image and release hold harmless any of the persons or agencies mentioned above who (through negligence or carelessness) might otherwise be liable to me (or my heirs or assigns) for damages. It is further understood and agreed that this Photographic Image Release Agreement is to be binding on my heirs and assigns.

I have read this entire Release Agreement, 1 fully understand and agree to be legally bound by it. This is a release of your rights, read carefully before signing.

Releaser's Signature

Address

Phone (__

Parent of Guardian, if Releaser is under 18 years of age:

Guardian name

Signature

Address

Phone ( $]$ 
F: Consumer Acceptance - Testing Questionnaire

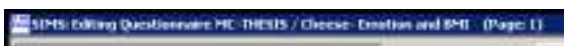

Sample:

10

Welcome to the Sensory Testing Lab and

thank you for participating in this research project.

Today you will be trying 4 different samples of cheese.

\begin{tabular}{ll} 
Sample: & SOC 10 \\
\hline
\end{tabular}

Ready to get started?

Press the Next Page Button above to proceed. 
** The following STOP Screen was shown before every sample.

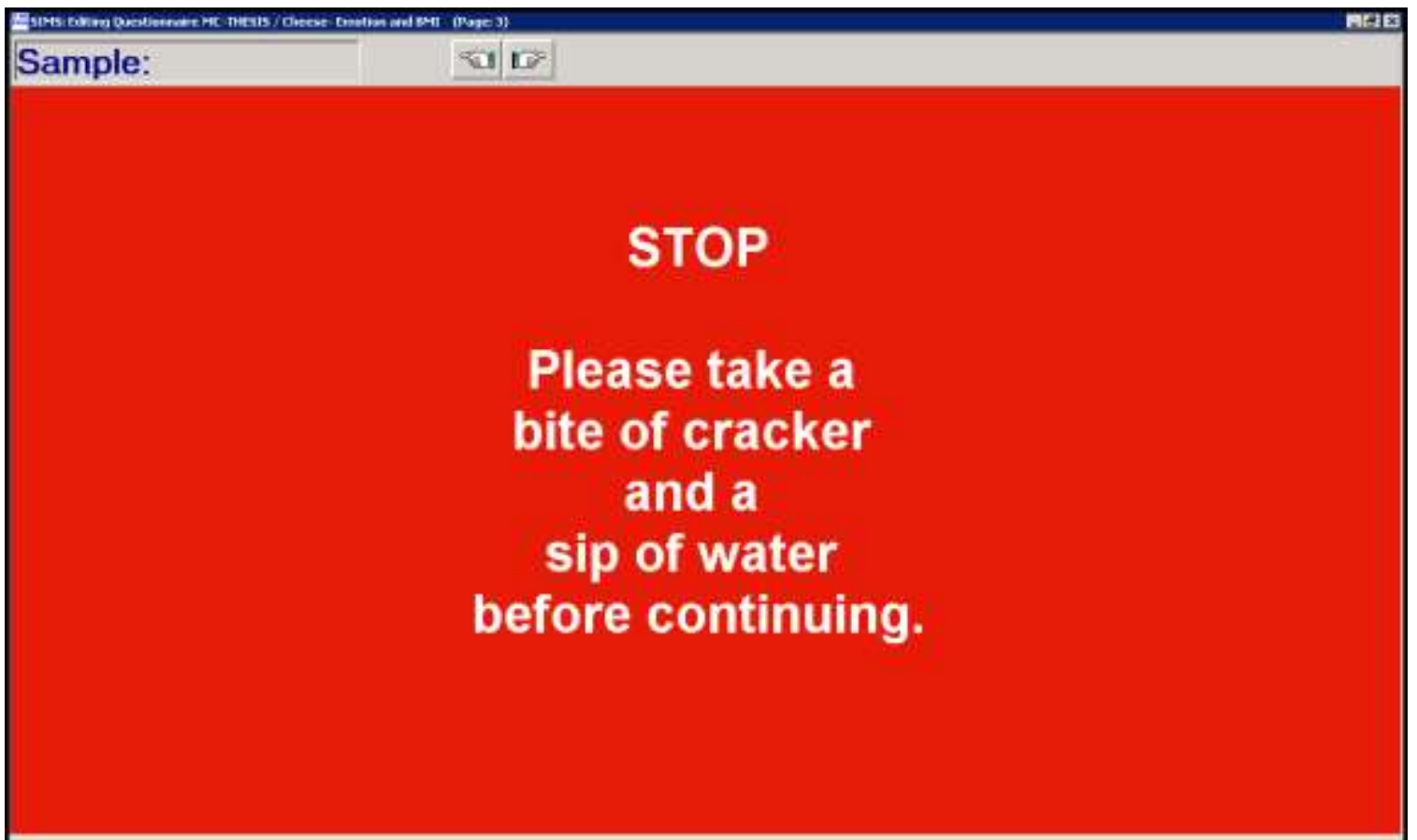

** Each individual cheese had a specific color assigned to that sample. The following screens were shown before the respective sample so panelists knew to hold up the respective index card at the camera (in order for the research/Face Reader to know which sample was being consumed)

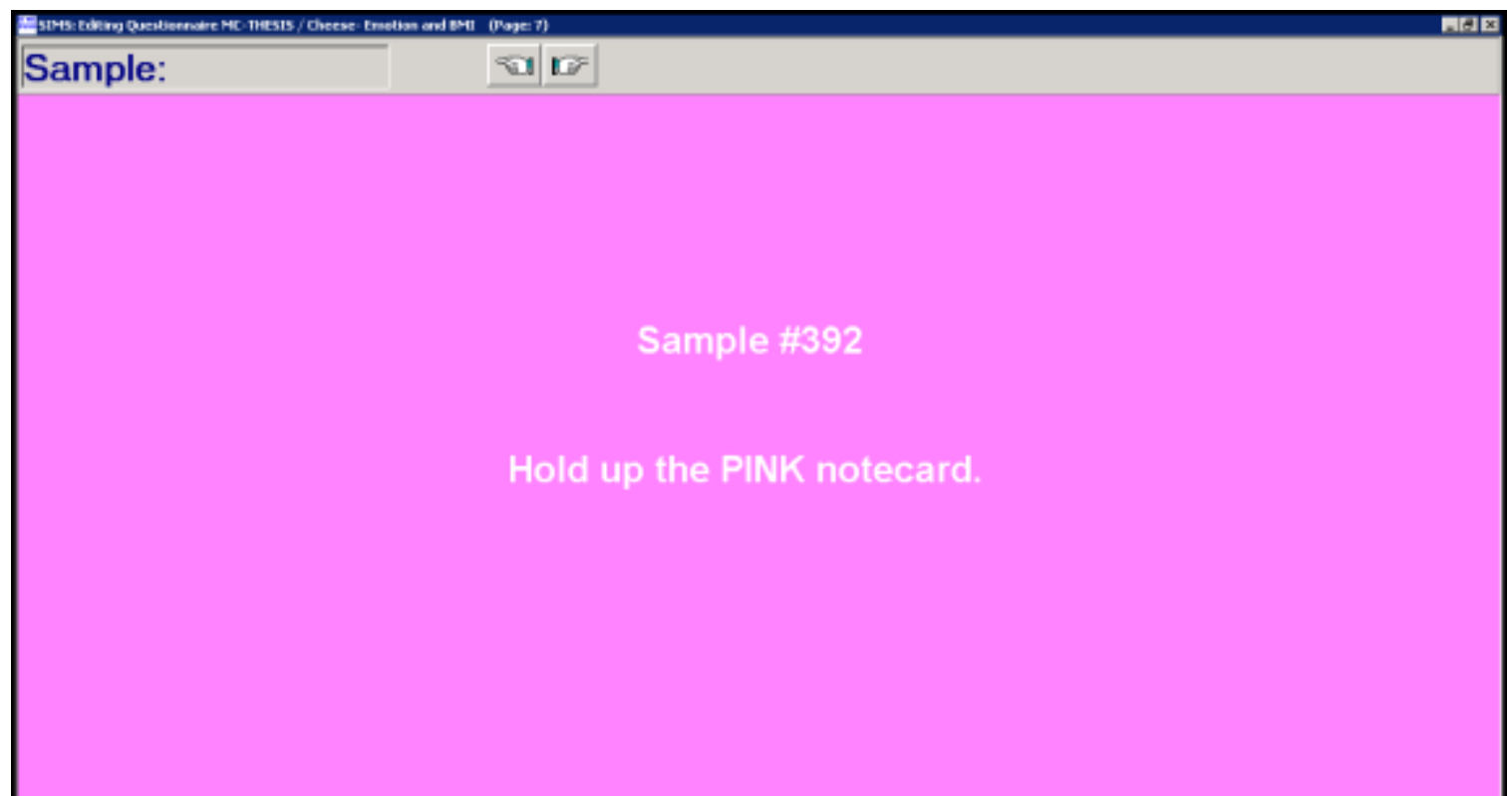




\section{Sample \#761}

\section{Hold up the GREEN notecard.}

Sample \#412

Hold up the BLUE notecard. 


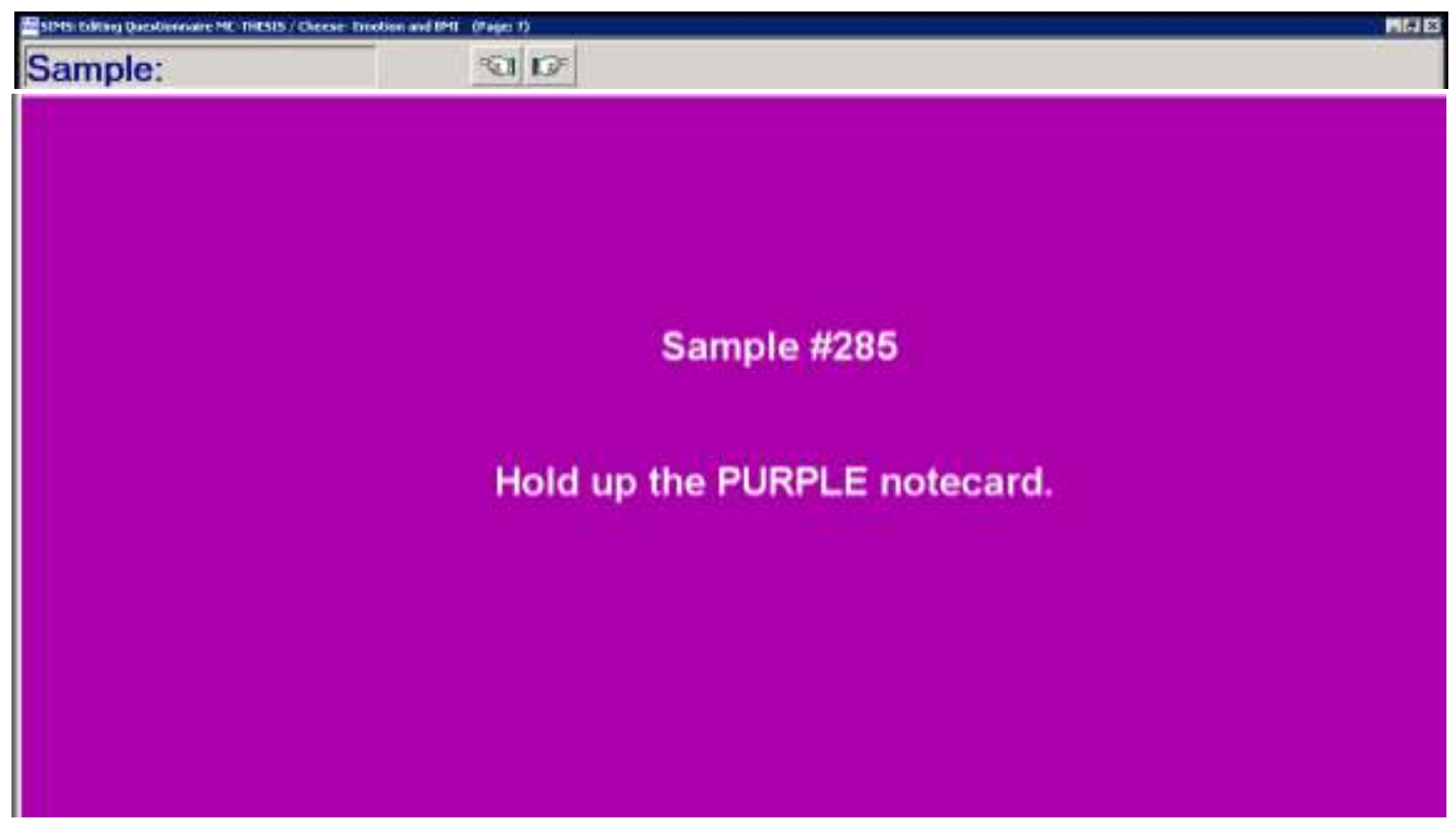

** The following questions were asked for every sample

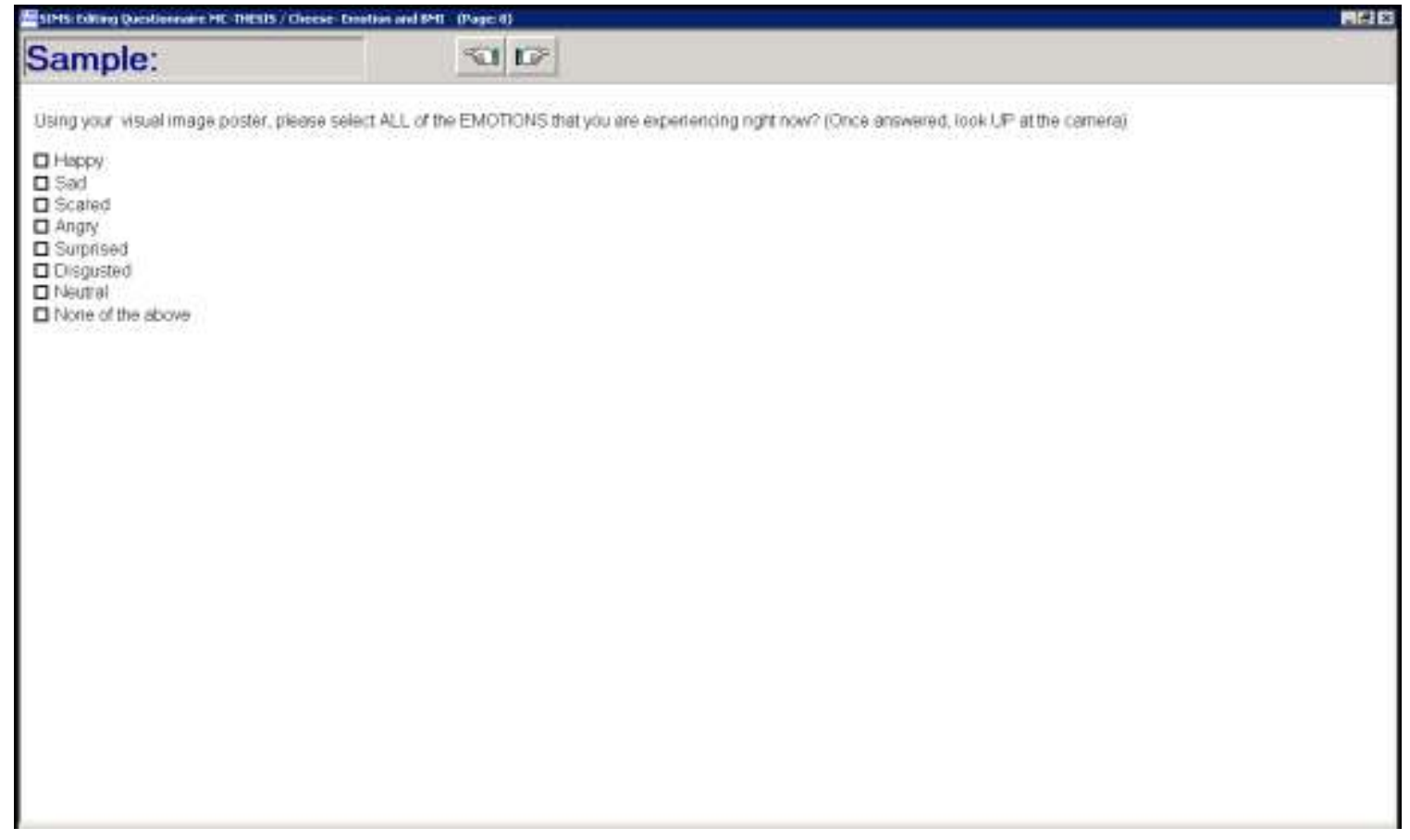




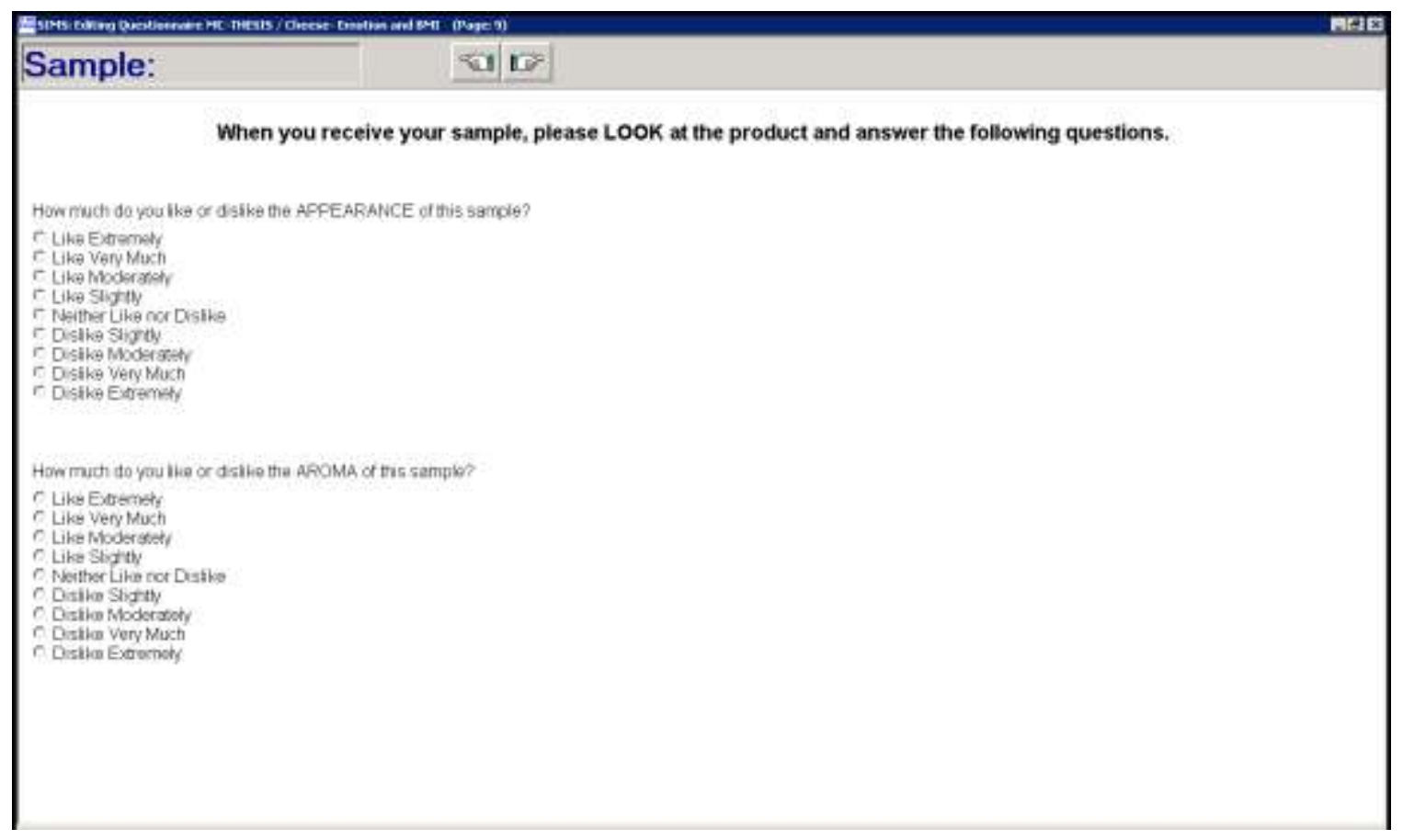

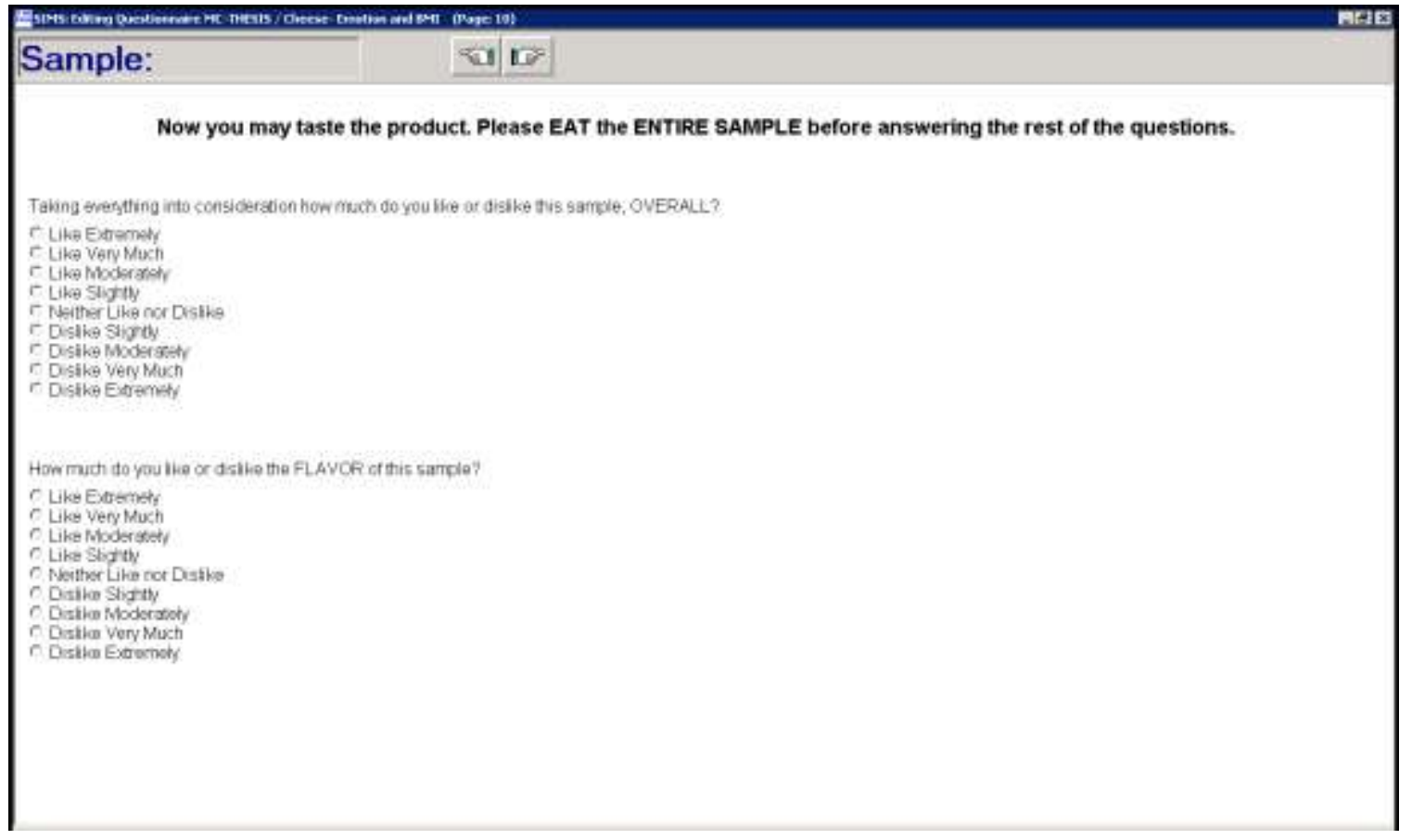



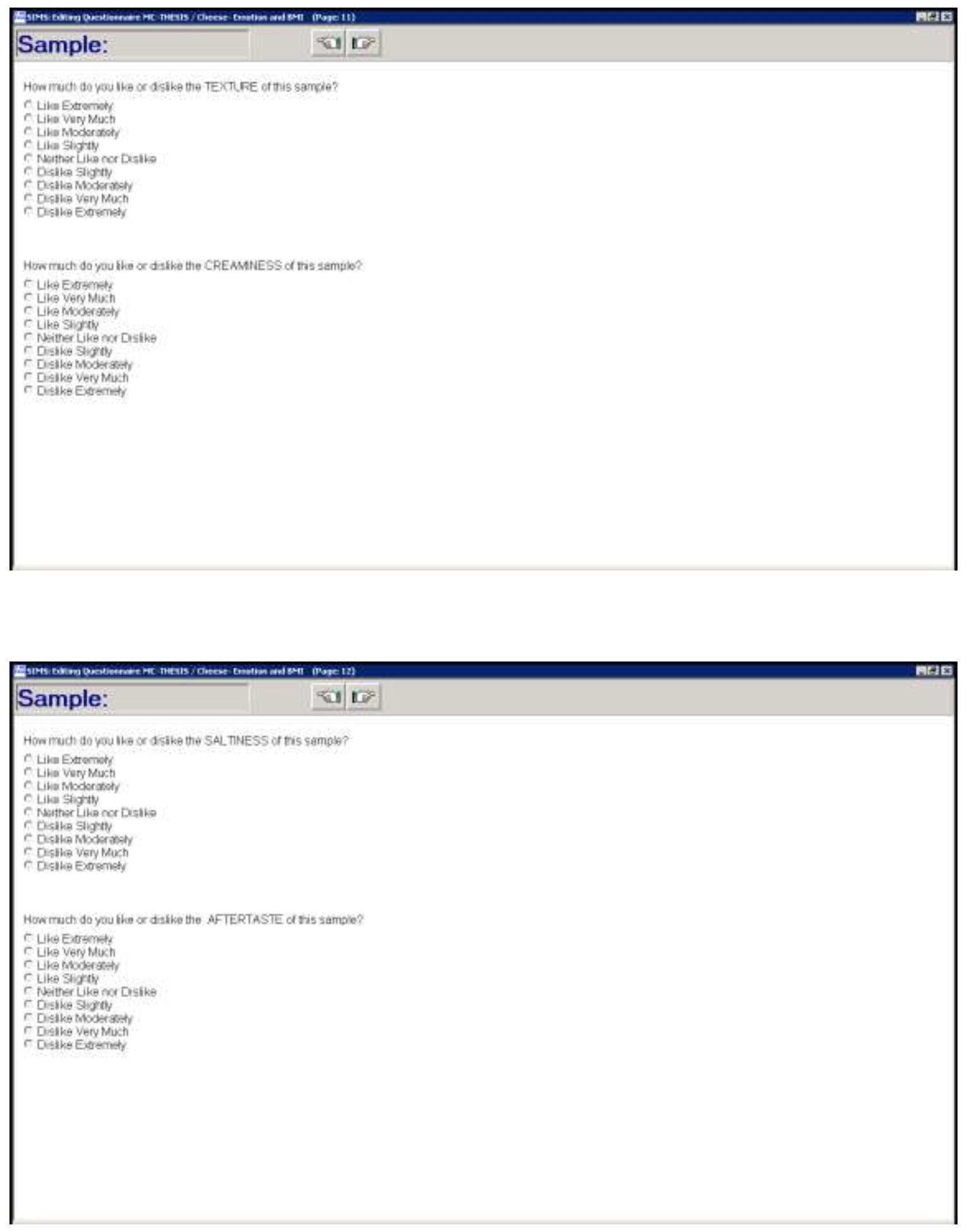


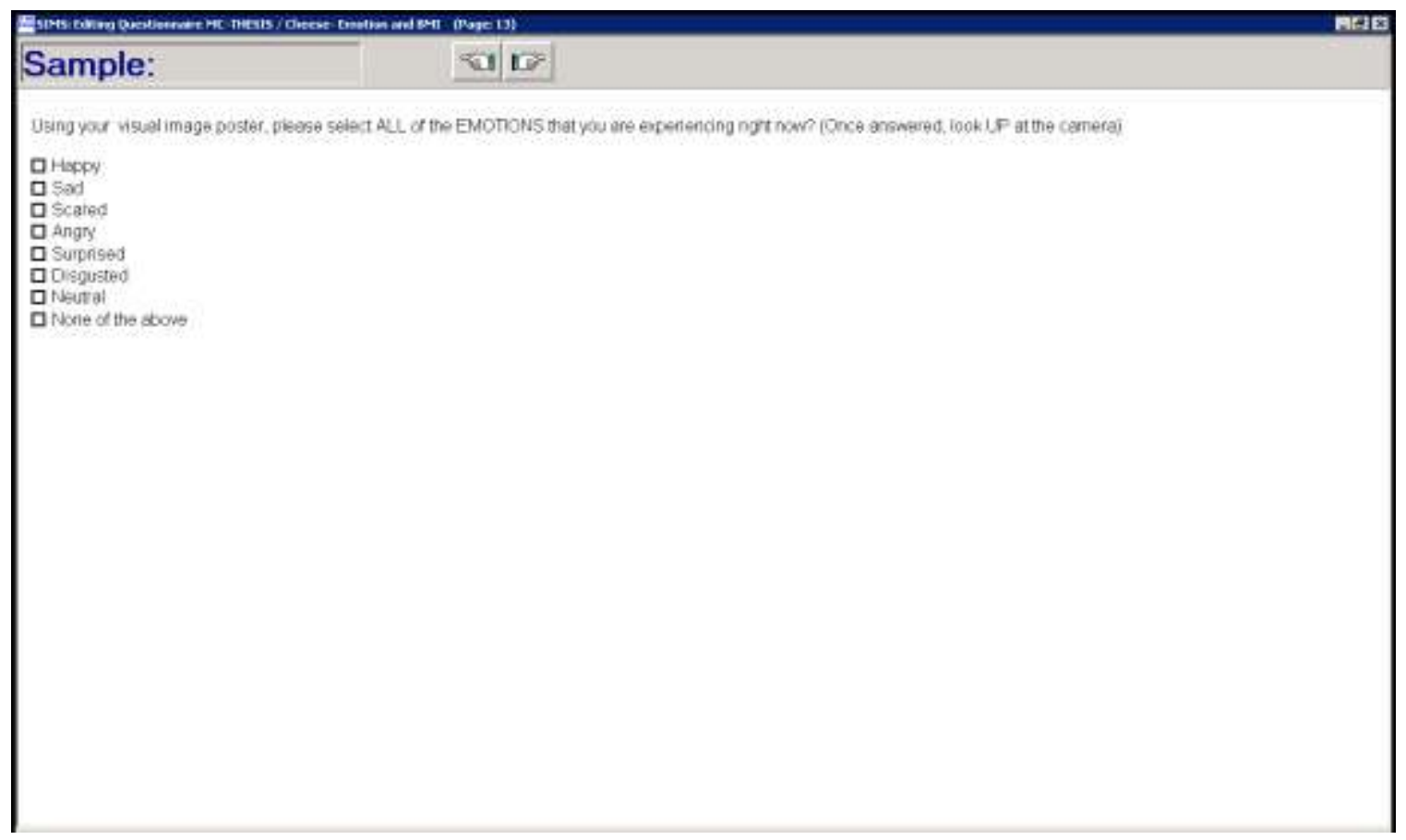

** Demographic questions were only asked after the last sample had been consumed.

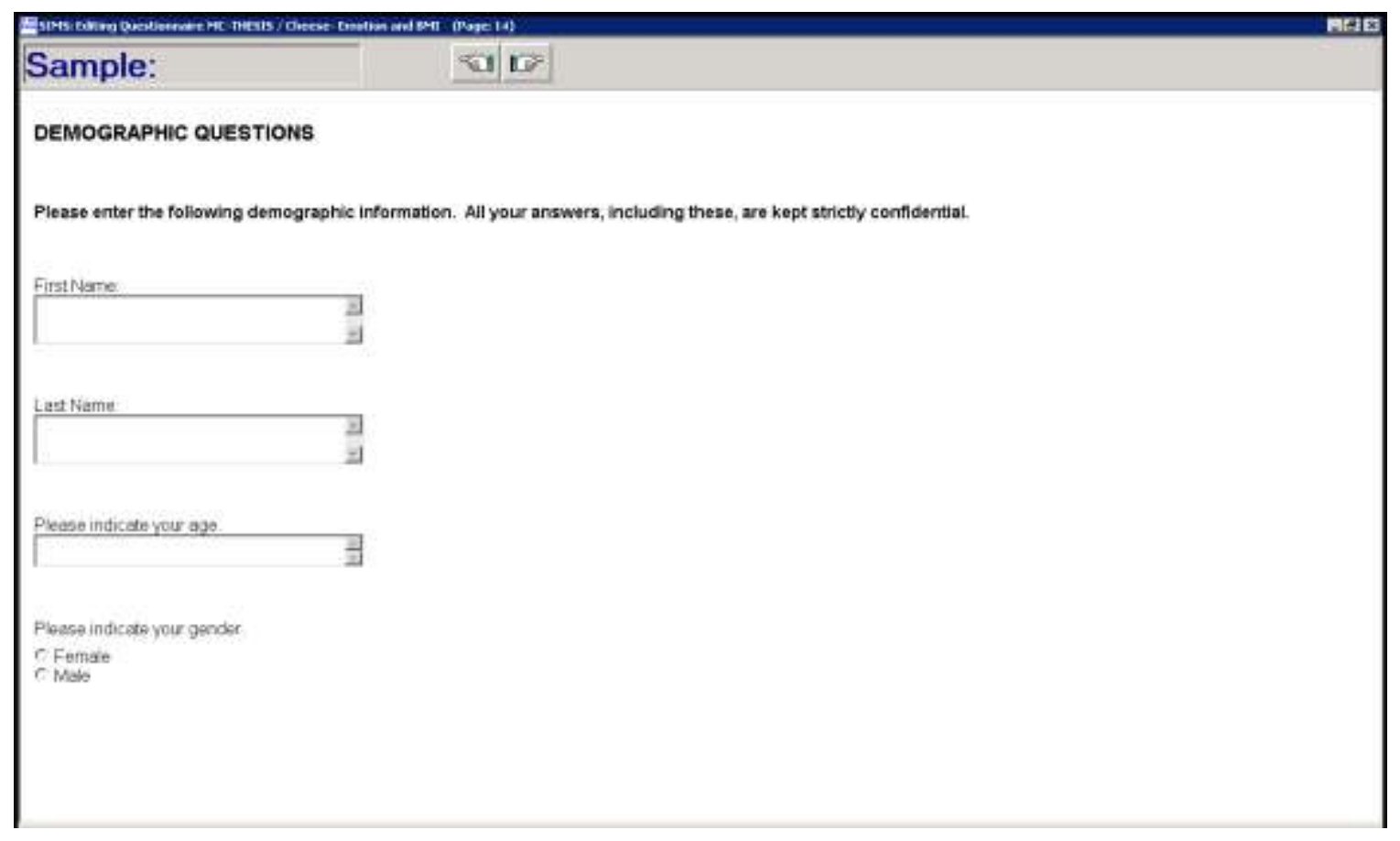



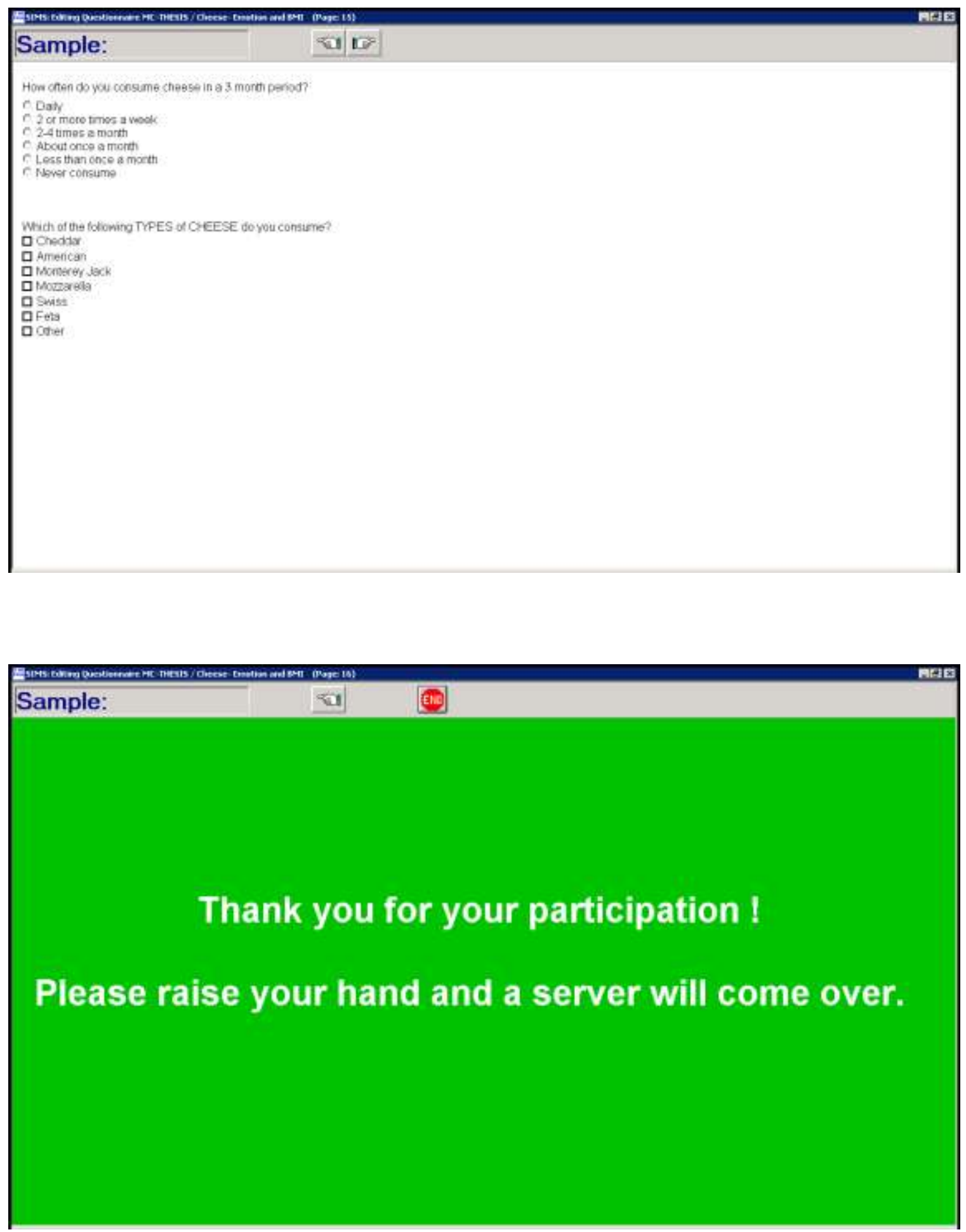